\author{
UNIVERSIDADE DE SÃO PAULO \\ ESCOLA DE ENFERMAGEM DE RIBEIRÃO PRETO
}

KARINA MARTINS MOLINARI MORANDIN

AVALIAÇÃO DO PERFIL PSICOSSOCIAL DAS GESTANTES ATENDIDAS NA REDE BÁSICA DE SAÚDE DO MUNICÍPIO DE CATANDUVA - SP

RIBEIRÃO PRETO - SP

2010 
KARINA MARTINS MOLINARI MORANDIN

\section{AVALIAÇÃO DO PERFIL PSICOSSOCIAL DAS GESTANTES ATENDIDAS NA REDE BÁSICA DE SAÚDE DO MUNICÍPIO DE CATANDUVA -SP}

Tese apresentada ao Programa Interunidades de Doutoramento em Enfermagem da Escola de Enfermagem da Universidade de São Paulo e Escola de Enfermagem de Ribeirão Preto da Universidade de São Paulo para obtenção do título de Doutor em Ciências.

Área de Concentração: Enfermagem

Linha de pesquisa: Sociedade, Saúde e Enfermagem.

Orientadora: Profa. Dr ${ }^{\mathrm{a}}$. Marli Villela Mamede 


\section{RIBEIRÃO PRETO - SP \\ 2010}

AUTORIZO A REPRODUÇÃO E DIVULGAÇÃO TOTAL OU PARCIAL DESTE TRABALHO, POR QUALQUER MEIO CONVENCIONAL OU ELETRÔNICO, PARA FINS DE ESTUDO E PESQUISA, DESDE QUE CITADA A FONTE.

Morandin, Karina Martins Molinari

AVALIAÇÃO DO PERFIL PSICOSSOCIAL DAS GESTANTES ATENDIDAS NA REDE BÁSICA DE SAÚDE DO MUNICÍPIO DE CATANDUVA - SP / Karina Martins Molinari Morandin, - Ribeirão Preto, 2010.

..f.; $30 \mathrm{~cm}$.

Tese de Doutorado, apresentada à Escola de Enfermagem de Ribeirão Preto / USP - Programa Interunidades de Doutoramento em Enfermagem. Área de concentração: Enfermagem.

Orientadora: Mamede, Marli Villela

1. Assistência pré-natal. 2. Estresse. 3. Apoio Social. 4. Autoestima. 5. Psicossocial. 


\section{FOLHA DE APROVAÇÃO}

Karina Martins Molinari Morandin

Avaliação do perfil psicossocial das gestantes atendidas na rede básica de saúde do município de Catanduva - SP.

Tese apresentada ao Programa Interunidades de Doutoramento em Enfermagem da Escola de Enfermagem da Universidade de São Paulo e Escola de Enfermagem de Ribeirão Preto da Universidade de São Paulo para obtenção do título de Doutor em Ciências.

Área de Concentração: Enfermagem

Aprovada em /2010

\section{BANCA EXAMINADORA}

Profa. Dra. Marli Villela Mamede

Instituição: EERP-USP

Assinatura:

Prof. Dr.

Instituição: Assinatura:

Prof. Dr. Instituição: Assinatura:

Prof. Dr. Instituição: Assinatura:

Prof. Dr. Instituição: Assinatura: 


\section{Dedicatóría}

Aos meus pais Roberto e Eliana, Por compartilharem dos meus sonhos, incentivando-me e apoiando-me nos momentos mais difíceis, em especial nesta importante etapa da minha vida. $\mathcal{A M O} \mathcal{M U I \mathcal { T } O}$ VOC $\hat{\mathbb{E} S !}$

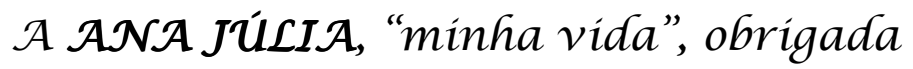
por me fazer descobrir um sentimento que então, não conhecía dentro de mim. Você é o methor presente que recebi de Deus.

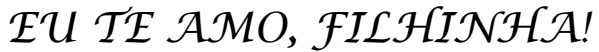




\section{Agradecimento Especial}

À querida Profa. Dra. Marli Vilella Mamede,

Por proporcionar meu crescimento pessoal e profissional. Obrigada pela amizade e acolhida, Por toda competência pela qual conduziu este trabalho, Por estar ao meu lado em todos os momentos que precisei, Por tornar este período tão agradável com a sua companhia,

Por me incentivar em um momento tão dífícil da minha vida, Pelo seu esforço e dedicação a qual nunca conseguireí retribuir o apoío concreto e afetivo para a realização deste doutorado! 


\section{Agradecimentos}

$\mathcal{A}$ Deus especialmente, toda a honra deste trabalho! Por me amar tanto assim, por me incentivar em uma carreira de fé e coragem, por sempre estar ao meu lado, Por ser minha força e refrigério nos momentos maís difíceis, Obrígada $\mathcal{P} \mathcal{A} I$, por tão especial amor! Pela fé e esperança que posso encontrar em seu fílho Jesus Cristo! E pela doce presença do Teu Espírito Santo consolador!

Às minhas queridas irmãs, Francine, Érica, Patrícia e Débora por todo apoio e incentivo incondicional para a concretização deste sonho!

Aos meus amigos Murilo e Natália, pela força e direção! 


\section{Agradecimentos}

Ao prof. Dr. Luiz de Souza, pela paciência, apoío, dedicação e competência no tratamento dos dados estatísticos. $\mathcal{M e u}$ muito Obrigada!

A prof. Dra. Lidia Aparecida Rossi, coordenadora do Programa Interunidades de Doutoramento da $\mathcal{E E R P}$, pelo apoío e confiança em mim depositados.

As Professoras Dra María José Clapis e Ana Maria de Almeida, pelas importantes contríbuições no Exame de Qualificação.

Á Secretaría da Pós-Graduação da $\mathcal{E E R P / U S P}$, em especial a Carla, Rosana e Ketheen, pela atenção e colaboração a mím dispensadas.

$\mathcal{A}$ todos os docentes da Pós-graduação da Escola de Enfermagem e Escola de enfermagem de Ríbeirão Preto / USP.

$\mathcal{A}$ Rosana, Monize, Mayara, Daniele, Patrícia e Mirian pela colaboração na coleta e digitação do banco de dados, obrígada a todas!

A Marisa pelas contríbuições imprescindíveis na formatação do trabalho.

Às professoras Fátima Serraditha e Jussara Sperandio da Faculdade de Enfermagem de Catanduva, pela compreensão e auxílio neste processo.

$\mathcal{A}$ professora Silvia Jorge, pela sua prontídão, dedicação e competência na correção do trabalho.

Ao meu tío Prof. Dr. Michel Saad, pelas contribuições a este estudo.

Às gestantes que participaram deste estudo. 
À toda mínha familia: avós, tíos, prímos, pelo apoío, incentivo e compreensão nesta fase tão importante da minha vida

$\mathcal{A}$ todos que direta ou indiretamente contribuiram para a realização deste trabalho.

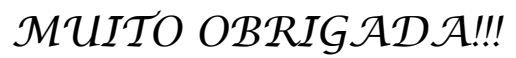


Não temas, porque $\mathcal{F u}$ sou contigo;

Não te assombres, porque Fu sou o teu Deus;

Fu te fortaleço, e te ajudo,

$\mathcal{E}$ te sustento com a minha destra fiel.

Porque Fu, o Senhor teu Deus, te tomo pela

tua mão direita; e te digo:

Não temas, pois Fu te ajudarei"

Isaias 41:10,13 


\section{RESUMO}

O bem-estar psicossocial da gestante deve ser valorizado, de forma a proteger a mulher de resultados desfavoráveis à gestação. O estresse, o apoio social, e o desequilíbrio emocional como construtos do bem-estar psicossocial são preditores de complicações na gravidez. Este estudo descritivo, transversal, de abordagem quantitativa buscou avaliar o perfil psicossocial das gestantes atendidas pelo Sistema Único de Saúde do município de Catanduva - SP e identificar fatores de risco para a percepção de estresse, autoestima e apoio social. Metodologia: Fizeram parte do estudo 227 gestantes com idade gestacional a partir de 20 semanas, as quais freqüentaram consultas de pré-natal na rede básica de saúde do município e no ambulatório de assistência pré-natal de alto risco. Foram utilizados durante a entrevista dois instrumentos para a coleta de dados: Formulário sobre Dados de Identificação socioeconômicos, clínicos e obstétricos e fatores de riscos psicossociais na gestação e o Prenatal Psicossocial Profile - PPP, validado e adaptado para a cultura brasileira, cuja consistência interna foi confirmada através do alpha de Cronbach. O PPP avalia o perfil psicossocial de gestantes, composto por 44 itens, divididos em 4 subescalas (estresse, do apoio social do companheiro e apoio social recebido de outras pessoas e autoestima). Análise dos dados: estatística descritiva, análise de variância (teste $F$ de Snedecor) valores de $p \leq 0,050$ foram considerados estatisticamente significantes e teste de comparações múltiplas de Scheffé. Resultados: a maioria das gestantes apresentou baixos níveis de estresse (media de 18,7 e dp $\pm 5,5$ ), moderado nível de autoestima (media de 29,2 e $d p \pm 3,2$ ) e expressou altos níveis de satisfação com o suporte social recebido do companheiro (média de 51,6 e dp $\pm 16,9$ ) e de outras pessoas (média de 50,1 e dp \pm $16,2)$. Foram encontrados elevados níveis de estresse estatisticamente significantes entre as gestantes com idade superior a 35 anos $(p=0,007)$; ausência de parceiro $(p=0,028)$; multiparidade $(p<0,001)$; ter passado pelo processo de parturição (qualquer tipo de parto) $(p<0,001)$; aborto $(p=0,016)$; problemas com o $R N(p=0,029)$; complicações em gestações anteriores $(p=0,006)$; e na atual $(p=0,004)$; perda de alguém especial $(p<0,001)$; história de violência física $(p<0,001)$; e emocional $(p<0,001)$; violência na gestação $(p<0,001)$. Menor apoio recebido do companheiro mostrou-se significante entre gestantes sem parceiros $(p=0,001)$ e com restrição de crescimento intrauterino $(p=0,006)$. Menor apoio recebido de outras pessoas 
mostrou-se significante entre gestantes com restrição de crescimento intrauterino ( $p=0,013)$ e com história de violência emocional $(p=0,029)$. Baixa autoestima foi identificada entre gestantes multíparas $(p=0,044)$; qualquer tipo de parto, $(p=0,036)$; problemas com o $R N(p=0,016)$; complicações em gestações anteriores $(p=0,027)$; história de violência $(p=0,043)$ e história de violência emocional $(p=0,001)$. Conclusão: Este estudo demonstra que as gestantes atendidas no SUS do município estudado apresentam riscos para o bem-estar psicossocial que podem repercutir na saúde, aumentando a vulnerabilidade para resultados adversos à gravidez.

Palavras-chave: Assistência pré-natal, estresse, apoio social, autoestima, psicossocial. 


\begin{abstract}
Psychosocial well-being during pregnancy should be valued in order to protect from unfavorable outcomes related to pregnancy. Stress, social support, and emotional imbalance as constructs of psychosocial well-being are predictors of pregnancy complications. This descriptive transversal study, a quantitative approach aims to assess the psychosocial profile of pregnant women attending the National Health System in Catanduva a city in São Paulo state, Brazil, and identify risk factors for stress perception, self-esteem and social support. Methods: Study participants were 227 pregnant women with 20 weeks gestational age, which attended local antenatal consultations in primary care network and outpatient high risk prenatal care. During the interview we used two instruments for data collection: Form Identification Data on socioeconomic, clinical and obstetric and psychosocial risk factors in pregnancy and the Prenatal Psychosocial Profile - PPP, validated and adapted to Brazilian culture whose internal consistency was confirmed by Cronbach's alpha test. The PPP assesses the psychosocial profile of pregnant women, comprising 44 items divided into four subscales (stress, social support received from partner and from others and self-esteem). Data analysis: descriptive statistics, analysis of variance (Snedecor $F$ test) $p$ values $\leq 0.050$ were considered statistically significant and multiple comparison Scheffé test. Results: Most patients showed low levels of stress (mean and SD of $18.7 \pm 5.5$ ), moderate level of self-esteem (mean and SD of $29.2 \pm 3.2$ ) and expressed high levels of satisfaction with social support received from their partners (mean \pm SD of 51.6 and 16.9) and others (mean \pm SD of 50.1 and 16.2). We found high levels of stress were statistically significant among pregnant women over 35 years old $(p=0.007)$, absence of partner $(p=0.028)$, multiparity $(p<0.001)$, having gone through the process of parturition (any type of delivery ) $(p<0.001)$, abortion ( $p=0.016)$, problems with $\mathrm{RN}(\mathrm{p}=0.029)$ complications in previous pregnancies $(p=0.006)$ and current $(p=0.004)$, loss of someone special $(p<0.001)$, history of physical violence $(p<0.001)$ and emotional $(p<0.001)$; violence during pregnancy $(p<0.001)$. Less support from partner was significant among pregnant women without partners $(p=0.001)$ and intrauterine growth restriction $(p=0.006)$. Minor support received from others showed significant among women with intrauterine growth restriction $(p=0.013)$ and with a history of emotional abuse $(p=$ 0.029 ). Low self-esteem was found among multiparous women ( $p=0.044)$, any type
\end{abstract}


of delivery $(p=0.036)$, problems with $R N(p=0.016)$ complications in previous pregnancies $(p=0.027)$, history of violence $(p=0.043)$ and a history of emotional abuse $(p=0.001)$. Conclusion: This study shows that pregnant women enrolled in the SUS from the municipality presented a risk to the psychosocial well-being that may impact on health, increasing vulnerability to adverse outcomes of pregnancy.

Keywords: Prenatal care, stress, social support, self esteem, psychosocial. 


\section{RESUMEN}

El bienestar psicosocial durante el embarazo debe ser valorado con el fin de protegerlo de los resultados desfavorables relacionados con el embarazo. El estrés, el apoyo social, y el desequilibrio emocional como constructores del bienestar psicosocial, son predictores de complicaciones en el embarazo. Este estudio descriptivo transversal, un enfoque cuantitativo tiene como objetivo evaluar el perfil psicosocial de las mujeres embarazadas que acuden al Sistema Nacional de Salud de la Ciudad de Catanduva - SP e identificar factores de riesgo para la percepción de estrés, autoestima y apoyo social. Métodos: Participaron del estudio 227 mujeres embarazadas con edad gestacional de 20 semanas, que asistieron a consultas prenatales en la red de atención primaria de la ciudad y cuidado prenatal de alto riesgo. Se utilizaron durante la entrevista de dos instrumentos de recogida de datos: Formulario sobre datos de identificación socioeconómicos, clínicos y obstétricos y factores de riesgos psicosociales en el embarazo y el Prenatal Psicossocial Profile PPP, validado y adaptado a la cultura brasileña, cuya consistencia interna fue confirmada por El coeficiente alfa. EI PPP evalúa el perfil psicosocial de las mujeres embarazadas, que comprende 44 artículos divididos en cuatro subescalas (estrés, apoyo social de la pareja y el apoyo social recibido de los demás y la autoestima). Análisis de datos: estadística descriptiva, análisis de varianza (prueba $F$ de Snedecor) $\mathrm{p} \leq 0,050$ valores fueron considerados estadísticamente significativos y test de comparaciones múltiples de Scheffé. Resultados: La mayoría de las pacientes presentaron niveles bajos de estrés (promedio y desviación estándar de $18,7 \pm 5,5$ ), moderado nivel de autoestima (media y desviación estándar de 29,2 \pm $3,2)$ y expresaron altos niveles de satisfacción con apoyo social recibido de sus parejas (media \pm desviación estándar de 51,6 y 16,9) y otros (media \pm desviación estándar de 50,1 y 16,2). Se han encontrado altos niveles de estrés, fueron estadísticamente significativos entre las mujeres embarazadas de más de 35 años ( $p$ $=0,007)$, ausencia de pareja $(p=0,028)$, la multiparidad $(p<0,001)$, haber pasado por el proceso del parto (cualquier tipo de parto ) $(p<0,001)$, el aborto $(p=0,016)$, problemas con la RN $(p=0,029)$ complicaciones en embarazos previos $(p=0,006)$ y actual $(p=0,004)$, la pérdida de alguien especial $(p<0,001)$, la historia de la violencia física $(p<0,001)$ y emocional $(p<0,001)$, la violencia durante el embarazo ( $p<0,001)$. menor apoyo de la pareja fue significativo entre las mujeres 
embarazadas que no tienen pareja $(p=0,001)$ y la restricción del crecimiento intrauterino $(p=0,006)$. Menor apoyo recibido de otras personas se mostró significante entre las mujeres con restricción del crecimiento intrauterino $(p=0,013)$ y con una historia de abuso emocional $(p=0,029)$. La baja autoestima se observó en las mujeres multíparas $(p=0,044)$, cualquier tipo de parto $(p=0,036)$, problemas con la RN $(p=0,016)$ complicaciones en embarazos previos $(p=0,027)$, la historia de violencia $(p=0,043)$ y una historia de abuso emocional $(p=0,001)$. Conclusión: Este estudio muestra que las mujeres embarazadas inscritas en el SUS del municipio estudiado presentan riesgos para el bienestar psicosocial que pueden afectar a la salud, aumentando la vulnerabilidad a los resultados adversos del embarazo.

Palabras clave- Atención prenatal, estrés, apoyo social, autoestima, psicosocial. 


\section{LISTA DE TABELAS}

Tabela 1 Distribuição das 227 gestantes, segundo características socioeconômicas. Catanduva - SP, 2010

Tabela 2 Distribuição das 227 gestantes, segundo características

clínico-obstétricas da gestação atual. Catanduva - SP, 2010

Tabela 3 Distribuição das 227 gestantes, segundo características clínico-obstétricas de gestações anteriores. Catanduva SP, 2010

Tabela 4 Distribuição das 227 gestantes, segundo os fatores de risco psicossociais (perda de alguém, tabagismo, usa de álcool e drogas ilícitas). Catanduva - SP, 2010

Tabela 5 Distribuição das 227 gestantes, segundo os fatores de risco psicossociais (relato de violência). Catanduva - SP, 2010

Tabela 6 Distribuição de frequências das respostas das 227 gestantes aos itens da subescala de Estresse do PPP. Catanduva, 2010

Tabela 7 Distribuição de frequências das respostas das 227 gestantes sobre o Apoio Social recebido do Companheiro, por item.

Tabela 8 Distribuição de frequências das respostas das 227 gestantes sobre Apoio Social de outras pessoas, por item. Catanduva, SP, 2010

Tabela 9 Distribuição de frequências das respostas das 227 gestantes sobre Autoestima por item. Catanduva, SP, 2010

Tabela 10 Tamanho da amostra, média e desvio padrão da somas dos pontos de estresse de cada nível da variável explicativa dos dados sócioeconômicos, e valor de $p$ do teste $\mathrm{F}$

Tabela 11 Tamanho da amostra, média e desvio padrão da somas 
dos pontos de estresse de cada nível da variável explicativa dos dados clínico-obstétricos de gestações anteriores, e valor de $p$ do teste $F$

Tabela 12 Tamanho da amostra, média e desvio padrão da somas dos pontos de estresse de cada nível da variável explicativa dos dados clínico-obstétricos da gestação atual, e valor de $p$ do teste $F$

Tabela 13 Tamanho da amostra, média e desvio padrão da somas dos pontos de estresse de cada nível da variável explicativa dos fatores de risco psicossociais (perdas de alguém, tabagismo, uso de álcool e drogas ilícitas), e valor de $p$ do teste $F$

Tabela 14 Tamanho da amostra, média e desvio padrão da somas 73 dos pontos de estresse de cada nível da variável explicativa dos fatores de risco psicossociais (relatos de violência), e valor de $p$ do teste $F$

Tabela 15 Tamanho da amostra, média e desvio padrão da somas dos pontos de apoio do companheiro de cada nível da variável explicativa dos dados sócio-econômicos, e valor de $p$ do teste $F$

Tabela 16 Tamanho da amostra, média e desvio padrão da somas dos pontos de apoio do companheiro de cada nível da variável explicativa dos dados clínico-obstétricos, da gestação atual, e valor de $p$ do teste $F$

Tabela 17 Tamanho da amostra, média e desvio padrão da somas dos pontos de apoio do companheiro de cada nível da variável explicativa dos dados clínico-obstétricos, de gestações anteriores e valor de $p$ do teste $F$

Tabela 18 Tamanho da amostra, média e desvio padrão da somas dos pontos de apoio do companheiro de cada nível da variável explicativa dos fatores de risco psicossociais (perdas de alguém, tabagismo, uso de álcool e drogas ilícitas), e valor de $\mathrm{p}$ do teste $\mathrm{F}$ 
Tabela 19 Tamanho da amostra, média e desvio padrão da somas dos pontos de apoio do companheiro de cada nível da variável explicativa dos fatores de risco psicossociais (relato de violência) e valor de $p$ do teste $F$

Tabela 20 Tamanho da amostra, média e desvio padrão da somas dos pontos de apoio de outras pessoas de cada nível da variável explicativa dos dados sócioeconômicos, e valor de $p$ do teste $F$

Tabela 21 Tamanho da amostra, média e desvio padrão da somas 82 dos pontos de apoio de outras pessoas de cada nível da variável explicativa dos dados clínico-obstétricos, da gestação atual e valor de $p$ do teste $F$

Tabela 22 Tamanho da amostra, média e desvio padrão da somas dos pontos de apoio de outras pessoas de cada nível da variável explicativa dos dados clínico-obstétricos de gestações anteriores, e valor de $p$ do teste $F$

Tabela 23 Tamanho da amostra, média e desvio padrão da somas dos pontos de apoio de outras pessoas de cada nível da variável explicativa dos fatores de risco psicossociais (perdas de alguém, tabagismo, uso de álcool e drogas ilícitas), e valor de $p$ do teste $F$

Tabela 24 Tamanho da amostra, média e desvio padrão da somas dos pontos de apoio de outras pessoas de cada nível da variável explicativa dos fatores de risco psicossociais (relatos de violência) e valor de $p$ do teste $F$

Tabela 25 Tamanho da amostra, média e desvio padrão da somas dos pontos de autoestima de cada nível da variável explicativa dos dados socioeconômicos, e valor de $p$ do teste $\mathrm{F}$

Tabela 26 Tamanho da amostra, média e desvio padrão da somas dos pontos de autoestima de cada nível da variável explicativa dos dados clínico-obstétricos da gestação atual, e valor de $p$ do teste $F$ 
Tabela 27 Tamanho da amostra, média e desvio padrão da somas dos pontos de autoestima de cada nível da variável explicativa dos dados clínico-obstétricos, de gestações anteriores e valor de $p$ do teste $F$

Tabela 28 Tamanho da amostra, média e desvio padrão da somas dos pontos de autoestima de cada nível da variável explicativa dos fatores de risco psicossociais (perdas de alguém, tabagismo, uso de álcool e drogas ilícitas) e valor de $p$ do teste $F$

Tabela 29 Tamanho da amostra, média e desvio padrão da somas dos pontos de autoestima de cada nível da variável explicativa dos fatores de risco psicossociais (relato de violência) e valor de $p$ do teste $F$ 


\section{LISTA DE QUADROS}

Quadro 1 Comparação dos valores das médias dos escores das 103 subescalas do PPP encontrados nas diferentes pesquisas 


\section{SUMÁRIO}

1 INTRODUÇÃO

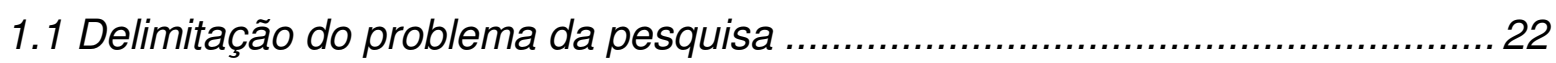

1.20 bem-estar psicossocial na gestação........................................................... 28

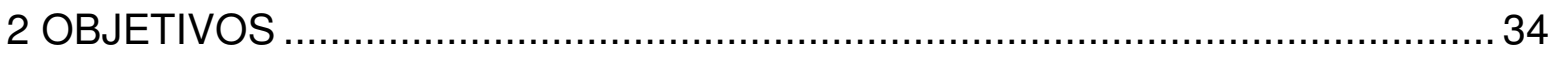

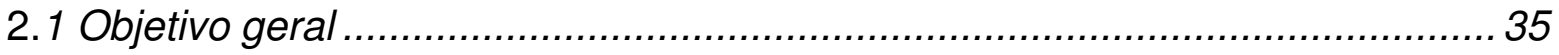

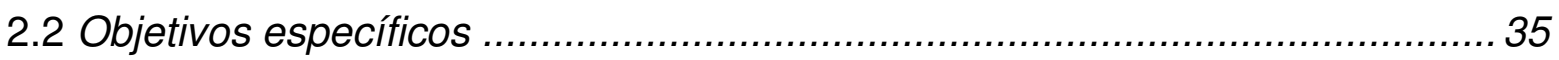

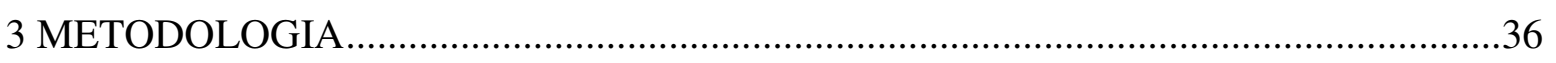

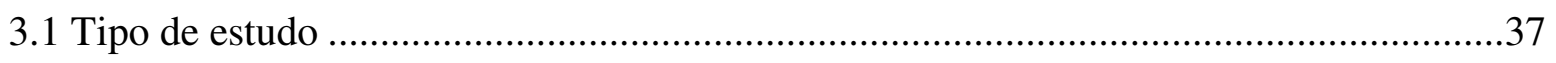

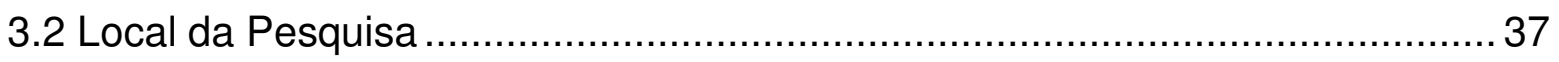

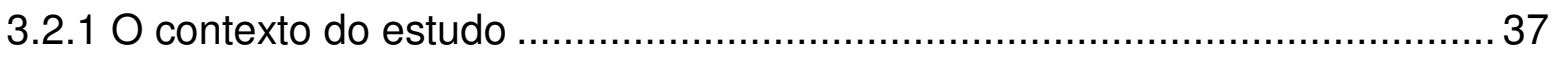

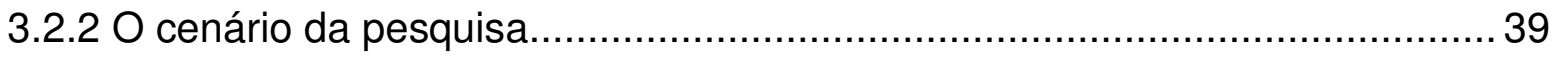

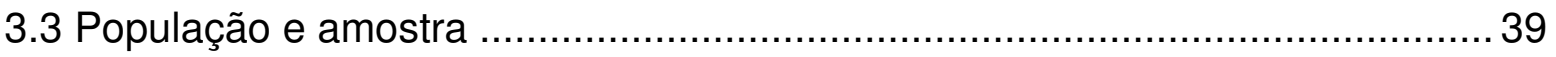

3.4 Período de Coleta de Dados ................................................................... 40

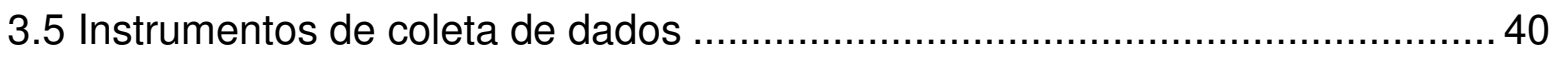

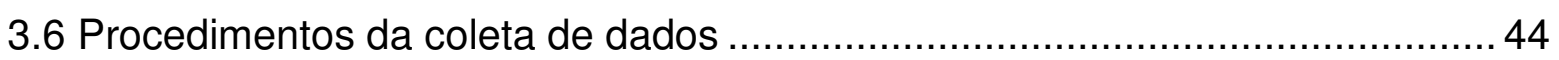

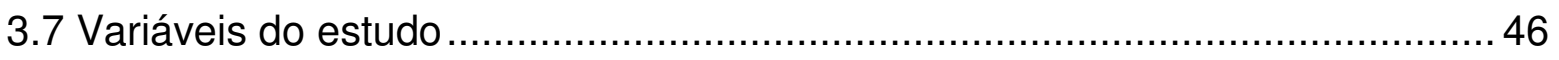

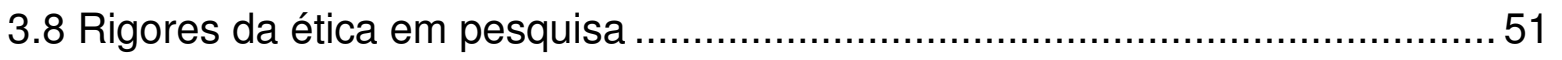

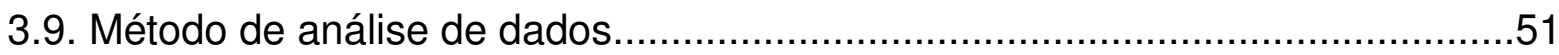

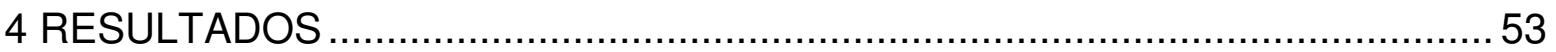

4.1 Caracterização socioeconômica das participantes do estudo .......................... 54

4.2 Condições clínico-obstétricas das participantes do estudo ............................. 55

4. 3 Fatores de risco psicossociais na gestação ……….................................... 58

4. 4 Perfil Psicossocial das participantes ......................................................... 60

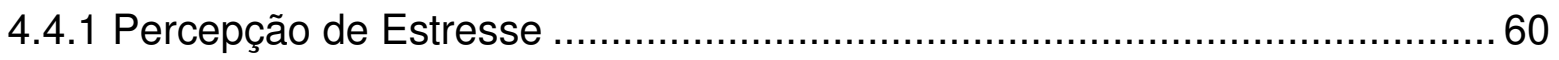

4.4.2 Percepção de Apoio Social do Companheiro ……….................................. 62

4.4.3 Percepção de Apoio Social de outras pessoas ........................................... 64

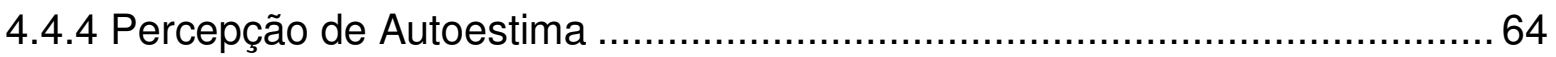

4. 5 Fatores de risco para o bem-estar psicossocial de gestantes: estresse,

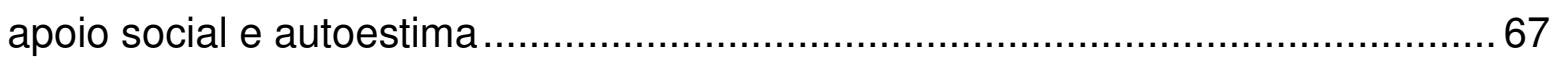

4.5.1 Fatores de risco e Percepção de Estresse .................................................. 67

4.5.2 Fatores de risco e Percepção de Apoio social recebido do companheiro ..... 75 
4.5.3 Fatores de risco e Percepção de Apoio social recebido de outras pessoas.. 81 4.5.4 Fatores de risco e Percepção de Autoestima........................................ 87

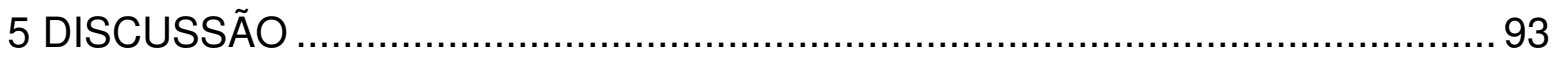

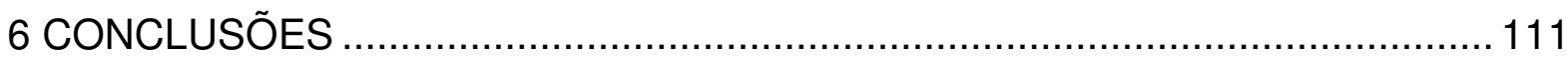

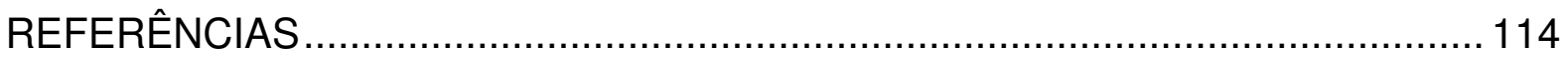

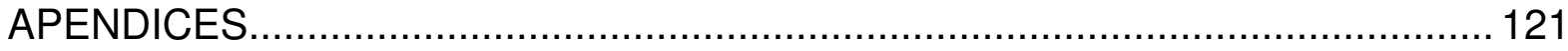

APÊNDICE A - Dados de identificação, socioeconômicos, clínicos e obstétricos 122 APÊNDICE $B$ - Termo de consentimento livre e esclarecido ............................... 125

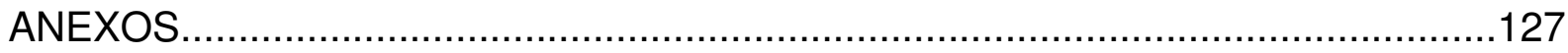

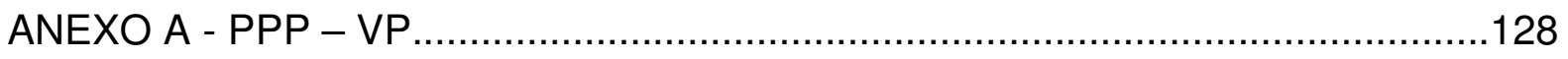

ANEXO B - Autorização Comitê de Ética...................................................... 132 

1 INTRODUÇÃO 


\subsection{Delimitação do problema da pesquisa}

Em uma época na qual muito se discute sobre a humanização do paciente, sobre olhá-lo como um ser único e individual, depara-se com um modelo de atenção à saúde ainda tecnicista, curativista, com ênfase nas doenças e não na promoção da saúde e prevenção de doenças e agravos.

$\mathrm{Na}$ atenção à saúde obstétrica segue-se esse mesmo modelo. Em meio a intervenções e tecnologias utilizadas para a fertilização, cirurgias intra-uterinas - não que não sejam importantes - porém, há que se atentar para a qualidade da assistência pré-natal, para fatores fisiológicos, patológicos, bem como psicossociais da gestação. Deixar de abordar algum desses fatores significa deixar de considerar a mulher na sua totalidade.

A gestação é um fenômeno fisiológico e, por isso mesmo, sua evolução se dá na maior parte dos casos sem intercorrências. Apesar disso, há pequena parcela de gestantes que, por terem características específicas, ou por sofrerem algum agravo, apresenta maiores probabilidades de evolução desfavorável, tanto para o feto como para si como mãe. Essa parcela constitui o grupo chamado de "gestantes de alto risco". Esta visão do processo saúde-doença, denominada Enfoque de Risco, fundamenta-se no fato de que nem todos os indivíduos têm a mesma probabilidade de adoecer ou morrer, sendo tal probabilidade maior para uns que para outros. Essa diferença estabelece um gradiente de necessidade de cuidados que vai desde o mínimo, para os indivíduos de baixo risco ou baixa probabilidade de apresentar esse dano, até o máximo, necessário para aqueles com alta probabilidade de sofrer danos à saúde. A identificação de indivíduos de alto e baixo risco faz com que a 
equipe de saúde disponha de instrumentos discriminadores no processo de recomendar, gerar e fornecer cuidados à saúde, de maneira diferenciada.

Na qualidade de enfermeira ou docente da graduação em enfermagem, há quase 13 anos, observei que a assistência obstétrica era muito tecnicista, com consultas muito rápidas e frias. Surgiram então questionamentos sobre a assistência obstétrica prestada.

Constatei na atenção primária, que na consulta pré-natal, bem como nos grupos de gestantes, a abordagem de questões relacionadas ao perfil psicossocial da gestante era inexistente ou, quando ocorria, muito superficial.

O amadurecimento deste estudo surgiu enquanto aluna do doutorado, através do constante aperfeiçoamento, aliado ao amadurecimento profissional e pessoal advindos da prática diária. Meus questionamentos tornaram-se então cada vez mais freqüentes quanto à abordagem de questões psicossociais na prática obstétrica.

As gestantes possuem necessidades para além das clínicas obstétricas. Passei a compreender a necessidade de atentar para as questões físicas e emocionais da gestante. A gestação por ser um período de transição na vida da mulher, pode ser permeado por situações de dificuldades psicossociais, como o estresse, a baixa autoestima, o inexpressivo apoio recebido do companheiro e de outras pessoas. É esperado que inúmeras alterações físicas e hormonais façam parte desse processo (CAMACHO et al., 2006; FALCONE et al., 2005, BONILHA, 2002).

As alterações físicas vão desde o aumento progressivo de peso, alteração da coloração da pele e das mucosas genitais, hiperflexibilidade das articulações até as mudanças fisiológicas maiores, como as ocorridas no sistema cardiovascular, 
urinário, digestivo, respiratório, de coagulação e dos órgãos reprodutivos (BONILHA, 2002).

No que diz respeito às alterações hormonais, existe nessa fase um aumento na produção dos hormônios sexuais no organismo, favorecendo um desequilíbrio imunológico, o qual torna a saúde susceptível a agressões, bem como ocasiona alterações do humor (BONILHA, 2002; CAMACHO, 2006; FALCONE, 2005).

Muitas vezes, a gravidez provoca reações psicológicas ambíguas na mulher, tais como o desejo intenso de ter um filho, ou o conflito anti a aceitação ou rejeição do mesmo. Esta ambivalência leva a uma situação de estresse e ansiedade, condicionada às demandas sociais (BONILHA, 2002; FALCONE et al., 2005; MOREIRA; SARRIEIRA, 2006).

O período gestacional não somente ocasiona grandes transformações no organismo da mulher, também no seu bem-estar, alterando seu psiquismo e o seu papel sócio-familiar. Nessa fase a mulher está vulnerável, exposta às múltiplas exigências, vivenciando um período de adaptação ou de reorganização física, hormonal, familiar e social (FALCONE et al., 2005).

A literatura indica que o período gravídico-puerperal é a fase de maior incidência de transtornos psíquicos na vida da mulher (BENNETTE et al., 2004; FALCONE et al., 2005; SZIGETHY; RUIZ, 2001). A intensidade das alterações psicológicas dependerá de fatores familiares, conjugais, sociais, culturais e da personalidade da gestante (FALCONE et al., 2005).

A avaliação de risco na gestação tem sido integrada dentro dos programas de atenção pré-natal nos Estados Unidos para poder identificar mulheres com possibilidades de risco de resultados adversos no parto e nascimento e, consequentemente, poder iniciar intervenções precoces na gestação. 
No entanto, Jesse, Seaver e Wallace (2003), chamam a atenção para o fato de que poucos sistemas de avaliação de risco na gestação incluem fatores psicossociais e argumentam, ainda, que a pobre habilidade dos sistemas de avaliação de risco para predizer resultados adversos na gestação, parto e nascimento, a exemplo do parto prematuro, baixo peso ao nascer, entre outros, pode ser devido à forma estreita de abordagem pela qual tais sistemas focalizam a questão, ou seja, apenas nos aspectos biomédicos, ao invés de usar um foco que inclua outros critérios psicossociais. Advertem ainda para o fato de que muitos desses sistemas avaliam uma única vez, ao invés de várias vezes ao longo da gestação, e, para o fato de enfatizarem fatores que não podem ser modificados, tais como idade, educação, raça/etnia, história de prematuridade, baixo peso entre outros. Concluem as autoras que tudo isto contribui para a dificuldade de avaliação e detecção de riscos reais para um resultado obstétrico e neonatal indesejável. No entanto, acrescentam que os fatores que poderiam ser modificados, tais como estilo de vida e critérios psicossociais, não têm sido efetivamente considerados nos sistemas de avaliação de riscos gestacionais.

Norbeck e Anderson (1989) identificam como construtos do bem-estar psicossocial na gestação o estresse, o apoio social e o desequilíbrio emocional. Esses construtos são preditores de complicações na gravidez. Essas mesmas autoras identificaram também a ansiedade e o uso de substâncias químicas como respostas em curto prazo ao estresse na gestação, ambos reconhecidamente nocivos para a mãe e para o feto.

Jesse e Reed (2004) definem o bem estar psicossocial em termos dos fatores que o compõem: níveis de estresse, níveis de autoestima e o suporte social do parceiro e de outras pessoas. 
Dentre os fatores psicossociais na gestação podemos destacar: dificuldades financeiras, como o desemprego da gestante ou do companheiro; falta de um parceiro ou de suporte familiar; conflitos conjugais; eventos estressantes experimentados nos últimos 12 meses, como a perda de um ente querido, abuso ou violência sexual ou física; idade inferior a 16 anos; história de transtorno psiquiátrico prévio (CAMACHO et al., 2006; JESSE; REED, 2004; NORBEC; ANDERSON, 1989; ZUCHI, 1999).

Se uma gestante possui alterações fisiológicas de risco reconhecidas, ela consequentemente apresentará alterações emocionais maiores nessa condição. Questões sobre importantes riscos psicossociais, como, por exemplo, violência nos seus diferentes tipos, estresse, depressão, apoio social os quais afetam diretamente a saúde e o bem-estar da mulher e também o resultado do parto e nascimento, frequentemente são omitidos nos sistemas de avaliação. Contrariamente a isso, o bem estar psicossocial na gestação deve ser valorizado, de forma a proteger a mulher de situações adversas.

Quando situações de risco são detectadas precocemente durante o período pré-natal, é possível auxiliar a gestante sobre a necessidade de mudanças de comportamentos de risco para a gestação, como o uso de álcool, tabaco, drogas e alimentação mais saudável e adequada. Em conseqüência, poder-se-á favorecer o nascimento de um recém-nascido de maior peso, saudável e evitar repercussões negativas tanto físicas, emocionais ou financeiras para as famílias e a sociedade (WEISSHEIMER, 2007).

É preciso reconhecimento do assunto, das repercussões causadas por comportamentos nem sempre saudáveis à gestação, exploração de aspectos que 
gerem mudança de comportamento, buscando compreender a necessidade de cada grupo de gestantes.

A falta de reconhecimento dos riscos que envolvem uma gestação com hábitos de vida nocivos ao binômio - mãe e filho - por si próprios e pelos profissionais de saúde, que as atendem, contribui para o agravamento da situação, ficando esses menos atentos a uma detecção precoce e encaminhamento para serviços especializados.

É esperado que o profissional esteja pronto para ajudar as gestantes diante de dificuldades relacionadas ao seu bem-estar psicossocial, para orientá-las, encontrando respostas para suas dúvidas, inquietações e medos, de forma a minimizar temores e ansiedade, e despertar nelas interesse para o desenvolvimento de cuidados nesse período (FELICE et al., 2007).

A informação segura à gestante, sobre a relevância do bem-estar psicossocial para resultados positivos e favoráveis à gestação e também a disponibilização de uma rede de serviços para acompanhamento e tratamento se necessário, de fatores de risco psicossociais, são estratégias que não deveriam ser negligenciadas no acompanhamento pré-natal. Acreditamos que os sentimentos de uma mulher em relação à sua gestação, a autoestima, o apoio social que recebe, e o estresse sofrido durante a gestação podem, afetar o desfecho da gravidez. Portanto, em uma assistência pré-natal qualificada, a identificação de fatores de risco psicossociais é imprescindível para o transcurso de uma gestação com menores riscos, promovendo a saúde da mulher e do concepto.

Baseado, nesta concepção e no sentido de contribuir para diminuir as lacunas identificadas na literatura, esta pesquisa tomou como objeto de estudo a avaliação do perfil psicossocial de gestantes atendidas no município de Catanduva-SP, 
procurando identificar fatores de risco para a percepção de estresse, autoestima e apoio social do companheiro e de outras pessoas significantes. Portanto, além de incorporar as variáveis sóciodemográficas e riscos biofísicos para resultados adversos à gestação, o presente estudo tomou como variáveis no domínio do bemestar psicossocial o estresse, suporte social (do companheiro e de outros significantes) e a autoestima.

\subsection{0 bem estar psicossocial na gestação}

O bem-estar, segundo Moreira e Sarriera (2006), é um sentimento atual, global e prazeroso, mas com projeção futura, originado pela aquisição pessoal de potencialidades e possibilidades de qualidade de vida. Pode também ser definido como a sensação de satisfação com a própria vida (REED, 1986).

A literatura aponta que o bem estar psicossocial protege a mulher e o seu concepto de situações adversas e é alcançado através de comportamentos que diminuam o risco a gestação (WEISSHEIMER, 2007).

A gravidez é um período de muitas adaptações fisiopatológicas e psicossociais para a vida da mulher. Embora seja um período de alegria e expectativas, normalmente está associada a algum nível de estresse, devido a alterações hormonais, ou mesmo devido à maternidade prematura (TIRAM; CHUMMUN, 2004).

Nesse período as mulheres experimentam algum grau de ansiedade, preocupação e medo em relação à sua própria saúde e a do seu bebê, assim como em relação à aproximação do parto. A preocupação com aspectos sociais, financeiros, com a profissão e com relacionamentos pode aumentar os níveis de 
estresse que consequentemente aumentam a possibilidade de complicações na gravidez (TIRAM; CHUMMUN, 2004).

Contudo, se o nível de estresse presente for leve ou moderado, é considerado benigno, pois aumenta a capacidade de enfrentamento da gestante. Porém, se o nível de estresse tiver um aumento significante, pode comprometer a saúde da mulher e do feto. Altos níveis de estresse ocasionam a liberação de catecolaminas tipo adrenalina e noradrenalina, as quais estimulam diretamente os receptores alfa do útero, aumentando assim, a contratilidade uterina, induzindo à deterioração da circulação uterina, culminando em uma asfixia neonatal (BONILHA, 2002; TIRAM; CHUMMUN, 2004).

A gestante pode ainda adotar comportamentos prejudiciais para si e para o bebê diante desses níveis elevados de estresse, como o consumo de álcool, tabaco e drogas, consumo exagerado de alimentos e sedentarismo.

Essas atitudes indiretamente aumentam ainda mais o nível de estresse, contribuindo para uma maior morbidade e mortalidade perinatal, gerando complicações como aborto espontâneo, pré-eclâmpsia, má nutrição fetal, restrição do crescimento intrauterino, diabete gestacional, trabalho de parto prematuro, distócia hipertônica, recém- nascidos de baixo peso, retardo mental, óbito fetal, entre outros (ROMERO; FIGUEROA; GARCIA, 1999; TIRAM; CHUMMUN, 2004).

É importante ressaltar que algumas mulheres sofrem diversas formas de violência - a física, sexual e emocional ou psicológica, bem como comportamentos dominantes praticados pelos companheiros atuais ou anteriores.

Espera-se que na gestação, a mulher vivencie seu bem-estar tão almejado, porém, pesquisas apontam que no período gravídico-puerperal os parceiros tornamse mais violentos, apresentando mudanças de comportamento. Os principais 
motivos dessa violência são: a desconfiança da sua paternidade, a dependência física e emocional do homem em relação à mulher, ocasionando ciúmes da criança que vai nascer, e o fato de a mulher sentir-se mais forte, durante a gestação, com coragem de reagir, quando agredida na essência da sua condição de mãe (OLIVEIRA, 2000).

A violência contra a mulher na gestação também compromete seu bem estar psicossocial. Está associada com o aumento do estresse, trazendo prejuízos à sua vida e à da criança, danos que incluem maiores problemas de saúde durante a gravidez, maior probabilidade de parto prematuros, início tardio do pré-natal, baixo peso ao nascer e maior medicalização durante o período pré-natal (HUTH-BOCKS; LEVENDOSKY; BOGAT, 2002).

O período gravídico-puerperal, segundo a literatura científica, é a fase de maior prevalência de transtornos mentais na mulher, principalmente no primeiro e terceiro trimestre de gestação e nos primeiros 30 dias após o parto.

Diante desse contexto, a depressão é o transtorno mental de maior prevalência durante a gravidez e o puerpério. Sua prevalência é da ordem de $17 \%$ a 37,9\%, acarretando complicações durante a gestação, o parto e o puerpério, bem como para o concepto (DA SILVA et al., 1998; FREITAS; BOTEGA et al., 2002; FALCONE, et al., 2005; JADRESIC, et al., 1992, JOSEFSSON et al., 2001; VILLANUEVA; PEREZ-FAJARDO; IGLESIAS, 2000).

A mulher deprimida no período gestacional, em razão dos sintomas depressivos, apresenta menor preocupação com seu estado de saúde, o que, muitas vezes, ocasiona não adesão ao pré-natal, além de maior consumo de álcool, tabaco e outras drogas, pessimismo, insônia, falta de apetite, acarretando 
diminuição da quantidade e qualidade da ingesta alimentar (PEREIRA; LOVISI, 2008).

Além disso, existe um mecanismo biológico, mediador da associação entre o estresse psicossocial materno e o baixo crescimento fetal, uma vez que na mulher com depressão há aumento do cortisol, o que pode acarretar prematuridade e baixo peso do feto ao nascer, afetar o desenvolvimento da criança e ocasionar problemas emocionais, cognitivos e comportamentais de longa duração nas crianças (HOBEL; ARORA; KORST, 1999; WADHWA, et al., 2001).

Segundo a literatura científica, os fatores de risco psicossociais para a depressão na gravidez são: fatores relacionados à pobreza, como baixa renda, dificuldades financeiras (gestante ou parceiro desempregados), baixa escolaridade; falta de parceiro, de suporte social, familiar e espiritual; conflitos conjugais; instabilidade nos relacionamentos; idade inferior a 16 anos; eventos estressantes experimentados nos últimos 12 meses; história de violência doméstica; gravidez não desejada; história de transtorno psiquiátrico prévio, sobretudo depressão; dependência de álcool, tabaco e outras drogas (CAMACHO et al., 2006; JESSE; GRAHAM; SWANSON, 2006; ZUCHI, 1999; PEREIRA; LOVISI, 2008).

Entre adolescentes essa prevalência é mais elevada que nas gestantes adultas, variando de $38,9 \%$ a $44 \%$, o que pode estar relacionado, além dos fatores acima citados, com a falta de maturidade afetiva e de relacionamento, o fato de grande parte de elas terem que abandonar seus estudos em razão da maternidade, pelo adiamento ou até mesmo uma suspensão de aspirações anteriormente desejadas, bem como pelo receio de serem discriminadas (CAMACHO, et al., 2006; ORTEGA; LARTIGUE; FIGUEROA, 2001; SZIGETHY; RUIZ, 2001; SABROZA et al., 2004). 
Dentro desse mesmo contexto, Freitas e Botega (2002) estudando adolescentes grávidas do Rio de Janeiro, além de identificarem depressão e ansiedade, encontraram $16,7 \%$ de ideação suicida entre as pesquisadas.

O apoio psicossocial é um dos fatores determinantes para que as gestantes alcancem o bem estar psicossocial além da manutenção de níveis de estresse adequados e de autoestima elevada. É através das teias das relações sociais, sejam elas familiares ou construídas por outros vínculos, que as gestantes obterão estabilidade para enfrentar o período gestacional naturalmente permeado de altos e baixos ocasionados pelas oscilações hormonais (BONILHA, 2002; PEREIRA; LOVISI, 2008; WEISSHEIMER, 2007).

O apoio social recebido antes e durante a gestação, principalmente 0 oferecido pelo cônjuge, tem sido apontado como determinante para o bem estar psicológico da gestante (ADEWUYA, et al., 2007; PEREIRA; LOVISI, 2008; RUDNICKI, et al., 2001).

Algumas situações de pobreza, abandono social e familiar, difícil acesso à educação e cuidados básicos de saúde, pouco ou inadequado conhecimento sobre os riscos à gestação fazem com que algumas mulheres assumam comportamentos nocivos para elas e para o concepto (WEISSHEIMER, 2007).

Harley e Eskenazi (2006), em estudo com gestantes mexicanas imigrantes nos Estados Unidos, observaram que maior número de filhos, menor nível educacional e baixa renda estavam associados com menor apoio social, enquanto que maior apoio social favorecia uma alimentação adequada, aumento do uso de vitaminas prescritas durante o período pré-natal e diminuição do hábito de fumar durante a gestação. 
Ao estudarem a associação entre recém nascidos de baixo peso (RNBP) e o apoio social com mulheres afro-americanas, Norbeck, Dejoseph, Smith (1996) apontaram que o suporte social foi efetivo para a redução das taxas de recémnascidos de baixo peso. Encontraram uma taxa de incidência de RNBP de 9,1\% nas gestantes que obtiveram apoio social contra $22.4 \%$ no grupo controle.

Alguns autores relacionam a autoestima com complicações para o recémnascido, como valores baixos de Apgar no quinto minuto de vida e maiores escores para risco obstétrico (CURRY; CAMPBELL; CHRISTIAN, 1994).

Considerando-se a isso tudo, observa-se que, a autoestima das gestantes está relacionada à maior satisfação nas suas relações sociais, e à sensação de controle sobre sua própria vida. A autoestima adequada também favorece adesão a comportamentos de saúde benéficos, que causam direta ou indiretamente, impacto positivo sobre os resultados da gestação (CURRY, CAMPBELL, CHRISTIAN 1994).

Na gestante adolescente, a chance de se apresentar autoestima mais baixa é mais elevada pelas dificuldades próprias da faixa etária, quando se justifica uma atuação profissional a fim de reforçar essa autoestima e estimular o melhor conhecimento de suas potencialidades (MOREIRA; SARRIEIRA, 2006).

Diante de tais observações, pode-se assumir que é crucial que os profissionais de saúde, sobretudo o enfermeiro, preste uma assistência pré-natal, visando à integralidade da atenção. A abordagem não deve se dirigir somente aos fatores clínico-obstétricos, mas também, à dimensão psicossocial, possibilitando a detecção precoce de fatores de risco, redução de comportamentos de risco na vida das gestantes e, consequentemente, evitando repercussões negativas para a saúde materno-infantil. 


\subsection{Objetivo geral}

Avaliar o perfil psicossocial das gestantes atendidas pelo Sistema Único de Saúde do município de Catanduva - SP.

\subsection{Objetivos específicos}

- Caracterizar o perfil psicossocial de gestantes atendidas pelo Sistema Único de Saúde do município de Catanduva - SP de acordo com as dimensões de bem estar psicossocial: estresse, auto - estima e apoio social.

- Identificar a presença de fatores de risco à gestação de gestantes atendidas pelo Sistema Único de Saúde do município de Catanduva - SP.

- Identificar fatores de risco para a percepção de estresse, autoestima e apoio social de gestantes atendidas pelo Sistema Único de Saúde do município de Catanduva - SP. 
3 METODOLOGIA 


\subsection{Tipo de estudo}

O presente trabalho trata de um estudo descritivo-transversal de abordagem quantitativa.

O delineamento de pesquisa, no estudo quantitativo, apresenta estratégias que o pesquisador planeja adotar para desenvolver informações precisas e interpretáveis (POLIT; BECK; HUNGLER, 2004).

O estudo descritivo permite ao profissional realizar o delineamento da realidade, uma vez que the permite observar, descrever, registrar, analisar e interpretar a natureza atual ou o processo dos fenômenos sem manipulá-los. Além de descobrir a frequência com que um fenômeno ocorre, com a maior precisão possível (CERVO; BERVIAN, 1996; POLIT; BECK; HUNGLER, 2004).

Já o estudo transversal, envolve a coleta de dados em uma ocasião, ou seja, coleta de dados em um ponto de tempo, onde os fenômenos sob estudo são obtidos durante um período de coleta de dados. Os delineamentos transversais são especialmente apropriados para descrever a situação, o status do fenômeno, ou as relações entre fenômenos em um ponto fixo (POLIT; BECK; HUNGLER, 2004).

\subsection{Local da Pesquisa}

\subsubsection{0 contexto do estudo}

A presente investigação foi realizada no município de Catanduva, localizado na região Noroeste do estado de São Paulo, a uma distância aproximada de 380 km da capital do estado. O município tem atualmente 114.812 habitantes, dentre estes, 
35.245 mulheres em idade fértil (10 a 49 anos). (IBGE, 2009).

A região administrativa de Catanduva conta com 18 municípios, absorvendo assim as necessidades dos demais municípios nos setores social, prestação de serviços, comércio e principalmente na assistência médica e hospitalar; portanto, a população total da região considerada é de 240.415 pessoas (SEADE, 2009).

O serviço de saúde do município agrupa o sistema público de saúde e medicina suplementar, com atenção primária à saúde, atenção ambulatorial especializada, atenção às urgências e internações hospitalares, distribuídas em três hospitais gerais, sendo que dois oferecem serviços de assistência ao parto e um é hospital psiquiátrico.

O modelo de gestão de atenção integral à saúde do Sistema Municipal de Saúde de Catanduva é do tipo Gestão Plena. As ações da atenção básica estão articuladas com média e alta complexidade. Na atenção básica, Catanduva conta com quatro Unidades Básicas de Saúde e 19 Programas de Saúde da Família. As Unidades de Saúde da Família, Centros de Saúde e Unidades Básicas de Saúde são as principais portas de entrada do Sistema.

Dentre as prioridades do Pacto pela Saúde, no componente Pacto pela vida, para o biênio 2008-2009, estão ações na área da Saúde da Mulher, priorizando a implementação de ações para melhoria da saúde da mulher e da criança, como o fortalecimento da atenção pré-natal, diminuição do número de partos cesáreas, a criação de protocolos clínicos para saúde da mulher, pré-natal e puerpério, reduzindo, sobretudo, a morbi-mortalidade materna e infantil.

Na assistência obstétrica, o município de Catanduva oferece assistência ao pré-natal, cadastrando todas as usuárias do Sistema Único de Saúde com gravidez comprovada no SISPRENATAL, garantindo, no mínimo, seis consultas de pré-natal 
e uma de puerpério. Os exames de rotina são todos oferecidos de acordo com a proposta do Ministério da Saúde.

No ano de 2008, no município de Catanduva foram cadastradas 887 gestantes no SISPRENATAL, com uma média mensal de 446 consultas de prénatal, dentre elas, 225 cadastradas no SIAB. No mesmo ano, foram realizados 1327 partos, sendo 291 partos vaginais (22\%) e 1036 partos cesáreas (78\%) (DATASUS, 2008).

\subsubsection{O cenário da pesquisa}

O cenário do estudo foi a rede básica de saúde (Programas de Saúde da Família e Unidades Básicas de Saúde) e o ambulatório de assistência pré-natal de alto risco do Hospital Escola Emílio Carlos.

\subsection{População e amostra}

Fizeram parte da amostra deste estudo 227 gestantes com idade gestacional a partir de 20 semanas, as quais 167 frequentaram consultas de pré-natal na rede básica de saúde do município e 60 no ambulatório de assistência pré-natal de alto risco do Hospital Escola Emílio Carlos que aceitaram participar deste estudo.

A idade gestacional superior a 20 semanas foi escolhida pelo fato de as gestantes estarem, a partir desse período, mais expostas aos aspectos do bem estar psicossocial: estresse, auto - estima e apoio social.

O cálculo do tamanho amostral foi baseado nos valores médios de respostas às subescalas do instrumento PPS - Prenatal Psicossocial Profile obtidos por 
Weissheimer (2007) com gestantes de Porto Alegre. Foi levado em consideração um intervalo de confiança de $95 \%$ e um erro amostral máximo de $5 \%$ da média da soma de pontos, além do número de nascidos vivos no ano de 2008 no município de Catanduva.

\subsection{Período de Coleta de Dados}

Os dados foram coletados após aprovação do Comitê de Ética de Pesquisa (CEP) das Faculdades Integradas Padre Albino de Catanduva. A coleta de dados foi realizada no período de março a maio de 2010 .

\subsection{Instrumentos de coleta de dados}

Para a coleta de dados foi utilizada a técnica da entrevista estruturada, na qual foram utilizados dois instrumentos:

A) Formulário sobre Dados de Identificação socioeconômicos, clínicos e obstétricos e fatores de riscos psicossociais na gestação;

B) Prenatal Psicossocial Profile - PPP.

\section{A) Formulário sobre Dados de Identificação socioeconômicos, clínicos e} obstétricos e fatores de riscos psicossociais - Esse formulário, baseado no instrumento Dados de Identificação, Clínicos e Obstétrico utilizado por Weissheimer (2007), acrescenta itens de fatores de risco psicossociais na gestação. É constituído de quatro partes: a primeira parte, composta por dados de identificação e sócio-econômicos; a segunda parte, por dados 
obstétricos referentes à gestação anterior e à atual; a terceira parte, por dados clínicos referentes à gestação anterior e a atual e última parte, referente aos fatores de risco psicossociais (APÊNDICE A).

B) Prenatal Psicossocial Profile - PPP, composto por 4 subescalas, que permitem a mensuração do estresse, o apoio social do companheiro e apoio social de outras pessoas, bem como a autoestima (ANEXO A).

\section{B.1 - Descrição do instrumento Perfil Psicossocial no Pré-natal - PPP:}

O Prenatal Psychosocial Profile-PPP foi o instrumento de escolha para avaliar o perfil psicossocial de gestantes, tendo em vista que o mesmo foi desenvolvido especificamente para gestantes por um grupo de enfermeiras norte-americanas, o qual é considerado como uma importante ferramenta clínica e de pesquisa na atenção pré-natal.

Trata-se de um instrumento que congrega as características de ser prático para a aplicação em estudos de campo, para avaliar a força relativa de cada domínio (estresse, apoio social do companheiro e de outras pessoas, e autoestima) da resposta psicossocial da gestante e para transformar medidas subjetivas em dados objetivos, quantificáveis e analisáveis. O PPP é validado para a população de língua inglesa e projetado para ser um instrumento de avaliação em estudos epidemiológicos que respeitam a natureza multidimensional do bem-estar psicossocial de mulheres grávidas. 
O PPP tem sido amplamente testado com mulheres urbanas e rurais de diversos países e de diferentes etnias (CURRY et al.,1998) e apresenta uma confiabilidade e validade bastante aceitável.

O instrumento foi validado e adaptado para a cultura brasileira em 2007, por Weissheimer, e seu processo de validação foi desenvolvido com 247 gestantes usuárias dos serviços de pré-natal da rede básica de saúde do município de Porto Alegre-RS. As propriedades psicométricas foram mantidas com valores do coeficiente de alfa de Cronbach $(0,71$ para estresse, 0,95 para apoio do companheiro, 0,96 para apoio de outras pessoas e 0,79 para autoestima) que demonstram consistência interna e pertinência de uso no Brasil.

No presente estudo, de acordo com os dados obtidos, a consistência interna foi mantida cujos valores do alpha de Cronbach para as subescalas: estresse $(0,97)$; apoio do companheiro $(0,99)$; apoio de outras pessoas $(0,99)$ e autoestima $(0,74)$.

O PPP contém 44 itens divididos em 4 subescalas. A subescala de avaliação do estresse, do apoio social do companheiro e apoio social recebido de outras pessoas e da autoestima, é composta de 11 frases em cada aspecto.

$\mathrm{Na}$ subescala de avaliação do estresse, as gestantes devem responder o quanto cada uma das situações explicitadas Ihes causa estresse. As sentenças relacionam problemas do dia-a-dia das pessoas, como preocupações financeiras com alimentação, transporte, contas a pagar, problemas de moradia, problemas relacionados à família, à perda recente de alguém especial, à gestação atual, a situações de abuso ou violência, a problemas com álcool e drogas, problemas com o trabalho ou com amigos, com sobrecarga. As respostas possíveis (e respectivos valores atribuídos a ela) são: "nenhum estresse" (1), "algum estresse" (2), "estresse 
moderado" (3), "estresse intenso" (4). Os valores dos escores podem variar de 11 a 44; quanto maior o escore, maior o nível de estresse.

Nas duas subescalas de avaliação do apoio social, a primeira avalia o apoio social recebido do companheiro e a segunda o apoio social recebido de outras pessoas. A primeira é destinada apenas as gestantes que possuem companheiro e a segunda a todas as gestantes, sendo a mesma a seqüência de frases que se repetem. Ambas as subescalas possuem 11 afirmações sobre situações de apoio, como compartilhar vivências, ajudar a manter o ânimo, ajudar a sair de situações difíceis, mostrar interesse em atividades diárias, sair da rotina para fazer coisas importantes, permitir falar de coisas pessoais, demonstrar que valorizam o que é feito para ele/elas, tolerar altos e baixos, levar a sério preocupações, dizer coisas que tornam a situação clara e fácil de ser compreendida, deixar claro que terão alguém por perto. As respostas são dadas através de uma escala de 1 a 6 , sendo que o valor 1 refere-se a "muito insatisfeita" e o valor 6 "muito satisfeita". Os escores podem variar de 11 a 66. Quanto maior o escore, maior a satisfação com o apoio social recebido do companheiro e/ou de outras pessoas.

A subescala de avaliação da autoestima também é composta de 11 itens. As frases referem-se à gestante, como sentir que tem valor e qualidades, sentir-se fracassada, ser capaz de fazer as coisas tão bem quanto outras pessoas, não ter do que orgulhar-se, ter atitude positiva consigo mesma, sentir-se satisfeita consigo mesma, ter mais respeito consigo mesma, sentir-se inútil, achar que controla a própria vida. Uma vez que algumas sentenças estão redigidas propositadamente de forma negativa, é previsto que as entrevistadas se sintam confusas no momento de preencher o instrumento, a assim, pensem melhor ao escolherem suas respostas. Os valores possíveis variam de 11 a 44. Quanto maior o escore, maior a autoestima. 


\subsection{Procedimentos da coleta de dados}

A coleta de dados se deu por meio de entrevista estruturada com aplicação dos dois instrumentos: Formulário sobre Dados de Identificação socioeconômicos, clínicos e obstétricos e fatores de riscos psicossociais na gestação; e o Prenatal Psicossocial Profile - PPP.

Para a realização das entrevistas contou-se com o auxílio de quatro enfermeiras recém-graduadas, além da pesquisadora. Com o objetivo de operacionalizar o período de coleta de dados e evitar vieses entre as entrevistadoras, foi realizado um treinamento pela pesquisadora para esclarecimento dos objetivos da pesquisa, orientações sobre os construtos que foram avaliados através do instrumento PPP, manuseio dos instrumentos, bem como a técnica de entrevista, enfatizando uma abordagem empática, acolhedora e facilitadora, gerando confiança nas gestantes. Essa atitude acolhedora por parte das entrevistadoras estimulou várias mulheres a expressarem seus sentimentos durante a entrevista.

Além do treinamento descrito, as enfermeiras acompanharam algumas entrevistas realizadas pela pesquisadora.

A abordagem para a entrevista das gestantes foi realizada enquanto as mesmas aguardavam a consulta pré-natal previamente agendada na rede básica de saúde, bem como no ambulatório de assistência pré-natal de alto risco do Hospital Escola Emílio Carlos, garantindo-Ihes que não perderiam a vaga da consulta médica.

Todas as entrevistadas assinaram o Termo de Consentimento Livre e Esclarecido. Houve algumas recusas em participar da pesquisa, quando as 
gestantes alegaram não disponibilizarem tempo disponível para a realização da entrevista, tendo que retornar rapidamente ao trabalho, ou para seus lares.

Quando o tempo de espera da gestante pela consulta pré-natal não foi suficiente para o término da entrevista, a coleta de dados foi interrompida para a realização da consulta médica e, após a consulta, foi dada continuidade à coleta de dados. Em alguns casos as gestantes não concordaram em dar continuidade à aplicação do instrumento, alegando indisponibilidade de tempo.

O questionário sobre os dados de identificação, sócio-econômico e obstétrico e fatores de risco psicossociais na gestação foi aplicado primeiramente, servindo como um elemento de aproximação entre o entrevistador e o sujeito antes de buscar as respostas às questões psicossociais na gestação.

Foi explicado para as gestantes que não existem respostas certas ou erradas, mas a resposta mais apropriada para a sua situação pessoal. O questionário foi lido pelas pesquisadoras para as gestantes, bem como o registro de cada uma das respostas. Foi dada uma cópia para a gestante do PPP, o instrumento foi lido pelas pesquisadoras e a entrevistada registrava a alternativa escolhida. Em cada subescala foi dada explicação sobre o seu preenchimento.

Foi dada preferência aos dados coletados primariamente com a própria participante, levando em consideração a fidedignidade das respostas. Foram extraídos do cartão da gestante dados clínico-obstétricos que as entrevistadas não souberam responder, como número do prontuário, idade gestacional, número de consultas de pré-natal, pressão arterial na primeira consulta. Foram extraídos do prontuário dados como complicações na gestação atual, bem como o uso de medicações e, quando necessário, o ultrassom obstétrico. 
Para o registro dos dados referentes à altura uterina foi solicitado aos médicos que verificassem esse dado e o anotassem no prontuário, sendo que muitas vezes não havia um consultório com divã disponível para a verificação da altura uterina pelas entrevistadoras, bem como para poupar a paciente de uma dupla verificação. Como em diversas vezes a anotação da altura uterina não foi realizada pelo médico, as entrevistadoras fizeram tal mensuração em algumas UBS.

As entrevistas foram realizadas em um local privativo em sua maioria; apenas em uma UBS não foi disponibilizada uma sala reservada, sendo a entrevista realizada em uma região mais afastada do corredor da Unidade.

As entrevistas, na grande maioria, foram realizadas sem a presença de acompanhantes, embora, em alguns casos, houvesse uma insistência por parte dos parceiros ou mães das mesmas, que permaneceram junto às gestantes durante a entrevista.

\subsection{Variáveis do estudo}

\section{Variável dependente:}

- O bem-estar psicossocial, com as dimensões do estresse, apoio social do companheiro, apoio social de outras pessoas e autoestima, será avaliado por meio do instrumento Prenatal Psicossocial Profile - PPP.

\section{Variáveis independentes:}

Podem estar associadas com as dimensões do bem estar psicossocial. Foram selecionados como variáveis explicativas ou explanatórias os possíveis fatores de 
risco para a gestação, conforme descrito nos manuais do Ministério da Saúde (BRASIL, 2005), a saber:

- História reprodutiva anterior: Morte perinatal explicada ou inexplicada; Recémnascido com restrição de crescimento, pré-termo ou malformado; Abortamento habitual; Esterilidade/infertilidade; Intervalo interpartal menor que dois anos ou maior que cinco anos; Nuliparidade e multiparidade; Síndromes hemorrágicas; Pré-eclâmpsia/eclâmpsia; Cirurgia uterina anterior; Macrossomia fetal.

- Intercorrências clínicas crônicas: Cardiopatias; Pneumopatias; Nefropatias; Endocrinopatias (especialmente diabetes mellitus); Hemopatias; Hipertensão arterial moderada ou grave e/ou em uso de anti-hipertensivo; Epilepsia; Infecção urinária; Portadoras de doenças infecciosas (hepatites, toxoplasmose, infecção pelo HIV, sífilis e outras DST); Doenças auto-imunes (lupus eritematoso sistêmico, outras colagenoses); Ginecopatias (malformação uterina, miomatose, tumores anexiais e outras).

- Doença obstétrica na gravidez atual: Desvio quanto ao crescimento uterino, número de fetos e volume de líquido amniótico.

Nas Variáveis de ajustamento foram consideradas as informações sobre:

\section{Variáveis socioeconômicas:}

- Idade: classificada em anos completos: sendo agrupados da seguinte forma: 1) menos de 18 anos, 2) de 18 a 34 anos e 3) 35 anos ou mais.

- Escolaridade: classificadas quanto ao grau máximo de instrução completo: 1) Ensino Fundamental, 2) Médio e 3) Superior; 
- Situação conjugal: classificadas como: 1) com companheiro (casadas, amasiadas, e com namorado); 2) sem companheiro, as solteiras;

- Ocupação: foi realizada a classificação da ocupação segundo OSLER (1993):

Primeiramente, os dados foram agrupados nas categorias:

1- Empregados assalariados com formação universitária ou pessoas em cargos executivos.

2- Pessoas com níveis baixos de gerência, ou assalariados com treinamento profissionalizante intermediário, como enfermeiras ou professores de escolas.

3- Assalariados com níveis baixos de gerência ou trabalhadores com período curto de educação, como policiais, auxiliares de enfermagem, etc.

4- Trabalhadores qualificados.

5- Trabalhadores semi-qualificados, do lar.

6- Trabalhadores não qualificados.

7- Desempregados, aposentados.

8- Pessoas sob treinamento ou estudantes.

9- Não sabe.

99 - ignorado.

Em seguida os dados foram submetidos à classificação;

1,2 , 3- trabalhadores não manuais $=1$

4- trabalhadores manuais qualificados $=2$

5- trabalhadores manuais semi-qualificados $=3$

6, 7, 8-trabalhadores manuais não qualificados, pessoas sob treinamento ou estudantes, desempregados, aposentados e donas de casa $=4$ 
Em nosso estudo a classificação 1 e 2 (trabalhadores não manuais e trabalhadores manuais qualificados) foi agrupada devido a um número muito pequeno da classificação 1, sendo considerado, portanto:

$1=$ Trabalhadores qualificados

$2=$ Trabalhadores semi-qualificados

3 = Trabalhadores não qualificados

- Renda familiar: expressa em salários míninos (na época do estudo o salário mínimo nacional era de $\mathrm{R} \$ 510,00)$ : 1) < de 1 salário; 2) de 1 a 2 salários; 3) 2 ou + salários.

Variáveis clínico-obstétricas:

- Idade gestacional: classificada em semanas completas e calculada na data da entrevista. Para esse cálculo utilizou-se prioritariamente o ultra-som realizado no primeiro trimestre; nos casos em que esse não se encontrava anexado ao prontuário ou anotado no prontuário ou cartão da gestante, foi utilizada a data da última menstruação.

- Número de gestações: indica o número de gestações que a mulher apresentou, sendo assim definido: 1) uma gestação; 2) 2 ou+ gestações.

- Número de consultas pré-natal: indica o número de consultas de pré-natal que a gestante realizou durante a gravidez, conforme registrado no cartão da gestante, inclusive a do dia da entrevista. Foi assim categorizado conforme protocolo ministerial: 1) adequado, 2) não adequado.

- Tipo de parto: 1) vaginal; 2) cesárea; 3) não se aplica.

- Aborto: 1) sim; 2) não; 3)não se aplica. 
- Problemas com o RN: recém-nascidos com prematuridade, baixo peso ao nascer ou malformados. Em nosso estudo nenhuma participante utilizou a classificação RN malformado, sendo, portanto, a categorização: 1) sim, 2) não, 3) não se aplica.

- Complicação gestação atual: 1) sim; 2) não.

- Complicação gestação anterior: 1) sim; 2) não; 3) não se aplica.

- Restrição de crescimento uterino: 1) sim; 2) não.

- Ganho de peso ponderal: indica o aumento de peso, em quilos, durante o período gestacional, conforme registrado no cartão da gestante ou prontuário. Como base de cálculo utilizaram-se as orientações do Ministério da Saúde (2006). Foi considerado ganho abaixo do esperado o ganho de peso semanal inferior a 0,3 Kg; adequado ou esperado, o ganho de peso semanal de 0,3 a 0,5 Kg; e acima do esperado, o ganho de peso semanal acima de 0,5 $\mathrm{Kg}$. Assim ficou classificado, portanto: 1) adequado, 2) acima do esperado, 3) abaixo do esperado.

\section{Variáveis Fatores de Risco Psicossocial:}

- Perda recente de alguém especial: 1) sim, 2) não.

- História de tabagismo: 1) sim, 2) não.

- Tabagismo em gestação atual: 1) sim, 2) não.

- Uso de álcool em gestação atual: 1) sim, 2) não.

- História de uso de drogas: 1) sim, 2) não.

- História de violência: 1) sim, 2) não.

- História de violência sexual: 1) sim, 2) não.

- História de violência física: 1) sim, 2) não. 
- História de violência emocional: 1) sim, 2) não.

- Violência na gestação: 1) sim, 2) não.

- Violência na física na gestação: 1) sim, 2) não.

- Violência emocional na gestação: 1) sim, 2) não.

\subsection{Rigores da ética em pesquisa}

A pesquisa foi aprovada pelo Comitê de Ética em Pesquisa das Faculdades Integradas Padre Albino - Catanduva - SP em atendimento à Resolução 196/96 do Conselho Nacional de Saúde (ANEXO B).

As participantes foram previamente orientadas sobre os objetivos e benefícios esperados da pesquisa; também lhes foi garantido o sigilo dos dados obtidos e a liberdade em recusar ou anular seu consentimento a qualquer momento da pesquisa, sem que isso interferisse na assistência prestada.

Foi elaborado um Termo de Consentimento Livre e Esclarecido TCLE (APÊNDICE B). Esse Termo foi impresso em duas vias, uma cópia foi mantida com a pesquisadora e a outra foi dada à participante do estudo. Somente participaram deste estudo as mulheres que assinaram o TCLE. No caso de gestantes adolescentes, o termo foi assinado pelo responsável.

\subsection{Método de análise de dados}

Após validação dos dados, os mesmos foram exportados para o STATA em sua versão 9.2 e analisados quantitativamente por meio da estatística descritiva e apresentados em freqüência absoluta, porcentual, médias $(\bar{x})$ e desvio padrão (s). 
Em todas as análises estatísticas foi adotado nível de significância $\alpha=0,050$, ou seja, valores de $p \leq 0,050$ foram considerados estatisticamente significantes.

A comparação das médias populacionais da pontuação de cada subescala do instrumento PPP (estresse, apoio social do companheiro, apoio social de outras pessoas e autoestima), com as categorias das variáveis independentes, foi realizada por meio da análise de variância (teste F de Snedecor).

Quando havia significância na análise de variância das variáveis independentes com mais de duas categorias, foi aplicado o teste de comparações múltiplas de Scheffé. 
4 RESULTADOS 


\subsection{Caracterização socioeconômica das participantes do estudo}

De acordo com os critérios de inclusão estabelecidos para o estudo, a amostra foi composta de 227 gestantes, atendidas nos serviços de saúde com assistência pré-natal no período de coleta de dados.

A Tabela 1 apresenta a caracterização socioeconômica das gestantes participantes do estudo onde se observa que, a idade variou de 12 a 43 anos, com média de 24,26 e desvio padrão de $\pm 6,5$; sendo que 34 (15\%) apresentavam idade inferior a 18 anos e a maioria delas 176 (77,9\%) estava entre 18 a 34 anos (Tabela 1).

No que se refere à escolaridade, observa-se na Tabela 1 que, 124 (54,9\%) gestantes cursaram o ensino médio; e apenas 18 (8\%) cursaram o ensino superior.

Com referência à situação conjugal, verifica-se na Tabela 1 que, a maioria das entrevistadas relatou possuir companheiro 200 (88,1\%). Em relação à ocupação ressalta-se que a maioria das gestantes informou não exercer atividade remunerada $152(67 \%)$, conforme observamos na Tabela 1. As demais $75(33 \%)$ afirmaram que realizavam alguma atividade remunerada, dentre as quais $15(6,6 \%)$ relacionavamse a atividades domésticas remuneradas (empregadas domésticas, faxineiras e cozinheiras); 21 (9,25\%) atividades ocupacionais relacionadas a indústrias; 24 (10,5\%) ao comércio; 5 (2,2\%) administração pública; 7 (3\%) autônomas; 2 (0,9\%) rurais e $1(0,4)$ presidiária.

A renda familiar informada pelas gestantes variou de nenhuma renda a 5 salários míninos, sendo que, conforme observado na Tabela 1, 43 (19\%) das entrevistadas referiram renda inferior a 1 salário mínimo, 105 (46,3\%) com 1 a 2 salários mínimos e 79 (34,8\%) com renda superior a 2 salários mínimos. 
Tabela 1 - Distribuição das 227 gestantes, segundo características socioeconômicas. Catanduva SP, 2010

\begin{tabular}{lrr}
\hline Variáveis socioeconômicas & N & \\
\hline Idade (anos) & 34 & 15 \\
$\quad$ Menos de 18 & 176 & 77,5 \\
18 a 34 & 17 & 7,5 \\
35 ou mais & & \\
& 85 & 37,4 \\
Escolaridade completa & 124 & 54,6 \\
$\quad$ Fundamental & 18 & 7,9 \\
$\quad$ Médio & & 11,9 \\
Superior & 27 & 88,1 \\
Situação Conjugal & 200 & \\
Sem parceiro & & 33 \\
Com parceiro & 75 & 67 \\
& 152 & \\
Ocupação & & 19 \\
Remunerada & 43 & 46,3 \\
Não remunerada & 105 & 34,8 \\
Renda familiar (salário mínimo) & 79 & \\
< 1 a menos que 2 & & \\
2 ou + & & \\
\hline
\end{tabular}

\subsection{Condições clínico-obstétricas das participantes do estudo}

Os dados clínicos obstétricos da gestação atual das participantes do estudo estão apresentados na Tabela 2.

Pode-se observar que a idade gestacional (calculada pelo ultra-som obstétrico em sua maioria) foi superior a 24 semanas entre as participantes totalizando 158 $(69,6 \%)$, com uma média de 28,25 e desvio padrão de $\pm 6,06$. Cabe destacarmos que a idade gestacional mínima foi de 20 semanas (critério estabelecido para o estudo) e a máxima foi de 42 semanas.

Em nosso estudo o número de consultas de pré-natal incluindo a consulta em que foi realizada a coleta de dados variou de uma a 10, com uma média de 5,1 e desvio padrão de $\pm 2,3$. 
Tabela 2 - Distribuição das 227 gestantes, segundo características clínico-obstétricas da gestação atual. Catanduva - SP, 2010

\begin{tabular}{lrr}
\hline Variáveis & N & $\%$ \\
\hline Idade gestacional (semanas) & 69 & \\
$\leq 24$ & 158 & 30,4 \\
$>24$ & & 69,6 \\
Complicações & 69 & \\
Sim & 158 & 30,4 \\
Não & & 69,6 \\
Ganho de peso ponderal na gestação & 65 & \\
Adequado & 17 & 28,6 \\
Acima esperado & 145 & 63,5 \\
Abaixo esperado & & \\
Restrição de crescimento intra-uterino & 24 & 10,6 \\
Sim & 203 & 89,4 \\
Não & & \\
\hline
\end{tabular}

No que se refere a complicações apresentadas na gestação atual, 69 (30,4\%) apresentaram alguma complicação como: hipertensão arterial, diabetes gestacional, descolamento prematuro de placenta, infecção do trato urinário, anemia, toxoplasmose, cardiopatias, hepatite C e síndrome anti fosfolípide. Da amostra estudada 24 (10,6\%) gestantes apresentaram restrição de crescimento intra-uterino conforme mostra a Tabela 2.

Cabe destacar que entre as 227 mulheres estudadas $60(26,4 \%)$ estavam sendo acompanhadas em um ambulatório de referência para gestação de alto risco no período estudado.

A Tabela 2 revela ainda que para a característica ganho de peso ponderal na gestação atual, até o momento da coleta de dados, houve uma predominância de ganho de peso abaixo do esperado na gestação para $145(64,2 \%)$ gestantes, e apenas $65(28,8 \%)$ apresentaram um ganho de peso considerado adequado, 
conforme orientação do Ministério da Saúde, 2006. O ganho de peso semanal teve uma média de 0,25 Kg, com desvio padrão de $\pm 0,37$.

Os dados clínicos obstétricos de gestações anteriores das participantes do estudo estão apresentados na Tabela 3.

Quanto ao número de gestações, segundo as participantes o número máximo de gestações foi sete, com uma média de 2,17 e desvio padrão de $\pm 1,29$. Quanto ao número de partos este variou de 1 a 4 partos. De acordo com os dados da Tabela 3 verifica-se que a maioria $147(64,8 \%)$ das gestantes apresentava uma ou mais gestações enquanto que 80 (35,2\%) encontravam-se na primeira gravidez.

Cabe ressaltar que, dentre as 147 multigestas, foi possível identificar que o intervalo mínimo entre as gestações foi de dois meses, e o máximo de 19 anos. Destas gestantes $51(34,7 \%)$ apresentaram um intervalo interpartal menor que dois anos sendo que, $3(2 \%)$ com um intervalo de 2 meses, uma $(0,7 \%)$ gestante com intervalo de 4 meses, uma (0,7\%) com intervalo de 6 meses e uma $(0,7 \%)$ com intervalo de 9 meses. Por outro lado observa-se que $52(35,4 \%)$ mulheres apresentaram intervalos entre as gestações maiores que cinco anos.

Em nosso estudo, 39 (26,5\%) das 147 gestantes com 2 ou mais gestações referiram complicações em gestações anteriores, entre as quais destacam-se: hipertensão arterial, diabetes gestacional, descolamento prematuro de placenta, infecção do trato urinário, toxoplasmose, cardiopatias, hepatite $\mathrm{C}$, amniorrexe prematura e envelhecimento placentário.

Podemos observar na Tabela 3 que, das 147 gestantes com duas ou mais gestações, 60 (40,8\%) das entrevistadas tiveram a experiência de parto vaginal, enquanto que $87(59,2 \%)$ relataram parto cesárea anterior. 
Tabela 3 - Distribuição das 227 gestantes, segundo características clínico-obstétricas de gestações anteriores. Catanduva - SP, 2010

\begin{tabular}{lrc}
\hline Variáveis & N & $\%$ \\
\hline Número de gestações & 80 & 35,2 \\
1 & 147 & 64,8 \\
2 ou + & & \\
Tipo de Parto & 60 & 26,4 \\
Vaginal & 87 & 38,3 \\
Cesárea & 80 & 35,2 \\
Não se aplica * & & \\
Complicações & 39 & 17,2 \\
Sim & 108 & 47,6 \\
Não & 80 & 35,2 \\
Não se aplica * & & \\
& 42 & 18,5 \\
Aborto & 105 & 46,2 \\
Sim & 80 & 35,2 \\
Não & & \\
Não se aplica * & 19 & 8,4 \\
Problemas com Rn & 128 & 56,4 \\
Sim & 80 & 35,2 \\
Não & & \\
Não se aplica * & & \\
& * Refere-se à 1ํ gestação
\end{tabular}

Quanto à presença de aborto, 42 (18,5\%) das estudadas tiveram história de aborto, com um mínimo de um e máximo de três. Ainda em relação às características clínico-obstétricas de gestações anteriores, 19 (8,4\%) gestantes referiram ter vivenciado problemas relacionados aos recém-nascidos, como prematuros ou com restrição de crescimento.

\section{3 Fatores de risco psicossociais na gestação}

Com referência à presença de fatores de risco psicossociais durante a gestação, conforme Tabela 4, constata-se que $60(26,7 \%)$ das gestantes sofreram perda recente de alguém especial. Quanto ao hábito do fumo, 63 (28\%) das gestantes afirmaram história pessoal de tabagismo e 21 (9,3\%) das participantes 
relataram que mantinham o hábito de fumar durante a gestação atual. Da mesma forma, identificou-se $6(2,8 \%)$ gestantes que ingeriam bebidas alcoólicas na gestação atual. Em relação ao uso de drogas ilícitas, nenhuma das participantes afirmou fazer uso durante a gestação, enquanto que 19 (8,4\%) afirmaram o uso de drogas antes da gestação atual.

Tabela 4 - Distribuição das 227 gestantes, segundo os fatores de risco psicossociais (perda de alguém, tabagismo, usa de álcool e drogas ilícitas). Catanduva - SP, 2010

\begin{tabular}{lrr}
\hline Variáveis & N & $\%$ \\
\hline Perda recente de & 60 & \\
alguém especial & 165 & 26,7 \\
Sim & & \\
Não & 63 & 28 \\
História de tabagismo & 162 & 72 \\
Sim & & \\
Não & 21 & 9,3 \\
Tabagismo em gestação atual & 204 & 90,7 \\
Sim & & \\
Não & 6 & 2,7 \\
Uso de álcool na gestação atual & 219 & 97,3 \\
Sim & & 8,4 \\
Não & 19 & 91,6 \\
História de uso de drogas & 206 & \\
Sim & & \\
Não & & \\
\hline
\end{tabular}

A Tabela 5 apresenta a distribuição das participantes do estudo segundo a presença de violência na gestação. Pode-se observar que vários tipos de violência estiveram presentes na vida das participantes: 85 (37,4\%) gestantes relaram história de violência, sendo que 64 (28,6\%) relataram história de violência emocional; 35 $(15,6 \%)$ de violência física e $10(4,4 \%)$ de violência sexual. Quanto à gestação atual, $38(16,7 \%)$ gestantes relaram história de violência, sendo que, 35 (15,3\%) relataram ter sofrido violência emocional, $7(3,1 \%)$ violência física e nenhuma relatou violência 
sexual. Chama ainda a atenção o fato de que três participantes preferiram não responder se tais experiências foram vivenciadas por elas na gestação atual.

Tabela 5 - Distribuição das 227 gestantes, segundo os fatores de risco psicossociais (relato de violência). Catanduva - SP, 2010

\begin{tabular}{lcccc}
\hline \multicolumn{1}{c}{ Violência } & Anterior & \multicolumn{3}{c}{ Atual $^{*}$} \\
\hline História de violência & $\mathbf{N}$ & $\%$ & $\mathbf{N}$ & $\%$ \\
História de violência sexual & 85 & 37,4 & 38 & 16,7 \\
História de violência física & 10 & 4,4 & 0 & 0 \\
História de violência emocional & 35 & 15,6 & 7 & 3,1 \\
\hline${ }^{*}$ 03 gestantes não responderam & 64 & 28,6 & 35 & 15,3 \\
\hline
\end{tabular}

\section{4 Perfil Psicossocial das participantes}

As Tabelas 6, 7, 8 e 9 apresentam a frequência de respostas de cada subescala das dimensões do PPP (estresse, apoio social do companheiro, apoio social de outras pessoas e autoestima) bem como a média de escores e desvio padrão em cada dimensão analisada.

\subsubsection{Percepção de Estresse}

De acordo com as respostas aos itens relacionados ao Estresse, apresentados na Tabela 6, a média da soma total dos pontos foi de $18,7( \pm 5,5)$, 
significando que as gestantes estudadas apresentaram baixos escores de estresse uma vez que o intervalo da soma das possíveis respostas é de 11 a 44 pontos.

Tabela 6 - Distribuição de frequências das respostas das 227 gestantes aos itens da subescala de Estresse $^{*}$ do PPP. Catanduva, 2010

\begin{tabular}{|c|c|c|c|c|}
\hline \multicolumn{5}{|l|}{ Itens } \\
\hline & 1 & 2 & 3 & 4 \\
\hline & Nenhum & Algum & Moderado & Intenso \\
\hline A. Preocupações financeiras & $70(30,8 \%)$ & $57(25,1 \%)$ & $63(27,8 \%)$ & $37(16,3 \%)$ \\
\hline B. Outras preocupações com dinheiro & $53(23,4 \%)$ & $71(31,3 \%)$ & $56(24,7 \%)$ & $47(20,7 \%)$ \\
\hline C. Problemas relacionados à família & $131(57,7 \%)$ & $35(15,4 \%)$ & $24(10,6 \%)$ & $37(16,3 \%)$ \\
\hline $\begin{array}{l}\text { D. Ter de mudar de endereço, mesmo que } \\
\text { tenha sido recentemente ou que } \\
\text { acontecerá no futuro }\end{array}$ & $140(61,7 \%)$ & $36(15,9 \%)$ & $29(12,8 \%)$ & $22(9,7 \%)$ \\
\hline E. Perda recente de alguém especial & $169(74,5 \%)$ & $15(6,6 \%)$ & $11(4,95)$ & $32(14,1 \%)$ \\
\hline F. Gestação atual & $111(48,9 \%)$ & $40(17,6 \%)$ & $48(21,1 \%)$ & $28(12,3 \%)$ \\
\hline $\begin{array}{l}\text { G. Estar sofrendo violência/abuso: sexual, } \\
\text { emocional, ou física }\end{array}$ & $210(92,5 \%)$ & $6(2,6 \%)$ & $5(2,2 \%)$ & $6(2,6 \%)$ \\
\hline H. Problemas com álcool e/ou drogas & $218(96,0 \%)$ & $6(2,6 \%)$ & $3(1,3 \%)$ & 0 \\
\hline I. Problemas no trabalho & $192(84,6 \%)$ & $12(5,3 \%)$ & $4(1,8 \%)$ & $19(8,3 \%)$ \\
\hline J. Problemas relacionados aos amigos & $195(85,9 \%)$ & $20(8,8 \%)$ & $8(3,5 \%)$ & $4(1,8 \%)$ \\
\hline K. Sentir-se geralmente sobrecarregada & $100(44,0 \%)$ & $53(23,3 \%)$ & $33(14,5 \%)$ & $41(18,0 \%)$ \\
\hline
\end{tabular}

${ }^{*}$ Média $=18,7$ (desvio padrão=5,5)

Observa-se, na Tabela 6, que a maioria das participantes do presente estudo pontuou como tendo nenhum estresse para questões como: Problemas relacionados 
à família, Ter de mudar de endereço, Perda recente de alguém especial, Estar sofrendo violência/abuso, Problemas com álcool elou drogas, Problemas no trabalho e Problemas relacionados aos amigos.

As preocupações financeiras e com dinheiro, além de sentir-se geralmente sobrecarregada foram os itens nos quais as participantes revelaram algum ou moderado estresse.

\subsubsection{Percepção de Apoio Social do Companheiro}

A Tabela 7 apresenta a distribuição da freqüência de respostas para cada item da subescala Apoio Social do Companheiro do PPP, cujas respostas variaram de muito insatisfeita (1) a muito satisfeita (6).

Os dados revelam que a maioria das participantes pontuou em nove dos 11 itens como muito satisfeita com o Apoio Social do Companheiro.

Embora os itens Sai de sua rotina para fazer coisas especiais e importantes para mim e Tolera meus "altos e baixos" e meus comportamentos inesperados não foram pontuados como muito satisfeita pela maioria das participantes: os mesmos obtiveram uma pontuação muito próxima à média daquela pontuação (44\% e 43,6\% respectivamente).

Os dados nos permitem afirmar que as gestantes estudadas apresentam uma percepção bastante positiva em relação ao suporte de seus companheiros. No conjunto apresentaram uma média de $51,6( \pm 16,9)$ pontos nos escores para essa subescala, tendo em vista que o valor máximo do escore para apoio social é de 66 pontos. 
Tabela 7 - Distribuição de frequências das respostas das 200 gestantes sobre o Apoio Social recebido do Companheiro*, por item

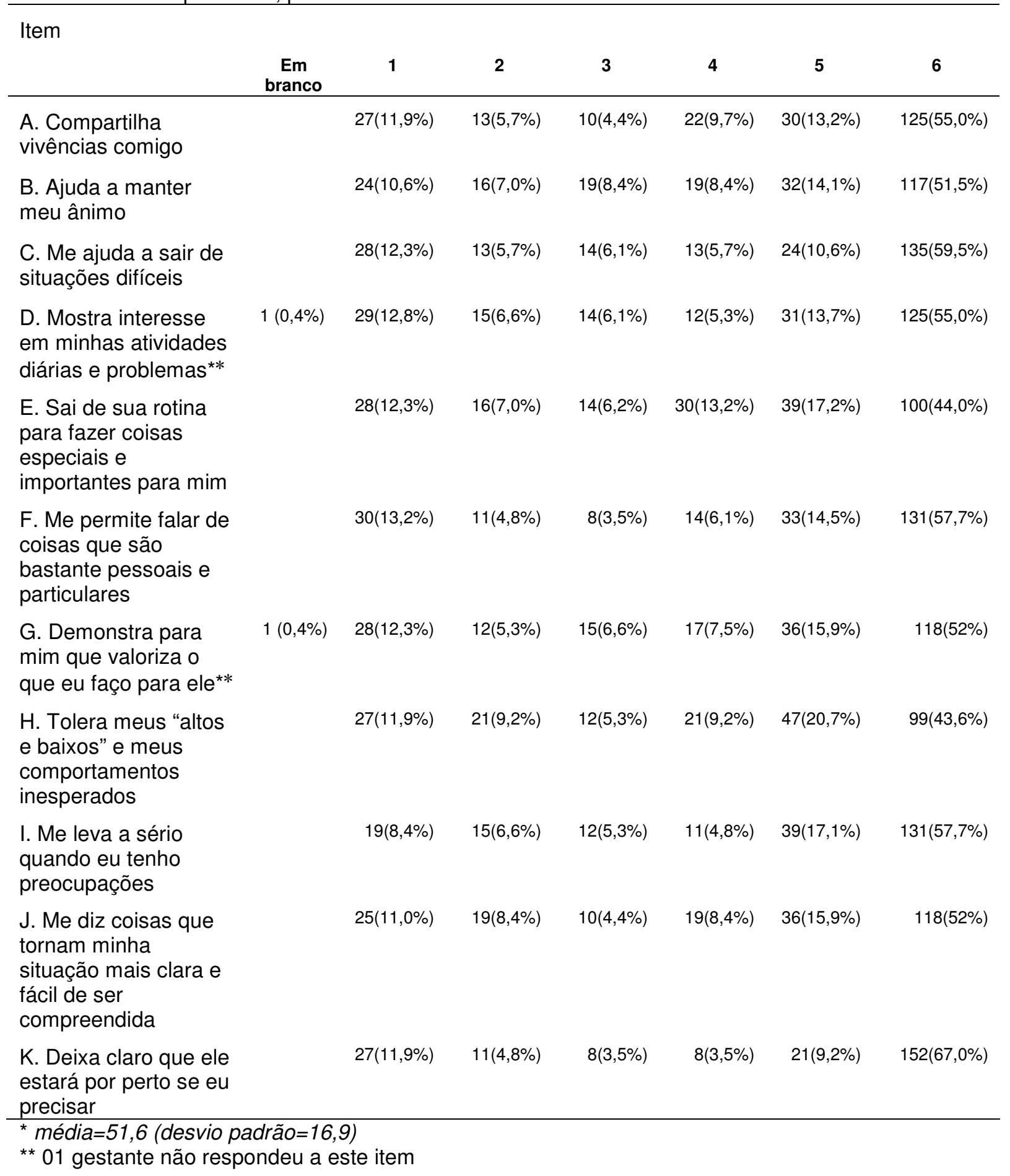




\subsubsection{Percepção de Apoio Social de outras pessoas}

No que se refere ao Apoio Social percebido pelas gestantes por outras pessoas significantes (Tabela 8), verifica-se que houve uma variabilidade na pontuação das respostas aos itens, sendo que apenas no item Deixa claro que ele estará por perto se eu precisar foi obtido o escore máximo de seis pontos, ou seja, muito satisfeita pela maioria das mulheres (66\%).

Por outro lado, apesar de se identificar essa variabilidade de respostas aos itens da subescala pode-se verificar que as maiores pontuações foram para os escores de seis pontos (muito satisfeitas). No conjunto das respostas pode-se verificar que as participantes do estudo apresentaram uma percepção positiva sobre o apoio oferecido por pessoas significantes, e o valor médio da soma dos escores foi $50,1( \pm 16,2)$.

\subsubsection{Percepção de Autoestima}

A Tabela 9 apresenta a frequência das respostas para cada um dos 11 itens da subescala sobre autoestima. Analisando tais dados, foi possível verificar que houve uma variabilidade de respostas para aqueles itens cujos significados representam uma postura positiva de si mesma. No entanto, foi possível identificar que a maioria das participantes concorda com as seguintes frases: $A$. Você sente que é uma pessoa de valor, ou pelo menos que é igual aos outros; B. Você sente que tem um grande número de qualidades; D. Você se sente capaz de fazer as coisas pelo menos tão bem quanto à maioria das pessoas; F. Você tem uma atitude positiva consigo mesma, revelando percepção de aspectos positivos para o bemestar psicossocial de si mesmas. 
Tabela 8 - Distribuição de frequências das respostas das 227 gestantes sobre Apoio Social de outras pessoas*, por item. Catanduva, SP, 2010

\begin{tabular}{|c|c|c|c|c|c|c|c|}
\hline \multicolumn{8}{|l|}{ Itens } \\
\hline & $\underset{\text { branco }}{\text { Em }}$ & 1 & 2 & 3 & 4 & 5 & 6 \\
\hline $\begin{array}{l}\text { A. Compartilha } \\
\text { vivências comigo }\end{array}$ & & $22(9,7 \%)$ & $15(6,6 \%)$ & $20(8,8 \%)$ & $26(11,4 \%)$ & $37(16,3 \%)$ & $107(47,1 \%)$ \\
\hline $\begin{array}{l}\text { B. Ajuda a manter } \\
\text { meu ânimo }\end{array}$ & & $19(8,4 \%)$ & $15(6,6 \%)$ & $16(7,0 \%)$ & $27(11,9 \%)$ & $49(21,6 \%)$ & $101(44,5 \%)$ \\
\hline $\begin{array}{l}\text { C. Me ajuda a sair } \\
\text { de situações } \\
\text { difíceis }\end{array}$ & & $23(10,1 \%)$ & $13(5,7 \%)$ & $18(7,9 \%)$ & $29(12,8 \%)$ & $38(16,7 \%)$ & $106(46,7 \%)$ \\
\hline $\begin{array}{l}\text { D. Mostra } \\
\text { interesse em } \\
\text { minhas atividades } \\
\text { diárias e } \\
\text { problemas }\end{array}$ & & $31(13,7 \%)$ & $14(6,1 \%)$ & $16(7,0 \%)$ & $31(13,7 \%)$ & $46(20,3 \%)$ & $89(39,2 \%)$ \\
\hline $\begin{array}{l}\text { E. Sai de sua } \\
\text { rotina para fazer } \\
\text { coisas especiais e } \\
\text { importantes para } \\
\text { mim }\end{array}$ & & $35(15,4 \%)$ & $18(7,9 \%)$ & $25(11,0 \%)$ & $26(11,4 \%)$ & $45(19,8 \%)$ & $78(34,3 \%)$ \\
\hline $\begin{array}{l}\text { F. Me permite } \\
\text { falar de coisas } \\
\text { que são bastante } \\
\text { pessoais e } \\
\text { particulares }\end{array}$ & & $31(13,7 \%)$ & $9(4,0 \%)$ & $20(8,8 \%)$ & $27(11,9 \%)$ & $39(17,1 \%)$ & $101(44,5 \%)$ \\
\hline $\begin{array}{l}\text { G. Demonstra } \\
\text { para mim que } \\
\text { valoriza o que eu } \\
\text { faço para ele }\end{array}$ & $1(0,4 \%)$ & $27(11,9 \%)$ & $14(6,1 \%)$ & $12(5,3 \%)$ & $29(12,8 \%)$ & $52(23,0 \%)$ & $92(40,5 \%)$ \\
\hline $\begin{array}{l}\text { H. Tolera meus } \\
\text { "altos e baixos" e } \\
\text { meus } \\
\text { comportamentos } \\
\text { inesperados }\end{array}$ & & $23(10,1 \%)$ & $23(10,1 \%)$ & $16(7,0 \%)$ & $33(14,5 \%)$ & $43(19,0 \%)$ & $89(39,2 \%)$ \\
\hline $\begin{array}{l}\text { I. Me leva a sério } \\
\text { quando eu tenho } \\
\text { preocupações }\end{array}$ & & $22(9,7 \%)$ & $13(5,7 \%)$ & $16(7,0 \%)$ & $24(10,6 \%)$ & $42(18,5 \%)$ & $110(48,5 \%)$ \\
\hline $\begin{array}{l}\text { J. Me diz coisas } \\
\text { que tornam minha } \\
\text { situação mais } \\
\text { clara e fácil de ser } \\
\text { compreendida }\end{array}$ & & $21(9,2 \%)$ & $15(6,6 \%)$ & $9(4,0 \%)$ & $25(11,0 \%)$ & $52(22,9 \%)$ & $105(46,2 \%)$ \\
\hline $\begin{array}{l}\text { K. Deixa claro que } \\
\text { ele estará por } \\
\text { perto se eu } \\
\text { precisar }\end{array}$ & & $24(10,6 \%)$ & $12(5,3 \%)$ & $7(3,0 \%)$ & $12(5,3 \%)$ & $22(9,7 \%)$ & $150(66,0 \%)$ \\
\hline
\end{tabular}


No entanto, os achados ainda revelam que um grande número de gestantes percebe situações que colocam suas autoestimas para baixo, conforme identificado nas respostas aos itens: E. Você sente que não tem muito do que se orgulhar; $G$. De modo geral, você se sente satisfeita consigo mesma; K. Você acha que controla a sua vida.

Tabela 9. Distribuição de frequências das respostas das 227 gestantes sobre autoestima* por item. Catanduva, SP, 2010

\begin{tabular}{|c|c|c|c|c|}
\hline item & $\begin{array}{c}1 \\
\text { Concordo } \\
\text { complet. }\end{array}$ & $\begin{array}{c}2 \\
\text { Concordo }\end{array}$ & $\begin{array}{c}3 \\
\text { discordo }\end{array}$ & $\begin{array}{c}4 \\
\text { Discordo } \\
\text { complet. }\end{array}$ \\
\hline $\begin{array}{l}\text { A. Você sente que é uma pessoa de } \\
\text { valor, ou pelo menos que é igual aos } \\
\text { outros }\end{array}$ & $101(44,5 \%)$ & $114(50,2 \%)$ & $8(3,5 \%)$ & $4(1,8 \%)$ \\
\hline $\begin{array}{l}\text { B. Você sente que tem um grande } \\
\text { número de qualidades }\end{array}$ & $60(26,4 \%)$ & $146(64,3 \%)$ & $18(7,9 \%)$ & $3(1,3 \%)$ \\
\hline $\begin{array}{l}\text { C. No final das contas, você sente que } \\
\text { é um fracasso }\end{array}$ & $10(4,4 \%)$ & $28(12,3 \%)$ & $124(54,6 \%)$ & $65(28,6 \%)$ \\
\hline $\begin{array}{l}\text { D. Você se sente capaz de fazer as } \\
\text { coisas pelo menos tão bem quanto a } \\
\text { maioria das pessoas }\end{array}$ & $72(31,7 \%)$ & $127(55,9 \%)$ & $22(9,7 \%)$ & $6(2,6 \%)$ \\
\hline $\begin{array}{l}\text { E. Você sente que não tem muito do } \\
\text { que se orgulhar }\end{array}$ & $20(8,8 \%)$ & $47(20,7 \%)$ & $113(49,8 \%)$ & $47(20,7 \%)$ \\
\hline $\begin{array}{l}\text { F. Você tem uma atitude positiva } \\
\text { consigo mesma }\end{array}$ & $77(33,9 \%)$ & $116(51,1 \%)$ & $24(10,6 \%)$ & $10(4,4 \%)$ \\
\hline $\begin{array}{l}\text { G. De modo geral, você se sente } \\
\text { satisfeita consigo mesma }\end{array}$ & $10(4,4 \%)$ & $34(15,0 \%)$ & $109(48,0 \%)$ & $74(32,6 \%)$ \\
\hline $\begin{array}{l}\text { H. Você queria ter mais respeito por si } \\
\text { mesma }\end{array}$ & $38(16,7 \%)$ & $101(44,5 \%)$ & $71(31,3 \%)$ & $17(7,5 \%)$ \\
\hline I. Às vezes, você se sente inútil & $27(11,9 \%)$ & $73(32,1 \%)$ & $81(35,7 \%)$ & $46(20,3 \%)$ \\
\hline $\begin{array}{l}\text { J. Às vezes, você acha que não é boa } \\
\text { que chega }\end{array}$ & $15(6,6 \%)$ & $65(28,6 \%)$ & $116(51,1 \%)$ & $31(13,7 \%)$ \\
\hline K. Você acha que controla a sua vida & $11(4,8 \%)$ & $53(23,3 \%)$ & $118(52,0 \%)$ & $45(19,8 \%)$ \\
\hline
\end{tabular}


Cabe aqui lembrar que, para efeito de cálculos estatísticos, conforme orientações das autoras do instrumento PPP, os itens $A, B, D, F, G, K$ foram computados de forma reversa, visto que tratam de frases redigidas como afirmativas. Isso porque os maiores escores significam maior autoestima.

Diante de tais acertos para o cálculo da média dos escores foi identificado, uma média na soma total dos escores de 29,2 (desvio padrão $=3,2$ ) pontos, significando que as participantes deste estudo tendem a apresentar uma autoestima positiva, uma vez que a pontuação para tal dimensão de bem-estar psicossocial varia de 11 a 44 pontos e o ponto médio desse intervalo situa-se em 27,5.

\section{5 Fatores de risco para o bem-estar psicossocial de gestantes: estresse, apoio social e autoestima}

\subsubsection{Fatores de risco e Percepção de Estresse}

Analisando a variável resposta presença de estresse na gestação, foi possível identificar entre as variáveis sócio-econômicas (Tabela 10) que a idade e a situação conjugal das participantes mostraram-se significativas à exposição ao estresse $(p=0,007, p=0,028$ respectivamente). De acordo com o teste $F$, pode-se afirmar que as mulheres com mais de 35 anos apresentaram maiores escores de estresse $\left({ }_{\bar{x}}=21,9\right)$, quando comparadas com o grupo de mulheres menores de 18 anos e de 18 a 34 anos. Por outro lado, as mulheres sem parceiros foram aquelas que apresentaram maiores escores de estresse $\left({ }_{\bar{x}}=20,8\right)$. 
Tabela 10 - Tamanho da amostra, média e desvio padrão da somas dos pontos de estresse de cada nível da variável explicativa dos dados socioeconômicos, e valor de $\mathrm{p}$ do teste $\mathrm{F}$

\begin{tabular}{|c|c|c|c|c|}
\hline variável & $\mathbf{n}$ & $\begin{array}{c}\text { Média } \\
(\bar{x})\end{array}$ & $\begin{array}{l}\text { Desvio } \\
\text { padrão } \\
\text { dp }\end{array}$ & $\mathbf{p}$ \\
\hline Idade (anos) & & & & 0,007 \\
\hline Menos de 18 & 34 & 16,8 & 4,2 & \\
\hline 18 a 34 & 176 & 18,7 & 5,3 & \\
\hline 35 ou mais & 16 & 21,9 & 7,6 & \\
\hline Escolaridade completa & & & & 0,465 \\
\hline Fundamental & 84 & 18,2 & 5,1 & \\
\hline Médio & 124 & 19 & 5,7 & \\
\hline Superior & 18 & 17,8 & 4,9 & \\
\hline Situação Conjugal & & & & 0,028 \\
\hline Sem parceiro & 27 & 20,8 & 7,5 & \\
\hline Com parceiro & 200 & 18,4 & 5,1 & \\
\hline Ocupação & & & & 0,364 \\
\hline Qualificados & 16 & 18 & 3,9 & \\
\hline Semi-qualificados & 35 & 19,8 & 7,5 & \\
\hline Não qualificados & 176 & 18,5 & 5,1 & \\
\hline $\begin{array}{l}\text { Renda familiar (salário } \\
\text { mínimo) }\end{array}$ & & & & 0,246 \\
\hline$<1$ & 43 & 18,4 & 5,7 & \\
\hline 1 a menos que 2 & 105 & 19,3 & 5,5 & \\
\hline $2 \mathrm{ou}+$ & 79 & 18 & 5,2 & \\
\hline
\end{tabular}

No que se refere aos dados clínico-obstétricos anteriores à gestação atual, foi possível observar que o número de gestações, o tipo de parto, aborto, complicações na gestação anterior e problemas com o RN (Tabela 11) foram variáveis: segundo o teste F, mostraram-se significantes à exposição ao estresse entre as gestantes estudadas $(p<0,001 ; p<0,001 ; p=0,0016 ; p=0,006 ; p=0,029$ respectivamente) . 
Tabela 11 - Tamanho da amostra, média e desvio padrão da somas dos pontos de estresse de cada nível da variável explicativa dos dados clínico-obstétricos de gestações anteriores, e valor de $p$ do teste $\mathrm{F}$

\begin{tabular}{|c|c|c|c|c|}
\hline variável & $\mathrm{n}$ & $\begin{array}{c}\text { Média } \\
(\bar{x})\end{array}$ & $\begin{array}{c}\text { Desvio } \\
\text { padrão } \\
\text { dp }\end{array}$ & $p$ \\
\hline Número de gestações & & & & $<0,001$ \\
\hline 1 & 80 & 16,9 & 3,9 & \\
\hline $2 \mathrm{ou}+$ & 147 & 19,7 & 5,9 & \\
\hline Tipo de Parto & & & & $<0,001$ \\
\hline Vaginal & 60 & 21,3 & 5,7 & \\
\hline Cesárea & 87 & 19,1 & 5,9 & \\
\hline Aborto & & & & 0,016 \\
\hline Sim & 42 & 20,5 & 6,6 & \\
\hline Não & 185 & 18,3 & 5,1 & \\
\hline Problemas com Rn & & & & 0,029 \\
\hline Sim & 19 & 21,3 & 5,3 & \\
\hline Não & 208 & 18,4 & 5,4 & \\
\hline $\begin{array}{l}\text { Complicação gestação } \\
\text { anterior }\end{array}$ & & & & 0,006 \\
\hline $\operatorname{Sim}$ & 39 & 20,8 & 6,2 & \\
\hline Não & 188 & 18,2 & 5,2 & \\
\hline
\end{tabular}

Os resultados indicam que as gestantes que tiveram duas ou mais gestações apresentaram maiores escores de estresse $\left(x_{x}=19,7\right)$ do que aquelas que se encontravam na primeira gestação $\left({ }_{\bar{x}}=16,9\right)$.

Em relação ao tipo de parto vivenciado pelas participantes do estudo, os achados revelam que as mulheres que tiveram a experiência de algum tipo de parto apresentaram escores maiores de estresse $\left(_{\bar{x}}=21,3\right.$ para parto vaginal e $\bar{x}=19,11$ para cesárea) do que as mulheres que nunca haviam experimentado a parturição (Tabela 11). Vale destacar que, embora apresentem uma pequena diferença no valor da média, as mulheres que tiveram experiência de parto vaginal apresentaram 
maiores escores de estresse comparado àquelas com cesárea, com um valor de $p$ quase significante, porém, sem significância estatística.

Com referência ao aborto experimentado pelas participante,s observa-se na Tabela 11 que tais mulheres apresentaram escores mais altos de estresse $\left({ }_{x}=20,5\right)$ quando comparados com aquelas que não vivenciaram tal experiência $\left({ }_{x}=18,3\right)$.

Outra variável que se mostrou significativa à exposição ao estresse foi a presença de complicações em gestações anteriores. De acordo com os testes estatísticos, as mulheres que apresentaram tais complicações $\left({ }_{x}=20,8\right)$ apresentaram escores maiores de estresse quando comparadas com aquelas que não tiveram complicações em gestações anteriores $\left({ }_{\bar{x}}=18,2\right)$.

Da mesma forma, os achados do presente estudo revelam que as mulheres cujos RNs apresentaram problemas, como baixo peso ao nascer e prematuridade, demonstraram níveis de estresse mais altos $\left({ }_{\bar{x}}=21,3\right)$ quando comparadas com aquelas cujos RNs não apresentaram tais problemas $\left({ }_{{ }_{x}}=18,4\right)$.

No que se refere aos dados clínico-obstétricos da gestação atual, foi possível ainda observar (tabela 12) que, as variáveis complicações na gestação atual e restrição de crescimento intrauterino mostraram-se significantes à exposição ao estresse entre às gestantes estudadas $(p=0,001 ; p=0,004)$.

Os resultados indicam que as gestantes que apresentaram alguma complicação na gravidez atual apresentaram maiores escores de estresse $\left({ }_{x}=20,3\right)$ do que aquelas que não passaram por tal experiência $(\bar{x}=17,9)$, conforme observado na Tabela 12. 
Tabela 12 - Tamanho da amostra, média e desvio padrão da somas dos pontos de estresse de cada nível da variável explicativa dos dados clínico-obstétricos da gestação atual, e valor de $\mathrm{p}$ do teste $\mathrm{F}$

\begin{tabular}{lrrrr}
\hline variável & $\mathbf{n}$ & média & $\mathbf{d p}$ & $\mathbf{p}$ \\
\hline Ganho de peso & 65 & 18,3 & 5,9 & 0,776 \\
$\begin{array}{l}\text { Adequado } \\
\text { Acima esperado }\end{array}$ & 16 & 18,6 & 5,8 & \\
Abaixo esperado & 145 & 18,8 & 5,2 & 0,556 \\
& & & & \\
$\begin{array}{l}\text { Idade gestacional } \\
\text { (semanas) }\end{array}$ & & & 0,001 \\
$\leq 24$ & 69 & 18,3 & 5,2 & \\
$>24$ & 158 & 18,8 & 5,5 & \\
Complicações gestação & & & & \\
atual & & & & \\
Sim & 69 & 20,3 & 5,4 & \\
Não & 158 & 17,9 & 5,3 & \\
Restrição de & & & & \\
crescimento intra- & & & & \\
uterino atual & & 21,6 & 7,1 & \\
Sim & 24 & 18,3 & 5,1 & \\
Não & 203 & & & \\
& & & & \\
\hline
\end{tabular}

Da mesma forma, os achados do estudo revelam que as gestantes apresentaram restrição de crescimento intra-uterino apresentaram maiores escores de estresse $(\bar{x}=21,6)$ cujas gestantes que apresentaram um crescimento intrauterino dentro dos padrões esperados $\left({ }_{x}=18,3\right)$, conforme orientação do Ministério da Saúde, 2006.

Nas Tabelas 13 e 14 estão apresentados os dados referentes ao estresse como variável resposta de acordo com os fatores de risco psicossociais.

Entre as variáveis explicativas referentes aos fatores de risco psicossociais distribuídos na Tabela 13 em resposta ao estresse foi possível identificar que apenas a perda recente de alguém se mostrou significativa $(p<0,001)$. 
Os resultados indicam na Tabela 13 que as gestantes que perderam alguém especial recentemente, apresentaram maiores escores de estresse $\left({ }_{x}=21,1\right)$ quando comparadas com o grupo de mulheres que não passaram por tal experiência.

Tabela 13 - Tamanho da amostra, média e desvio padrão da somas dos pontos de estresse de cada nível da variável explicativa dos fatores de risco psicossociais (perdas de alguém, tabagismo, uso de álcool e drogas ilícitas), e valor de $\mathrm{p}$ do teste $\mathrm{F}$

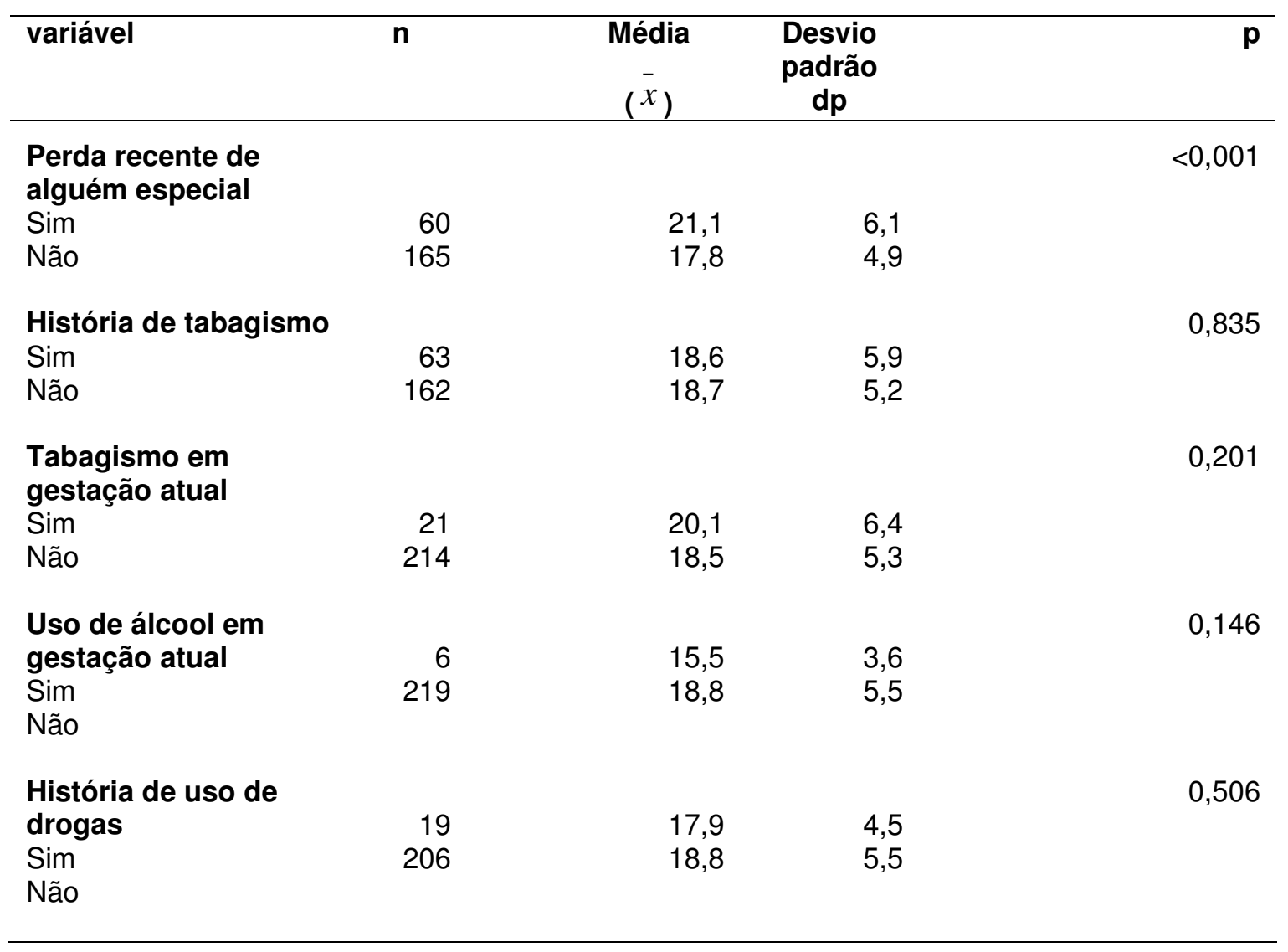

No que se refere ainda aos dados referentes à Tabela 13 cabe ressaltar que para a amostra de gestantes estudadas o hábito de fumo anteriormente e na gestação atual bem como o uso de álcool e drogas não se mostraram significativos para explicar a exposição aos níveis de estresse. 
Tabela 14 - Tamanho da amostra, média e desvio padrão da somas dos pontos de estresse de cada nível da variável explicativa dos fatores de risco psicossociais (relatos de violência), e valor de $p$ do teste $\mathrm{F}$

\begin{tabular}{|c|c|c|c|c|}
\hline variável & $n$ & $\begin{array}{l}\text { Média } \\
(\bar{x})\end{array}$ & $\begin{array}{l}\text { Desvio } \\
\text { padrão } \\
\text { dp }\end{array}$ & $p$ \\
\hline $\begin{array}{l}\text { História de violência } \\
\text { Sim } \\
\text { Não }\end{array}$ & $\begin{array}{r}85 \\
142\end{array}$ & $\begin{array}{l}21,2 \\
17,1\end{array}$ & $\begin{array}{l}5,9 \\
4,6\end{array}$ & $<0,001$ \\
\hline $\begin{array}{l}\text { História de violência } \\
\text { sexual } \\
\text { Sim } \\
\text { Não }\end{array}$ & $\begin{array}{r}10 \\
215\end{array}$ & $\begin{array}{l}20,7 \\
18,6\end{array}$ & $\begin{array}{l}7,8 \\
5,3\end{array}$ & 0,235 \\
\hline $\begin{array}{l}\text { História de violência } \\
\text { física } \\
\text { Sim } \\
\text { Não }\end{array}$ & $\begin{array}{r}35 \\
190\end{array}$ & $\begin{array}{l}21,5 \\
18,2\end{array}$ & $\begin{array}{l}4,8 \\
5,4\end{array}$ & $<0,001$ \\
\hline $\begin{array}{l}\text { História de violência } \\
\text { emocional } \\
\text { Sim } \\
\text { Não }\end{array}$ & $\begin{array}{r}64 \\
160\end{array}$ & $\begin{array}{l}21,9 \\
17,4\end{array}$ & $\begin{array}{l}5,9 \\
4,7\end{array}$ & $<0,001$ \\
\hline $\begin{array}{l}\text { Violência na gestação } \\
\text { Sim } \\
\text { Não }\end{array}$ & $\begin{array}{r}38 \\
189\end{array}$ & $\begin{array}{l}21,9 \\
18,0\end{array}$ & $\begin{array}{l}5,4 \\
5,2\end{array}$ & $<0,001$ \\
\hline $\begin{array}{l}\text { Violência física na } \\
\text { gestação } \\
\text { Sim } \\
\text { Não }\end{array}$ & $\begin{array}{r}7 \\
217\end{array}$ & $\begin{array}{l}21,3 \\
18,6\end{array}$ & $\begin{array}{l}3,2 \\
5,5\end{array}$ & 0,206 \\
\hline $\begin{array}{l}\text { Violência emocional na } \\
\text { gestação } \\
\text { Sim } \\
\text { Não }\end{array}$ & $\begin{array}{r}35 \\
189\end{array}$ & $\begin{array}{r}22,1 \\
18\end{array}$ & $\begin{array}{l}5,5 \\
5,2\end{array}$ & $<0,001$ \\
\hline
\end{tabular}

Em contrapartida, os dados da Tabela 14 revelaram que as variáveis história de violência $(p<0,001)$, de violência física $(p<0,001)$, e de violência emocional $(p<0,001)$ em algum momento da vida o relato de violência de qualquer tipo na gestação $(p<0,001)$ e a violência emocional na gestação $(p<0,001)$ mostraram-se significantes à exposição ao estresse entre as gestantes estudadas . 
De acordo com a análise estatística pode-se afirmar que os vários tipos de violência presentes na vida das participantes do estudo, as expuseram a um risco maior de estresse, quando comparadas ao grupo de mulheres que não vivenciaram a violência. As diferenças entre os maiores escores de estresse foram identificadas no grupo de gestantes que apresentaram história de violência em geral $\left({ }_{\bar{x}}=21,2\right)$; história de violência física $\left({ }_{\bar{x}}=21,5\right)$; e violência emocional em algum momento das suas vidas $\left({ }_{\bar{x}}=21,9\right)$. No item que trata da gestação atual, assim como os achados anteriores, as participantes que relataram história de qualquer tipo de violência naquela gestação apresentam um escore de estresse $\left({ }_{\bar{x}}=21,9\right)$ mais alto do que as que não relataram história de violência na gestação atual $\left({ }_{x}=18,0\right)$. Destaca-se ainda que aquelas mulheres que sofreram violência emocional durante a gestação estavam expostas a níveis mais elevados de estresse $\left({ }_{x}=22,1\right)$ do que as que não mencionaram esse tipo de violência na gestação $\left({ }_{x}=18,0\right)$.

Fato que chama a atenção, de acordo com os dados da Tabela 14 relacionase àqueles valores de $p$ extremamente baixos $(p<0,001)$ para a exposição ao estresse e sua relação com violência, revelando alta significância estatística entre os tipos de violência; sejam elas anteriores à gestação (violência em geral, violência física e emocional) ou não (violência em geral e violência emocional na gestação). Vale a pena ainda destacar que, na gestação, a violência tanto física $(p=0,206)$ como sexual, em qualquer momento de vida das gestantes $(p=0,235)$ não apresentou significância estatística. Possivelmente isso se deva ao número reduzido de respostas a tais itens, considerando ser a violência contra a mulher um tema ainda difícil de ser exposto pelas participantes, que muitas vezes se sentem inseguras e constrangidas em relatar tais aspectos da vida privada. 


\subsubsection{Fatores de risco e Percepção de Apoio social recebido do companheiro}

Analisando a variável resposta Apoio social recebido pelo companheiro na gestação, foi possível identificar, entre as variáveis socioeconômicas apresentadas na Tabela 15, que a situação conjugal foi a única variável que se mostrou significativa na identificação de fatores de risco para as gestantes $(p=0,001)$. De acordo com o teste $\mathrm{F}$ pode-se afirmar que as gestantes sem parceiros apresentaram menores escores da somas dos pontos de apoio do companheiro $(\bar{x}=39,8)$, revelando, portanto, menos satisfação com o apoio social recebido do companheiro quando comparadas às gestantes que tinham seus parceiros $\left({ }_{x}=53,2\right)$.

A variável renda familiar apresentou-se quase significativa $(p=0,058)$ na identificação de fatores de risco, conforme observado na Tabela 15. Os menores escores de percepção de apoio social recebido pelos companheiros foram identificados nas participantes do estudo com renda inferior a 1 salário mínimo ${ }_{(\bar{x}}=$ 48,4), quando comparados com as gestantes com renda familiar superior a 1 salário mínimo.

Em comparação com as variáveis sócio-econômicas anteriores (situação conjugal e renda familiar), a idade, escolaridade e ocupação não se mostraram significativas, conforme dados apresentados na Tabela 15 ( $p=0,246, p=0,609$ e $\mathrm{p}=0,329)$. 
Tabela 15 - Tamanho da amostra, média e desvio padrão das somas dos pontos de apoio do companheiro de cada nível da variável explicativa dos dados socioeconômicos, e valor de $p$ do teste $\mathrm{F}$

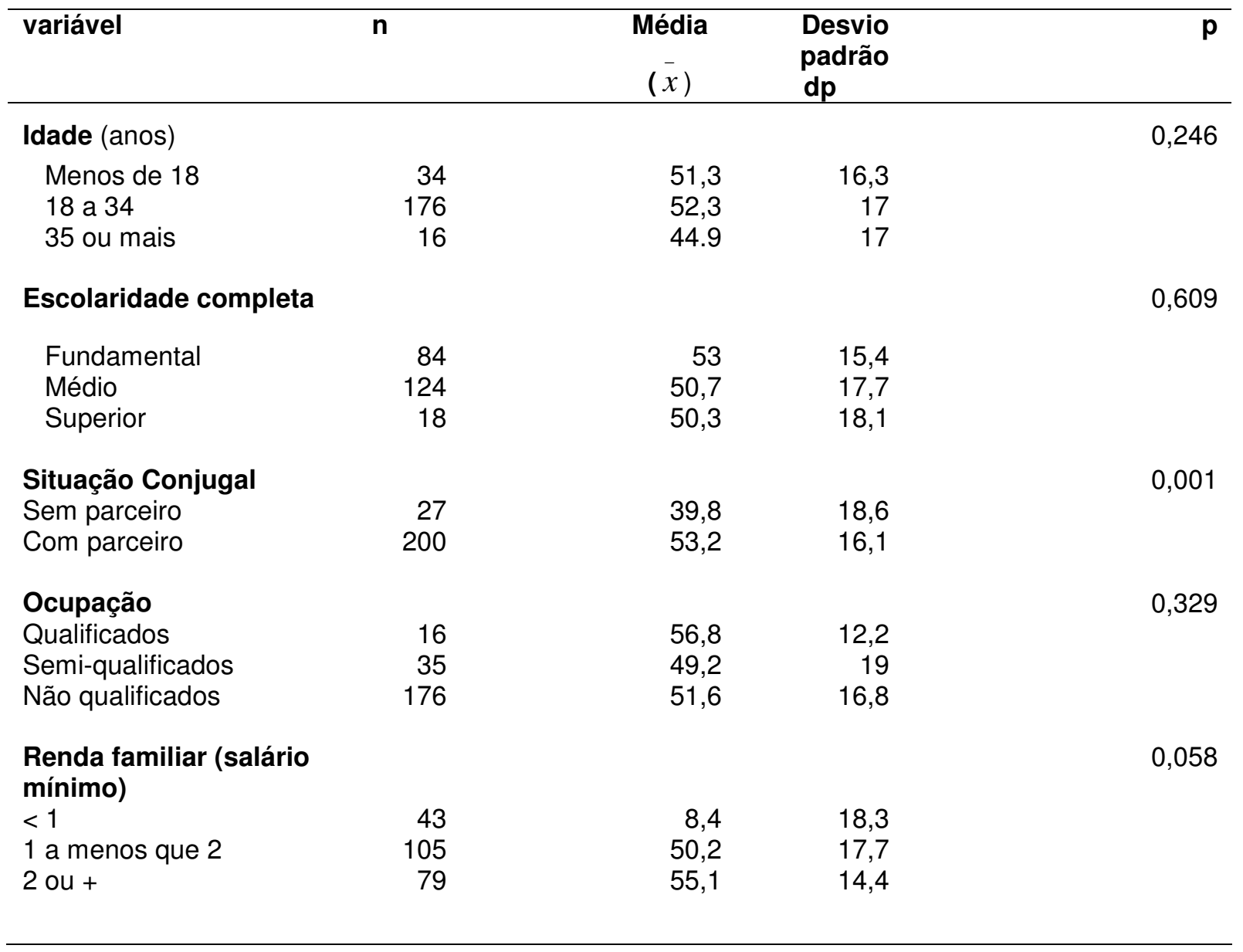

A Tabela 16 apresenta a distribuição de frequência dos pontos da variável resposta apoio do companheiro de acordo com as variáveis relacionadas aos dados clínico-obstétricos, da gestação atual.

Assim, analisando os valores de p para cada variável estudada, na Tabela 16, pode-se constatar que apenas a variável restrição de crescimento intrauterino mostrou-se significante entre as participantes do estudo $(p=0,006)$. Portanto, podese afirmar que as gestantes que tiveram restrição de crescimento intra-uterino apresentaram menores escores das somas dos pontos de apoio do companheiro 
$\left({ }_{x}=42,8\right)$ quando comparadas àquelas com crescimento uterino considerado adequado, isso revela, que aquelas que apresentaram restrição de crescimento intrauterino identificam-se como tendo menos apoio social de seus parceiros.

Tabela 16 - Tamanho da amostra, média e desvio padrão da somas dos pontos de apoio do companheiro de cada nível da variável explicativa dos dados clínico-obstétricos, da gestação atual, e valor de $\mathrm{p}$ do teste $\mathrm{F}$

\begin{tabular}{|c|c|c|c|c|}
\hline variável & n & $\begin{array}{l}\text { Média } \\
(\bar{x}) \\
\end{array}$ & $\begin{array}{l}\text { Desvio } \\
\text { padrão } \\
\text { dp }\end{array}$ & $p$ \\
\hline $\begin{array}{l}\text { Ganho de peso } \\
\text { Adequado } \\
\text { Acima esperado } \\
\text { Abaixo esperado }\end{array}$ & $\begin{array}{l}65 \\
16 \\
145\end{array}$ & $\begin{array}{l}51,6 \\
52,7 \\
51,4\end{array}$ & $\begin{array}{l}16,7 \\
16,2 \\
17,2\end{array}$ & 0,955 \\
\hline $\begin{array}{l}\text { Idade gestacional } \\
\text { (semanas) }\end{array}$ & & & & 0,802 \\
\hline $\begin{array}{l}\leq 24 \\
>24\end{array}$ & $\begin{array}{r}69 \\
158\end{array}$ & $\begin{array}{r}52 \\
51,4\end{array}$ & $\begin{array}{l}17,1 \\
16,9\end{array}$ & \\
\hline $\begin{array}{l}\text { Complicação gestação } \\
\text { atual }\end{array}$ & & & & 0,251 \\
\hline $\begin{array}{l}\text { Sim } \\
\text { Não }\end{array}$ & $\begin{array}{r}69 \\
158\end{array}$ & $\begin{array}{l}49,6 \\
52,4\end{array}$ & $\begin{array}{l}17,5 \\
16,6\end{array}$ & \\
\hline $\begin{array}{l}\text { Restrição de } \\
\text { crescimento intra- } \\
\text { uterino }\end{array}$ & & & & 0,006 \\
\hline Sim & 24 & 42,8 & 17,1 & \\
\hline Não & 203 & 52,6 & 16,6 & \\
\hline
\end{tabular}

A Tabela 17 apresenta a distribuição de freqüência dos pontos da variável resposta apoio do companheiro de acordo com as variáveis relacionadas aos dados clínico-obstétricos, de gestações anteriores.

Analisando os valores de $\mathrm{p}$ para cada variável estudada, na tabela acima descrita, pode-se constatar que nenhuma variável relacionada aos dados clínicoobstétricos de gestações anteriores, mostrou-se significante.

Porém, cabe ressaltar que a variável que trata de informação de problemas com o recém-nascido mostrou-se quase significante $(p=0,075)$ neste estudo, 
segundo os dados da Tabela 17. As gestantes cujos RNs apresentaram problemas como baixo peso e prematuridade em gestações anteriores apresentaram menores escores para apoio do companheiro $\left({ }_{x}=45\right)$, revelando portanto, menos satisfação com o apoio recebido do companheiro, quando comparadas com aquelas cujos RNs não apresentaram tais problemas.

Tabela 17 - Tamanho da amostra, média e desvio padrão da somas dos pontos de apoio do companheiro de cada nível da variável explicativa dos dados clínico-obstétricos, de gestações anteriores e valor de $p$ do teste $F$

\begin{tabular}{lrrrr}
\hline variável & $\mathbf{n}$ & $\begin{array}{c}\text { Média } \\
(\bar{x})\end{array}$ & $\begin{array}{l}\text { Desvio } \\
\text { padrão } \\
\text { dp }\end{array}$ & $\mathbf{p}$ \\
\hline $\begin{array}{l}\text { Número de gestações } \\
1\end{array}$ & & & & 0,213 \\
2 ou + & 80 & 53,5 & 16 & \\
Tipo de Parto & 147 & 50,6 & 17,3 & 0,268 \\
Vaginal & 45 & 50,6 & 17,5 & \\
Cesárea & 87 & 49,8 & 17,9 & 0,814 \\
Aborto & & & & 0,075 \\
Sim & 42 & 51 & 16,9 & \\
Não & 185 & 51,7 & 16,9 & 0,600 \\
Problemas com Rn & & & & \\
Sim & 19 & 45 & 21 & \\
Não & 208 & 52,2 & 16,4 & \\
Complicação gestação & & & & \\
anterior & & & & \\
Sim & 39 & 50,3 & 19 & \\
Não & 188 & 51,8 & 16,5 & \\
\hline
\end{tabular}

As Tabelas 18 e 19 apresentam os dados referentes à variável resposta apoio social do companheiro de acordo com a variável explicativa relacionada aos fatores psicossociais.

Como pode ser constatado na Tabela 18, para as variáveis relacionadas a fatores de risco psicossociais - perda de alguém, tabagismo, uso de álcool e drogas ilícitas, não se constataram níveis de significância nos escores da soma dos pontos de apoio do companheiro relacionada aos aspectos psicossociais. 
No entanto, cabe destacar que a exposição ao hábito de tabagismo na gestação atual apresentou-se próxima à significância estatística ( $p=0,077)$.

As gestantes estudadas que mantiveram o hábito de fumar durante a gravidez atual revelaram-se menos satisfeitas com o apoio recebido de seus parceiros $\left({ }_{\bar{x}}=45,3\right)$, quando comparadas com as que não tinham esse hábito $\left({ }_{\bar{x}}=52,2\right)$.

Tabela 18 - Tamanho da amostra, média e desvio padrão da somas dos pontos de apoio do companheiro de cada nível da variável explicativa dos fatores de risco psicossociais (perdas de alguém, tabagismo, uso de álcool e drogas ilícitas), e valor de $\mathrm{p}$ do teste $\mathrm{F}$

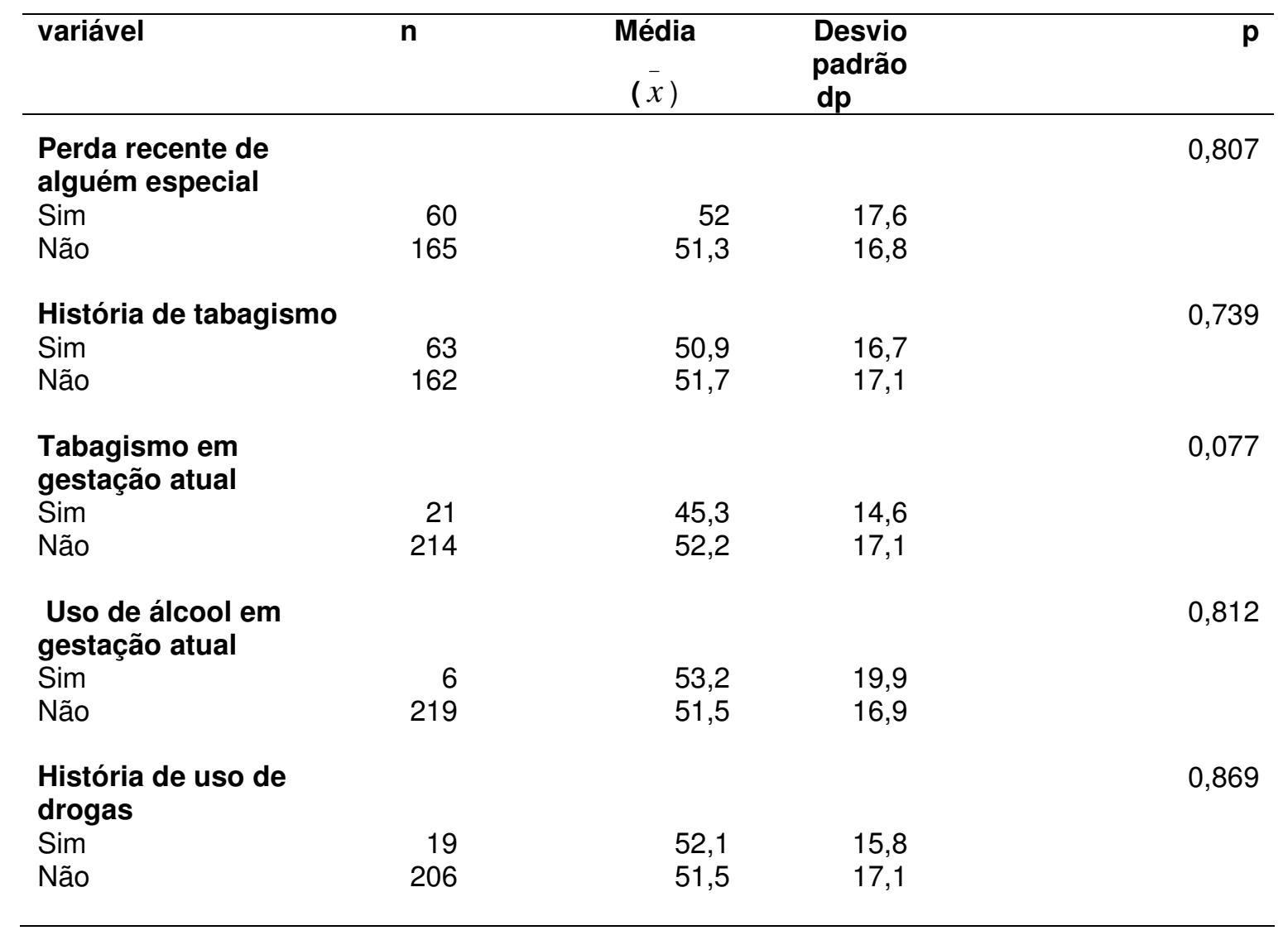

Do mesmo modo, as gestantes com história de violência emocional apresentaram escores menores na soma dos pontos $(\bar{x}=48,4)$, revelando menos satisfação com o apoio recebido do parceiro, quando comparadas àquelas que não relataram tal vivência $(\bar{x}=52,7)$. 
Da mesma forma, pode ser constatado na tabela 19 para as variáveis relacionadas a fatores de risco psicossociais - relatos de violência, também não foram constatados níveis de significância nos escores da soma de pontos destas variáveis. No entanto, história de violência emocional apresentou-se próxima à significância estatística $(p=0,083)$.

Tabela 19 - Tamanho da amostra, média e desvio padrão da somas dos pontos de apoio do companheiro de cada nível da variável explicativa dos fatores de risco psicossociais (relato de violência) e valor de $p$ do teste $F$

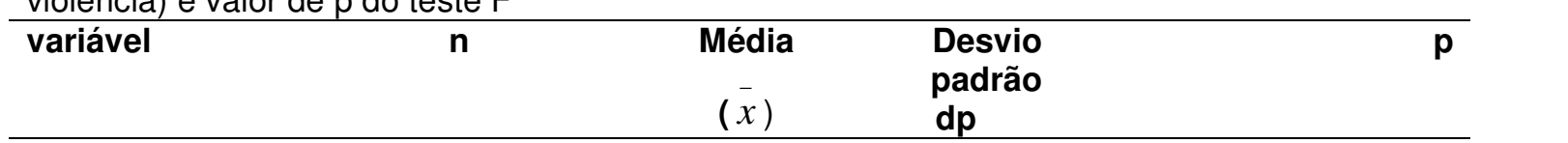

História de violência

0,560

sexual

Sim

10

Não

215

54,6

51,4

15,9

17

História de violência

física

Sim

35

Não

190

51

51,6

0,083

História de violência emocional

Sim

64

160

48,4

52,7

16,9

Não

História de Violência

Sim

85

142

50,1

52,5

0,299

Não

2

Violência física na

gestação

Sim

7

Não

217

47,7

51,5

13,7

16,3

17,2

0,778

Violência emocional na gestação

Sim

Não

$48,6 \quad 17,8$

$52 \quad 16,8$

Violência na gestação

Sim

Não

48,1

52,3

17,5

16,7

0,275

0,162 


\subsubsection{Fatores de risco e Percepção de Apoio social recebido de outras pessoas}

Buscando-se conhecer a relação entre a variável resposta Apoio social recebido de outras pessoas na gestação e as variáveis socioeconômicas apresentadas na Tabela 20, observa-se que não se constataram níveis de significância estatística nos escores da soma dos pontos da subescala apoio social de outras pessoas em nenhuma das variáveis estudadas. Esses resultados mostram que a soma dos escores apresentados na percepção de apoio social de outras pessoas não identifica nenhuma das variáveis sócio-econômicas relacionadas à idade, escolaridade, situação conjugal, ocupação e renda familiar como importante para a percepção de alto ou baixo nível de apoio social de outras pessoas.

Tabela 20 - Tamanho da amostra, média e desvio padrão da somas dos pontos de apoio de outras pessoas de cada nível da variável explicativa dos dados socioeconômicos, e valor de $\mathrm{p}$ do teste $\mathrm{F}$

\begin{tabular}{|c|c|c|c|c|}
\hline variável & $\mathbf{n}$ & média & $\mathrm{dp}$ & $\mathbf{p}$ \\
\hline \multicolumn{4}{|l|}{ Idade (anos) } & 0,147 \\
\hline Menos de 18 & 34 & 51 & 14,1 & \\
\hline 18 a 34 & 176 & 50,5 & 16,4 & \\
\hline 35 ou mais & 16 & 42,4 & 16,8 & \\
\hline \multicolumn{4}{|c|}{ Escolaridade completa } & 0,238 \\
\hline Fundamental & 84 & 52,4 & 13,7 & \\
\hline Médio & 124 & 48,8 & 17 & \\
\hline Superior & 18 & 48 & 20 & \\
\hline \multicolumn{4}{|c|}{ Situação Conjugal } & 0,995 \\
\hline Sem parceiro & 27 & 50,1 & 17,1 & \\
\hline Com parceiro & 200 & 50,1 & 16,1 & \\
\hline \multicolumn{4}{|l|}{ Ocupação } & 0,585 \\
\hline Qualificados & 16 & 54,1 & 10,6 & \\
\hline Semi-qualificados & 35 & 49,5 & 18,1 & \\
\hline Não qualificados & 176 & 49,9 & 16,2 & \\
\hline \multicolumn{4}{|c|}{$\begin{array}{l}\text { Renda familiar (salário } \\
\text { mínimo) }\end{array}$} & 0,369 \\
\hline$<1$ & 43 & 50,7 & 15,2 & \\
\hline 1 a menos que 2 & 105 & 48,5 & 17,1 & \\
\hline $2 \mathrm{ou}+$ & 79 & 51,9 & 15,4 & \\
\hline
\end{tabular}


A Tabela 21 distribui os dados relacionados à variável resposta, apoio social de outras pessoas de acordo com a variável explicativa dados clínico-obstétricos da gestação atual.

Tabela 21 - Tamanho da amostra, média e desvio padrão da somas dos pontos de apoio de outras pessoas de cada nível da variável explicativa dos dados clínico-obstétricos, da gestação atual e valor de $\mathrm{p}$ do teste $\mathrm{F}$

\begin{tabular}{|c|c|c|c|c|}
\hline variável & $\mathbf{n}$ & $\begin{array}{l}\text { Média } \\
(\bar{x})\end{array}$ & $\begin{array}{l}\text { Desvio } \\
\text { padrão } \\
\text { dp }\end{array}$ & $\mathbf{p}$ \\
\hline Ganho de peso & & & & 0,272 \\
\hline Adequado & 65 & 48,6 & 16,9 & \\
\hline Acima esperado & 16 & 55,9 & 13,1 & \\
\hline Abaixo esperado & 145 & 50 & 16.1 & \\
\hline $\begin{array}{l}\text { Idade gestacional } \\
\text { (semanas) }\end{array}$ & & & & 0.396 \\
\hline$\leq 24$ & 69 & 48,7 & 16,7 & \\
\hline$>24$ & 158 & 50,7 & 15,9 & \\
\hline $\begin{array}{l}\text { Complicação gestação } \\
\text { atual }\end{array}$ & & & & 0,724 \\
\hline Sim & 69 & 50,7 & 15,9 & \\
\hline Não & 158 & 49,9 & 16,4 & \\
\hline $\begin{array}{l}\text { Restrição de } \\
\text { crescimento intra- } \\
\text { uterino }\end{array}$ & & & & 0,013 \\
\hline Sim & 24 & 42,4 & 16,4 & \\
\hline Não & 203 & 51 & 15,9 & \\
\hline
\end{tabular}

Assim, analisando-se os resultados desta Tabela é possível verificar que apenas a variável restrição de crescimento intrauterino mostrou-se significante $(p=$ 0,013) entre as demais variáveis clínico-obstétricas da gestação atual para explicar as diferenças de escores na subescala sobre percepção de apoio social de outras pessoas. Pode-se então definir que o grupo de gestantes que não tiveram restrição de crescimento intrauterino apresentaram maiores escores de percepção de apoio de outras pessoas $\left({ }_{\bar{x}}=51\right)$ do que aquelas que passaram pela experiência $\left({ }_{\bar{x}}=42,4\right)$.

Expressando-nos de outra forma, podemos dizer que as gestantes que apresentaram restrição de crescimento intrauterino pontuaram menores escores da soma de pontos de apoio de outras pessoas $\left({ }_{\bar{x}}=42,4\right)$, quando comparadas àquelas 
com crescimento uterino considerado adequado. Isso indica que as gestantes que apresentaram restrição de crescimento intra-uterino identificam-se como tendo menos apoio de outras pessoas.

Em relação aos dados clínicos obstétricos de gestações anteriores observase na Tabela 22 que não se constatou níveis de estatística nos escores da soma dos pontos da subescala apoio social de outras pessoas em nenhuma das variáveis estudadas. Os resultados mostram que a soma dos escores apresentados na percepção de apoio social de outras pessoas não identifica nenhuma das variáveis clínico-obstétricas de gestações anteriores relacionadas ao número de gestações, tipo de parto aborto, problemas com RNs, e complicações nas gestações anteriores como importante para a percepção de alto ou baixo nível de apoio social de outras pessoas $(p=0,150 ; p=0,423 ; p=0,065 ; p=0,070 ; 0,579$, respectivamente).

Tabela 22 - Tamanho da amostra, média e desvio padrão da somas dos pontos de apoio de outras pessoas de cada nível da variável explicativa dos dados clínico-obstétricos de gestações anteriores, e valor de $\mathrm{p}$ do teste $\mathrm{F}$

\begin{tabular}{|c|c|c|c|c|}
\hline variável & $\mathbf{n}$ & $\begin{array}{l}\text { Média } \\
(\bar{x})\end{array}$ & $\begin{array}{l}\text { Desvio } \\
\text { padrão } \\
\text { dp }\end{array}$ & $p$ \\
\hline Número de gestações & & & & 0,150 \\
\hline 1 & 80 & 52,2 & 15 & \\
\hline $2 \mathrm{ou}+$ & 147 & 49 & 16,7 & \\
\hline Tipo de Parto & & & & 0,423 \\
\hline Vaginal & 45 & 50,4 & 14,3 & \\
\hline Cesárea & 87 & 48,4 & 17.4 & \\
\hline Aborto & & & & 0,065 \\
\hline Sim & 42 & 45,9 & 19,3 & \\
\hline Não & 185 & 51 & 15,3 & \\
\hline Problemas com RN & & & & 0,070 \\
\hline Sim & 19 & 43,7 & 16,9 & \\
\hline Não & 208 & 50,7 & 16 & \\
\hline $\begin{array}{l}\text { Complicação gestação } \\
\text { anterior }\end{array}$ & & & & 0,579 \\
\hline Sim & 39 & 48,8 & 17,8 & \\
\hline Não & 188 & 50,4 & 15,8 & \\
\hline
\end{tabular}


Porém, cabe ressaltar que assim como foi observado nos dados referentes à percepção do apoio do companheiro, a variável relacionada a problemas com o RN também se mostrou quase significante entre as entrevistadas $(p=0,070)$ conforme apresentado na Tabela 22.

As gestantes cujos RNs apresentaram baixo peso e prematuridade em gestações anteriores e as que relataram aborto apresentaram menores escores para apoio de outras pessoas $\left({ }_{\bar{x}}=43,7 ; \bar{x}_{\mathrm{x}}=45,9\right.$, respectivamente) revelando, portanto, menos satisfação com o apoio recebido de outras pessoas, quando comparadas com aquelas cujos RNs não apresentaram problemas e com aquelas que não vivenciaram o aborto.

A vivência de aborto também se mostrou quase significante $(p=0,065)$ à percepção de apoio social de outras pessoas, conforme demonstra a Tabela 22.

As Tabelas 23 e 24 apresentam os valores estatísticos relacionados à variável resposta apoio social de outras pessoas, de acordo com as variáveis relacionadas aos aspectos psicossociais.

Observamos na tabela 23 que em relação aos fatores de risco psicossociais tais como perda de alguém, tabagismo, uso de álcool e drogas ilícitas não se constatou níveis significativos nos escores da soma de pontos da subescala apoio social de outras pessoas em nenhuma das variáveis estudadas $(p=0,936 ; p=0,397$; 0,$131 ; 0,693 ; 0,949$, respectivamente). Os resultados mostram que a soma dos escores apresentados na percepção de apoio social de outras pessoas não identifica nenhuma variáveis de fatores de risco psicossociais relacionadas à perda de alguém, tabagismo, uso de álcool e drogas ilícitas como importante para a percepção de alto ou baixo nível de apoio social de outras pessoas. 
Tabela 23 - Tamanho da amostra, média e desvio padrão da somas dos pontos de apoio de outras pessoas de cada nível da variável explicativa dos fatores de risco psicossociais (perdas de alguém, tabagismo, uso de álcool e drogas ilícitas), e valor de $\mathrm{p}$ do teste $\mathrm{F}$

\begin{tabular}{|c|c|c|c|c|}
\hline variável & $\mathrm{n}$ & $\begin{array}{c}\text { Média } \\
(\bar{x})\end{array}$ & $\begin{array}{l}\text { Desvio } \\
\text { padrão } \\
\text { dp }\end{array}$ & $\mathbf{p}$ \\
\hline $\begin{array}{l}\text { Perda recente de } \\
\text { alguém especial }\end{array}$ & & & & 0,936 \\
\hline Sim & 60 & 50,2 & 17,2 & \\
\hline Não & 165 & 50 & 15,9 & \\
\hline História de tabagismo & & & & 0,397 \\
\hline Sim & 63 & 48,6 & 16 & \\
\hline Não & 162 & 50,7 & 16,3 & \\
\hline $\begin{array}{l}\text { Tabagismo em } \\
\text { gestação atual }\end{array}$ & & & & 0,131 \\
\hline Sim & 21 & 45 & 16,9 & \\
\hline Não & 214 & 50,6 & 16,1 & \\
\hline $\begin{array}{l}\text { Uso de álcool em } \\
\text { gestação atual }\end{array}$ & & & & 0,693 \\
\hline Sim & 6 & 52,7 & 20,7 & \\
\hline Não & 219 & 50 & 16,1 & \\
\hline $\begin{array}{l}\text { História de uso de } \\
\text { drogas }\end{array}$ & & & & 0,949 \\
\hline Sim & 19 & 50,3 & 15,3 & \\
\hline Não & 206 & 50 & 16,3 & \\
\hline
\end{tabular}

A Tabela 24 apresenta os valores estatísticos relacionados à variável resposta ao apoio social de outras pessoas de acordo com as variáveis relacionadas aos aspectos psicossociais, relatos de violência.

Diante da análise estatística de tais dados foi possível identificar que apenas a história de violência emocional apresentou significância estatística $(p=0,029)$ para a percepção de apoio de outras pessoas. Portanto, constata-se que as gestantes com história de violência emocional apresentaram menores escores na soma dos pontos de percepção de apoio de outras pessoas $\left(\bar{x}_{x}=46,3\right)$ indicando, portanto, que 
as gestantes que apresentaram história de violência emocional identificam-se como tendo menos apoio de outras pessoas.

Tabela 24 -Tamanho da amostra, média e desvio padrão da somas dos pontos de apoio de outras pessoas de cada nível da variável explicativa dos fatores de risco psicossociais (relatos de violência) e valor de $p$ do teste $F$

\begin{tabular}{|c|c|c|c|c|}
\hline variável & $\mathbf{n}$ & $\begin{array}{c}\text { Média } \\
(\bar{x})\end{array}$ & $\begin{array}{l}\text { Desvio } \\
\text { padrão } \\
\text { dp }\end{array}$ & $\mathbf{p}$ \\
\hline $\begin{array}{l}\text { História de violência } \\
\text { sexual }\end{array}$ & & & & 0,318 \\
\hline Sim & 10 & 55,1 & 10,7 & \\
\hline Não & 215 & 49,8 & 16,4 & \\
\hline $\begin{array}{l}\text { História de violência } \\
\text { física }\end{array}$ & & & & 0,830 \\
\hline Sim & 35 & 50,6 & 16,9 & \\
\hline Não & 190 & 50 & 16,1 & \\
\hline $\begin{array}{l}\text { História de violência } \\
\text { emocional }\end{array}$ & & & & 0,029 \\
\hline $\operatorname{Sim}$ & 64 & 46,3 & 17,8 & \\
\hline Não & 160 & 51,5 & 15,4 & \\
\hline História de violência & & & & 0,105 \\
\hline Sim & 85 & 47,8 & 17,4 & \\
\hline Não & 142 & 51,4 & 15,3 & \\
\hline $\begin{array}{l}\text { Violência física na } \\
\text { gestação }\end{array}$ & & & & 0,862 \\
\hline Sim & 7 & 49 & 18,3 & \\
\hline Não & 217 & 50,1 & 16,2 & \\
\hline $\begin{array}{l}\text { Violência emocional na } \\
\text { gestação }\end{array}$ & & & & 0,164 \\
\hline Sim & 35 & 46,5 & 17,6 & \\
\hline Não & 189 & 50,7 & 15,9 & \\
\hline Violência na gestação & & & & 0,116 \\
\hline Sim & 38 & 46,3 & 17,5 & \\
\hline Não & 189 & 50,9 & 15,8 & \\
\hline
\end{tabular}




\subsubsection{Fatores de risco e Percepção de Autoestima}

Analisando a variável resposta Autoestima na gestação, é possível identificar entre as variáveis socioeconômicas apresentadas na Tabela 25 que a renda familiar foi a única variável que se mostrou significativa na identificação da autoestima como fator de bem-estar psicossocial para as gestantes $(p=0,001)$.

De acordo com os achados deste estudo, as gestantes com renda superior a 2 salários mínimos apresentaram escores maiores de autoestima $(\bar{x}=30,2)$ quando comparadas às gestantes com renda inferior. Pode-se afirmar, portanto, que as gestantes com renda superior a dois salários mínimos apresentaram-se com maior autoestima, quando comparadas com aquelas com renda familiar inferior.

Cabe ainda chamar a atenção para o fato de que, embora não possa ter sido identificado, relevância estatística, mas muito próximo, à significância $(p=0,068)$, a ocupação se mostrou como uma variável de interesse na definição da autoestima entre as gestantes estudadas. A Tabela 25 mostra que as mulheres que referiram ter como ocupação atividades consideradas qualificadas foram aquelas que obtiveram escores mais altos $(\bar{x}=30,8)$ de percepção de autoestima mais positiva.

Quanto às variáveis clínico-obstétricas da gestação atual, foi possível observar de acordo com os dados apresentados na Tabela 26, que nenhuma das variáveis (ganho de peso, idade gestacional, complicações e restrição de crescimento intra-uterino) se mostrou significativa na identificação da autoestima entre as gestantes $(p=0,776 ; p=0,766 ; 0,882 ; 0,181)$. 
Tabela 25 - Tamanho da amostra, média e desvio padrão da somas dos pontos de autoestima de cada nível da variável explicativa dos dados socioeconômicos, e valor de $p$ do teste $F$

\begin{tabular}{|c|c|c|c|c|}
\hline variável & $\mathbf{n}$ & média & dp & $p$ \\
\hline \multicolumn{4}{|l|}{ Idade (anos) } & 0,316 \\
\hline Menos de 18 & 34 & 28,6 & 3,6 & \\
\hline 18 a 34 & 176 & 29,4 & 3,1 & \\
\hline 35 ou mais & 16 & 28,6 & 3,2 & \\
\hline \multicolumn{4}{|c|}{ Escolaridade completa } & 0,189 \\
\hline Fundamental & 84 & 29,2 & 3,2 & \\
\hline Médio & 124 & 29 & 3,1 & \\
\hline Superior & 18 & 30,5 & 2,4 & \\
\hline \multicolumn{4}{|l|}{ Situação Conjugal } & 0,534 \\
\hline Sem parceiro & 27 & 28,8 & 3,1 & \\
\hline Com parceiro & 200 & 29,2 & 3,2 & \\
\hline \multicolumn{4}{|l|}{ Ocupação } & 0,068 \\
\hline Qualificados & 16 & 30,8 & 3,6 & \\
\hline Semi-qualificados & 35 & 29,5 & 3,1 & \\
\hline Não qualificados & 176 & 29 & 3,1 & \\
\hline \multicolumn{4}{|c|}{$\begin{array}{l}\text { Renda familiar (salário } \\
\text { mínimo) }\end{array}$} & 0,001 \\
\hline$<1$ & 43 & 28,7 & 3,6 & \\
\hline 1 a menos que 2 & 105 & 28,6 & 2,9 & \\
\hline $2 \mathrm{ou}+$ & 79 & 30,2 & 3,1 & \\
\hline
\end{tabular}

Tabela 26 - Tamanho da amostra, média e desvio padrão da somas dos pontos de autoestima de cada nível da variável explicativa dos dados clínico-obstétricos da gestação atual, e valor de p do teste $\mathrm{F}$

\begin{tabular}{|c|c|c|c|c|}
\hline variável & $\mathbf{n}$ & $\begin{array}{c}\text { Média } \\
(\bar{x})\end{array}$ & $\begin{array}{l}\text { Desvio } \\
\text { padrão } \\
\text { dp }\end{array}$ & $\mathbf{p}$ \\
\hline Ganho de peso & & & & 0,776 \\
\hline Adequado & 65 & 29,2 & 3,2 & \\
\hline Acima esperado & 16 & 28,6 & 2,9 & \\
\hline Abaixo esperado & 145 & 29,2 & 3,2 & \\
\hline $\begin{array}{l}\text { Idade gestacional } \\
\text { (semanas) }\end{array}$ & & & & 0,766 \\
\hline$\leq 24$ & 69 & 29,1 & 3,2 & \\
\hline$>24$ & 158 & 29,2 & 3,2 & \\
\hline $\begin{array}{l}\text { Complicação nesta } \\
\text { gestação }\end{array}$ & & & & 0,882 \\
\hline Sim & 69 & 28,5 & 3 & \\
\hline Não & 158 & 29,5 & 3,2 & \\
\hline $\begin{array}{l}\text { Restrição de } \\
\text { crescimento intra- } \\
\text { uterino }\end{array}$ & & & & 0,181 \\
\hline Sim & 24 & 28,7 & 3,7 & \\
\hline Não & 203 & 29,3 & 3,1 & \\
\hline
\end{tabular}


Foi possível observar que entre as variáveis clínico-obstétricas de gestações anteriores (Tabela 27), que o número de gestações, o tipo de parto, problemas com RNs e complicações na gestação mostraram-se significantes na identificação da autoestima entre as gestantes estudadas $(p=0,044 ; p=0,036 ; p=0,016 ; p=0,027$ respectivamente), assim como observado na exposição ao estresse.

Tabela 27 - Tamanho da amostra, média e desvio padrão da somas dos pontos de auto estima de cada nível da variável explicativa dos dados clínico-obstétricos, de gestações anteriores e valor de $p$ do teste $\mathrm{F}$

\begin{tabular}{|c|c|c|c|c|}
\hline variável & $\mathbf{n}$ & $\begin{array}{c}\text { Média } \\
(\bar{x})\end{array}$ & $\begin{array}{l}\text { Desvio } \\
\text { padrão } \\
\text { dp }\end{array}$ & $\mathbf{p}$ \\
\hline Número de gestações & & & & 0,044 \\
\hline 1 & 80 & 29,8 & 3 & \\
\hline 2 ou + & 147 & 28,9 & 3,2 & \\
\hline Tipo de Parto & & & & 0,036 \\
\hline Vaginal & 45 & 28,3 & 2,9 & \\
\hline Cesárea & 87 & 29,1 & 3,3 & \\
\hline Aborto & & & & 0,752 \\
\hline $\operatorname{Sim}$ & 42 & 29,3 & 3,1 & \\
\hline Não & 185 & 29,2 & 3,2 & \\
\hline Problemas com Rn & & & & 0,016 \\
\hline Sim & 19 & 29,3 & 4 & \\
\hline Não & 208 & 29,2 & 3,1 & \\
\hline $\begin{array}{l}\text { Complicação gestação } \\
\text { anterior }\end{array}$ & & & & 0,027 \\
\hline Sim & 39 & 28,6 & 3,6 & \\
\hline Não & 188 & 29,4 & 3,1 & \\
\hline
\end{tabular}

Em relação ao número de gestações das participantes do estudo, os achados revelam que as mulheres que tiveram duas ou mais gestações apresentaram escores menores $(\bar{x}=28,9)$ para a autoestima quando comparadas com as gestantes com uma gestação. Constata-se, portanto, que as gestantes com mais de duas gestações apresentaram-se com menor autoestima quando comparadas com as que tiveram apenas uma gestação. 
Os resultados indicam que as mulheres que tiveram a experiência de algum tipo de parto apresentaram escores menores para autoestima $\left({ }_{x}=28,3\right)$ quando comparadas às mulheres que nunca experimentaram a parturição. Afirma-se, portanto, que as mulheres que tiveram experiência de algum tipo de parto, apresentaram uma percepção de autoestima mais negativa, quando comparadas àquelas que nunca deram à luz.

Tabela 28 - Tamanho da amostra, média e desvio padrão da somas dos pontos de autoestima de cada nível da variável explicativa dos fatores de risco psicossociais (perdas de alguém, tabagismo, uso de álcool e drogas ilícitas) e valor de $\mathrm{p}$ do teste $\mathrm{F}$

\begin{tabular}{|c|c|c|c|c|}
\hline variável & $\mathbf{n}$ & $\begin{array}{c}\text { Média } \\
(\bar{x})\end{array}$ & $\begin{array}{l}\text { Desvio } \\
\text { padrão } \\
\text { dp }\end{array}$ & $p$ \\
\hline $\begin{array}{l}\text { Perda recente de alguém } \\
\text { especial }\end{array}$ & & & & 0,235 \\
\hline $\operatorname{Sim}$ & 60 & 28,8 & 3,2 & \\
\hline Não & 165 & 29,3 & 3,2 & \\
\hline História de tabagismo & & & & 0,681 \\
\hline Sim & 63 & 29 & 3 & \\
\hline Não & 162 & 29,2 & 3,2 & \\
\hline $\begin{array}{l}\text { Tabagismo em gestação } \\
\text { atual }\end{array}$ & & & & 0,342 \\
\hline $\operatorname{Sim}$ & 21 & 28,6 & 2,8 & \\
\hline Não & 214 & 29,3 & 3,2 & \\
\hline $\begin{array}{l}\text { Uso de álcool em gestação } \\
\text { atual }\end{array}$ & & & & 0,874 \\
\hline Sim & 6 & 29 & 2,5 & \\
\hline Não & 219 & 29,2 & 3,2 & \\
\hline História de uso de drogas & & & & 0,460 \\
\hline Sim & 19 & 28,7 & 2,6 & \\
\hline Não & 206 & 29,2 & 3,2 & \\
\hline
\end{tabular}


Tabela 29 - Tamanho da amostra, média e desvio padrão da somas dos pontos de autoestima de cada nível da variável explicativa dos fatores de risco psicossociais (relato de violência) e valor de $p$ do teste $\mathrm{F}$

\begin{tabular}{|c|c|c|c|c|}
\hline variável & $\mathbf{n}$ & $\begin{array}{c}\text { Média } \\
(\bar{x})\end{array}$ & $\begin{array}{l}\text { Desvio } \\
\text { padrão } \\
\text { dp }\end{array}$ & $p$ \\
\hline História de violência & & & & 0,043 \\
\hline $\operatorname{Sim}$ & 85 & 28,6 & 3,2 & \\
\hline Não & 142 & 29,5 & 3,1 & \\
\hline $\begin{array}{l}\text { História de violência } \\
\text { sexual }\end{array}$ & & & & 0,611 \\
\hline Sim & 10 & 28,7 & 2,3 & \\
\hline Não & 215 & 29,2 & 3,2 & \\
\hline História de violência física & & & & 0,724 \\
\hline Sim & 35 & 29 & 3,5 & \\
\hline Não & 190 & 29,2 & 3,1 & \\
\hline $\begin{array}{l}\text { História de violência } \\
\text { emocional }\end{array}$ & & & & 0,001 \\
\hline Sim & 64 & 28,1 & 3,3 & \\
\hline Não & 160 & 29,6 & 3 & \\
\hline $\begin{array}{l}\text { Violência física na } \\
\text { gestação }\end{array}$ & & & & 0,378 \\
\hline Sim & 7 & 28,1 & 4 & \\
\hline Não & 217 & 29,2 & 3,1 & \\
\hline $\begin{array}{l}\text { Violência emocional na } \\
\text { gestação }\end{array}$ & & & & 0,171 \\
\hline Sim & 35 & 28,5 & 3,2 & \\
\hline Não & 189 & 29,3 & 3,2 & \\
\hline Violência na gestação & & & & 0,290 \\
\hline Sim & 38 & 28,7 & 3,3 & \\
\hline Não & 189 & 29,3 & 3,1 & \\
\hline
\end{tabular}

Com referência às mulheres cujos RNs apresentaram problemas como baixo peso e prematuridade essas apresentaram escores para autoestima mais baixos $\left({ }_{\bar{x}}=29,3\right)$ quando comparadas com aquelas cujos RNs não apresentaram tais problemas. Estes achados permitem afirmar que gestantes que tiveram seus RNs com problemas, como baixo peso e prematuridade, apresentam percepção de autoestima mais negativa quando comparadas com gestantes que não tiveram seus RNs nessas condições 
Da mesma forma, as gestantes que apresentaram complicações em gestações anteriores apresentaram menores escores para autoestima quando comparadas com aquelas que não vivenciaram essa experiência $\left({ }_{\bar{x}}=28,6\right)$. Através dos achados deste estudo podemos afirmar, portanto, que as gestantes com complicações em gravidezes anteriores apresentaram percepção de autoestima mais baixa, quando comparadas com as que não tiveram tal experiência.

Ao analisar os dados da Tabela 28 que tratam da variável resposta autoestima e as variáveis relacionadas aos fatores de risco psicossociais perdas de alguém, tabagismo, uso de álcool e drogas ilícitas, foi possível observar que, nenhuma se mostrou significante na identificação da autoestima entre as gestantes estudadas $(p=0,235 ; p=0,681 ; 0,342 ; 0,874 ; 0,460$, respectivamente).

Como pode ser constatado na Tabela 29 que trata da variável resposta autoestima e as variáveis relacionadas aos fatores de risco psicossociais, relacionadas a relatos de violência, foi possível observar que história de violência, e história de violência emocional, mostraram-se significantes na identificação da autoestima entre as gestantes estudadas ( $p=0,043 ; p=0,001$, respectivamente).

Os resultados indicam que as gestantes que apresentaram história de violência, e história de violência emocional apresentaram menores escores para autoestima ( ${ }_{\bar{x}}=28,6 ;{ }_{\bar{x}}=28,1$, respectivamente). Portanto, os achados deste estudo nos permitem afirmar que as gestantes que apresentaram história de violência, e história de violência emocional em suas vidas, apresentaram percepção de autoestima mais baixa quando comparadas com gestantes que não vivenciaram esta experiência. 
5 DISCUSSÃO 
Este estudo descritivo - transversal, mostrou que as gestantes atendidas nos serviços de pré-natal do Sistema Único de Saúde de Catanduva caracterizam-se como mulheres pertencentes a grupos de risco a resultados adversos à gravidez. Trata-se de mulheres jovens, em média com 24,26 anos sendo a faixa etária predominante de 18 a 34 anos (77,5\%), com ensino médio completo $(54,6 \%)$ e a grande maioria $(88,1 \%)$ refere ter companheiro. Quanto à ocupação, a maioria não exerce atividade remunerada (67\%), e sobrevive com renda familiar predominante de 1 a menos de 2 salários mínimos (46,3\%). Este perfil sócio-demográfico se mostra semelhante ao de outros estudos com gestantes no país, como os de Carvalho e Novaes (2004); Mamede (2005) e Weisshemer (2007). Um aspecto negativo a ser considerado no perfil sócio-demográfico encontrado no presente estudo está relacionado à condição econômica das estudadas, visto que a grande maioria delas não exerce atividades remuneradas.

Estes achados reforçam que a gestação e o puerpério são períodos da vida da mulher que precisam ser avaliados com especial atenção, pois envolvem inúmeras alterações físicas, hormonais, psíquicas e de inserção social, que podem refletir diretamente na saúde mental dessas pacientes. Os principais fatores de risco psicossociais relacionados à depressão maior no puerpério são: idade inferior a 16 anos, história de transtorno psiquiátrico prévio, eventos estressantes experimentados nos últimos 12 meses, conflitos conjugais, ser solteira ou divorciada, estar desempregada (a paciente ou o seu cônjuge) e apresentar pouco suporte social (CAMACHO, 2006).

Quanto ao perfil obstétrico, as participantes do estudo apresentam um conjunto de riscos à saúde para resultados adversos à gravidez incluindo condições físicas, ganho de peso abaixo do esperado, mutiparidade, complicações em 
gestações anteriores e, na atual, infecções ginecológicas, partos operatórios entre outros.

As mulheres estudadas caracterizam-se como gestantes com uma média de 28,25 semanas de gestação, a maioria delas com ganho ponderal de peso abaixo do esperado $(64,2 \%)$, e apenas $28,6 \%$ das gestantes obtiveram um ganho de peso adequado segundo os parâmetros recomendados pelo Ministério da Saúde.

Esta condição relacionada ao ganho de peso identificado no presente estudo revela características diferentes das encontradas em outros estudos com gestantes no Brasil, como os encontrados por Weisshemer (2007), e Mamede (2005) nos quais o ganho de peso se encontrava dentro dos parâmetros recomendados,

O ganho ponderal de peso abaixo do recomendado é um fator de risco preocupante na amostra estudada, visto que a literatura, cada vez mais vasta sobre o assunto, vem reforçando a existência de associação de baixo peso com parto prematuro. Heaman et al., (2005) advertem que o peso total ganho na gestação não deve ser uma medida apropriada para identificação de risco, pois ele está relacionado à duração da gestação. No entanto, os autores sugerem como mais adequado o uso de padrões de ganho de peso para classificação de risco gestacional.

No presente estudo, foi identificado um ganho médio de peso semanal de $0,25 \mathrm{Kg}( \pm 0,37)$, o que fortemente classifica as estudadas dentro de um padrão de alto risco para gestação pré-termo e prematuridade neonatal. De acordo com a literatura, um ganho de peso de 0,46 - 0,61 $\mathrm{Kg}$ por semana no segundo e terceiro trimestre gestacional é um fator de proteção e redução de risco para partos prematuros (HEAMAN et al., 2005). Estas considerações são importantes para a interpretação dos resultados do presente trabalho na medida em que as 
participantes encontravam-se no segundo e terceiro trimestre de gestação e o ganho de peso foi muito inferior aos sugeridos na literatura Heaman et al., (2005) argumentam que estudos de revisão observaram que o risco de parto prematuro foi mais baixo em mulheres com ganho de peso intermediário, ou seja, de 0,35 - 0,4 $6 \mathrm{Kg}$ por semana. Tais valores ainda encontram-se acima dos valores de ganho de peso das participantes deste estudo. Estes dados sugerem como as intervenções poderiam ser ajustadas às necessidades específicas das mulheres grávidas, do município estudado, tomando por base o perfil nutricional.

A esse respeito, cabe destacar o esforço de instituições, serviços e profissionais que têm investido em estratégias de mudanças de estilo alimentar para a população de gestantes, como a elaboração e fornecimento de manuais, brochuras escritas sobre alimentação saudável na gestação. No entanto, pesquisas trazem questionamentos sobre a pertinência de se colocar esse material à disposição dos serviços e profissionais que atendem ao pré-natal bem como dispôlos às gestantes. De acordo com os achados de Szwajcer et al., 2009, tais estratégias não funcionam, não servem a qualquer propósito real. Reforçam as autoras que os resultados do estudo desenvolvido com parteiras profissionais mostraram que a estratégia das organizações de saúde para envolver tais profissionais nas atividades de promoção nutricional, oferecendo manuais/ brochuras impressas não funcionou como pretendido. Chamam a atenção para o fato de que a provisão de tais recursos não significa que os mesmos serão usados e incorporados como parte integral da comunicação das parteiras profissionais sobre aspectos nutricionais com suas clientes. Isto porque as autoras verificaram que as mulheres incorporam práticas mais saudáveis quando as orientações são realizadas em um ambiente de interação pessoal e profissional, visto que elas apreciam muito 
mais em falar sobre nutrição com as parteiras por causa de suas competências nas questões que envolvem a gestação como um todo.

Outra característica do perfil obstétrico que apresenta risco à saúde para resultados adversos à gravidez diz respeito à presença de complicações na gravidez atual a qual foi encontrada em $30,4 \%$ das estudadas aqui. Tais complicações relacionavam-se à hipertensão, diabetes gestacional, infecção do trato urinário, hepatite, anemia, descolamento de placenta entre outros, além de que 10\% apresentavam restrição de crescimento intra-uterino: são riscos consideráveis para um efetivo planejamento de atenção.

O número de mulheres que apresentaram complicações na gestação atual se mostra como superior aos encontrados por Weisshemer (2007), que encontrou 17, $3 \%$ de gestantes com complicações na gestação. Essa diferença pode ser explicada pelo fato de que muitas das gestantes $(26,4 \%)$ foram recrutadas nos ambulatórios de referência também para gestação de alto risco.

O reconhecimento precoce de complicações na gestação torna-se imprescindível para que ocorra um tratamento correto de cada uma das complicações pertinentes ou não ao período gravídico, prevenindo assim, riscos de vida materno e fetal. A assiduidade da gestante nas consultas de pré-natal deveria ser algo almejado pelos profissionais de saúde, sobretudo daquelas que apresentam algum tipo de complicação nesse período. Essa assiduidade é importante para adesão ao tratamento correto, acompanhamento e avaliações das condições de vitalidade fetais constantes, evitando, assim, o retardo no crescimento intra-uterino e morte fetal (BRASIL, 2000c).

$\mathrm{Na}$ gestação de alto risco as dificuldades de adaptação emocional são maiores do que as que não apresentam complicações, a começar pelo rótulo de 
"alto risco", portanto, "diferente das demais". Somam-se a isso, o próprio fator de risco que elas apresentam, possível perda da autoestima, sentimento de incompetência e a exacerbação do estresse e da ansiedade (BRASIL, 2000c).

Toda a equipe de saúde necessita de conhecimentos específicos da área, bem como de sensibilidade para identificar e entender o processo emocional que permeia uma gestação de risco (BRASIL, 2000c). O Cuidado com a saúde de uma gestante de risco, em geral, requer instrumentos discriminadores nesse processo de recomendação, geração e fornecimento de cuidados à saúde de uma maneira diferenciada (BRASIL, 2000).

A enfermeira deve estar atenta a essas questões em sua prática diária, seja em ambulatórios, centros de saúde, ou unidades de saúde da família. Mesmo que a consulta de pré-natal de alto risco esteja sob os cuidados e responsabilidade do profissional médico obstetra, a enfermeira deve ser capacitada para o acompanhamento e suporte emocional nesse período.

Alguns órgãos internacionais têm mobilizado estratégias de ação para promover gestações e partos mais seguros, diminuindo, assim, os elevados índices de mortalidade materna e neonatal (OMS, 1996). A assistência obstétrica deve ser prestada por profissionais qualificados, capazes de oferecer cuidados competentes durante o período gravídico puerperal (MAcDONALD; STARRS, 2003).

Outra característica identificada no perfil obstétrico das gestantes estudadas é a multiparidade. O número elevado de mulheres com mais de dois filhos $(64,8 \%)$ sinaliza preocupação para com o desfecho da gravidez, característica também encontrada por Weissheimer (2007), encontrou 63,1\% de multíparas em seu estudo.

Embora existam controvérsias no que diz respeito à alta paridade e os resultados maternos e fetais, a morte materna ainda é associada a multiparidade 
(mais de 5 partos) (ALIYU et al, 2005). Portanto, segundo Soares, Tavares e Schor (2008), a identificação e o monitoramento das multigestas (gesta $\leq 5$ ) com idade avançada e em desvantagem social, associada à serviços obstétricos qualificados para gestação de alto risco, poderão reduzir a mortalidade materna.

A oferta de programas efetivos de planejamento familiar nos serviços de saúde pode ser utilizada como estratégia para redução do número de gestações, para aumentar o intervalo entre as mesmas e evitar gestações nas faixas etárias de maior risco, contribuindo assim, para a redução dos possíveis riscos associados à multiparidade (SOARES, TAVARES e SCHOR, 2008).

Portanto, ações conjuntas como programas efetivos de planejamento familiar aliados ao acesso a cuidados obstétricos qualificados, intervenções oportunas e corretas em emergências obstétricas, diminuição da injustiça social e melhorias nos níveis socioeconômico culturais, não só contribuirão para a diminuição da multiparidade, como também da morbimortalidade materna e infantil. (ALIYU et al., 2005; SOARES, TAVARES e SCHOR, 2008).

Em relação ao tipo de parto, as mulheres que tiveram 2 ou mais gestações, $40,8 \%$ tiveram a experiência de parto vaginal, enquanto 59,2\% relataram parto cesárea anterior. No estudo de Weisshemer (2007), em Porto Alegre - RS, o número de parto cesárea foi menor que os apresentados neste estudo. A autora encontrou $65,8 \%$ de partos vaginais e $28,3 \%$ de cesarianas. Apesar de chamar a atenção a alta percentagem de mulheres que relataram ter tido parto cesárea entre as estudadas, esses valores estão abaixo da média de partos operatórios ocorridos no município estudado no ano 2008 quando foram registrados $78 \%$ de cesárea (DATASUS, 2008). Porém, por se tratar de um estudo transversal, e a coleta de 
dados ter sido realizada em apenas três meses esses valores podem não refletir a realidade (PROGRAMA SINASC, 2006; PROGRAMA SINASC, 2008).

Altas taxas de cesariana estão relacionadas a sérias complicações maternas e perinatais, contribuindo para o aumento dos índices de morbimortalidade materna e fetal, sem contar com gastos desnecessários ao sistema de saúde. Atualmente, várias iniciativas têm sido propostas com o propósito de reduzir a mortalidade materna e perinatal: a adoção de um modelo menos intervencionista e melhoria da assistência ao parto e ao nascimento, como o Programa de Humanização no Prénatal e Nascimento, o Projeto de Capacitação de Parteiras Tradicionais e o financiamento de cursos de especialização em enfermagem obstétrica e o Projeto Maternidade Segura (BRASIL 2000a; BRASIL 2000b; BRASIL, 2003).

Intervenções eficazes devem ser priorizadas para a redução dos elevados índices de partos operatórios, focalizadas nas ações multidisciplinares, na organização dos serviços nas maternidades, levando informações sobre riscos e das implicações dessa prática abusiva às mulheres através do aconselhamento médico nos casos de uma solicitação feita pela própria mulher, além de combater o estigma errôneo da cesariana como um "bem de consumo" (BEHAGUE, VICTORA, BARROS, 2002; FREITAS et al, 2005; MACHADO JUNIOR, et al., 2009).

Quanto aos fatores de risco psicossociais identificados na amostra estudada, relatados pelas entrevistadas, $26,7 \%$ perderam alguém especial recentemente, 9,3\% mantiveram o hábito de fumar durante a gestação atual. Nossos resultados correspondem ao descrito na literatura que aponta índices de 2 a 30\% de tabagismo na gestação, diversificando-os entre países e regiões brasileiras. O tabagismo durante a gestação é considerado nos Estados Unidos, a maior causa de efeitos adversos nos bebês. O hábito de fumar na gestação é responsável por um aumento 
da mortalidade infantil em até $40 \%$, além de contribuir para o aumento da mortalidade infantil. Também está associado com o baixo peso do nenê ao nascer, prematuridade, baixos escores de Apgar, bem como síndrome da membrana hialina (KASSAR, et al., 2006; KROEFF et al., 2004; MARIN, et al., 2003).

Encontramos em nosso estudo $2,7 \%$ de gestantes que ingeriam bebidas alcoólicas na gestação atual, resultados inferiores aos descritos por Ruiz (2007) que encontrou índice de 4,9\%; por Kassar et al., (2006) que encontraram 8,4\% e Freire et al. (2005), que apontaram índice de 20, $7 \%$.

Assim como o tabaco, o álcool também é nocivo para o feto, trazendo inúmeros riscos à saúde materno-infantil, como malformações fetais, síndrome alcoólica fetal, retardo mental, múltiplas disfunções no organismo da criança, distúrbios no crescimento, deficiência no aprendizado e baixos coeficientes de inteligência (QI), bem como trabalho de parto prematuro, hipertonia uterina, descolamento prematuro de placenta, dentre outros (HOYME et al., 2005; PASSINI JUNIOR, 2005).

Pesquisas têm descoberto a relação entre vários tipos de violência e estresse e, associações, combinadas ou independentes, entre abuso/violência e estresse sobre os resultados da gravidez, incluindo parto prematuro e baixo peso ao nascer (CURRY, et al. 2006).

Ainda em relação aos fatores de risco psicossociais, em nosso estudo foram investigados os três tipos de violência contra a mulher: a sexual, a física e a emocional em algum período da vida e na gestação atual. Observa-se que a violência esteve presente na vida de $37,4 \%$ das mulheres, 28,6\% relataram história de violência emocional; 15,6\% de violência física e 4,4\% de violência sexual. Quanto à gestação atual 16,7\% gestantes relaram história de violência sendo que, 15,3\% 
relataram ter sofrido violência emocional, 3,1\% violência física e nenhuma relatou violência sexual.

Nossos achados sobre violência na gestação corroboram os encontrados por outros autores, Kronbauer e Meneguel, (2005) encontrou 17\% de violência na gestação; Rodrigues (2007) encontrou 19, 6\%, Durand (2005), 20\% e Okada (2007) $12 \%$.

A identificação e análise do perfil psicossocial por meio do PPP mostrou-se adequada na presente pesquisa, especialmente porque essa dimensão da saúde das mulheres geralmente é negligenciada na atenção pré-natal e principalmente nos sistemas de avaliação de risco gestacional.

Os achados deste estudo com 227 gestantes confirmam a confiabilidade e validade do instrumento PPP traduzido para a versão brasileira como medida de estresse, apoio social do companheiro, apoio social de outras pessoas e autoestima entre mulheres no período de gestação. Os valores do alfa de Cronbach verificados no presente estudo, estresse $(0,97)$; apoio do companheiro $(0,99)$; apoio de outras $(0,99)$ e autoestima $(0,74)$ se mostraram muito próximos tanto aos os das autoras do instrumento original como do instrumento adaptado para a cultura brasileira (CURRY, BURTON, 1998; WEISSHEIMER, 2007). Portanto, o PPP, na sua versão adaptada, mostra-se como uma ferramenta importante em nosso país na detecção de fatores de risco à gestação, especialmente quando os recursos financeiros destinados à saúde são escassos, Esse instrumento torna-se um meio facilitador, confiável e pouco dispendioso na detecção dos riscos psicossociais de gestantes em tempo hábil de intervenções necessárias, diminuindo o ônus financeiro do Estado e das famílias (WEISSHEIMER, 2007). 
No presente estudo, os resultados referentes aos valores das medidas psicossociais (estresse, apoio social do companheiro, apoio social de outras pessoas e autoestima) registraram escores de moderados a altos naquelas dimensões do bem-estar psicossocial, não havendo, portanto, nenhum valor abaixo da média dos possíveis escores para cada sub-escala. A maioria das mulheres apresentou alto nível de satisfação com o apoio social do companheiro e de outras pessoas $(\bar{x}=51,6 ; \pm 16,9 ; \quad \bar{x}=50,1 \pm 16,2$, respectivamente). A percepção para 0 estresse $(\bar{x}=18,7 \pm 5,5)$ e autoestima $(\bar{x}=29,2 \pm 3,2)$ teve uma pontuação mais baixa do que a do apoio social, embora muito próxima dos valores médios das respectivas subescalas (variação de 11 a 44 pontos).

Tais achados se mostram muito próximos de estudos que utilizaram o mesmo instrumento (CURRY; CAMPBELL; CHRISTIAN, 1994; CURRY; BURTON; FIELDS, 1998; JESSE; SEAVER; WALLACE, 2003; JESSE et al., 2005; WEISSHEIMER, 2007), como exemplificado no quadro abaixo.

Quadro 1 - Comparação dos valores das médias dos escores das sub-escalas do PPP encontrados nas diferentes pesquisas

\begin{tabular}{|l|l|l|l|}
\hline Subescala & Resultado 2010 & Weissheimer, 2007 & Jesse et al., 2005 \\
\hline Estresse & 18,7 & 18,84 & 18,93 \\
\hline Apoio comp & 51,6 & 53,49 & $\mathrm{~T}=98,80$ \\
\hline Apoio outras & 50,1 & 50,33 & \\
\hline Autoestima & 29,2 & 32,54 & 36,4 \\
\hline
\end{tabular}

Tomando como certo que as subescalas autoestima e apoio social (companheiro e outras pessoas) correlacionam-se positivamente (WEISSHEIMER, 2007), a somatória máxima dos pontos possíveis para estas três subescalas (desconsiderando a de estresse) obtém-se um valor de 176 pontos. Acrescentando 11 pontos para cada uma, visto que os escores vão de 11 a 44 (autoestima) e 11 a 
66 (apoio do companheiro e de outras) pontos obtém-se um total de 209 pontos, significando, portanto, que o valor médio do intervalo possível é 104,5.

Considerando tal raciocínio para os dados do presente estudo chega-se a um valor médio para o perfil psicossocial (autoestima e apoio social companheiro e outras pessoas) das estudadas de 130,9, ou seja, superior ao ponto médio da somatória de todos os escores máximos, revelando, portanto, que as estudadas apresentam a tendência para um perfil psicossocial mais positivo. Tais observações devem ser vistas com cautela, pois, embora seja prematuro fazer uma recomendação sobre notas de corte sem um adequado estudo prospectivo, com medidas de resultados, os escores médios relatados aqui fornecem um guia seguro para avaliar as respostas das mulheres, conforme recomendações das próprias autoras do PPP (CURRY; CAMPBELL; CHRISTIAN, 1994).

Jesse e Alligood, (2002) esclarecem que a autoestima muitas vezes é um fator de comportamento intermediário quanto a riscos na gravidez, e mulheres com baixos níveis de autoestima podem ser mais propensas a ter cuidado pré-natal deficiente. No entanto, as autoras descobriram em seus estudos que baixos níveis de autoestima estiveram diretamente associados com nascimento prematuro. Tais resultados chamam para investigação a relação da autoestima com os fatores biofísicos, domínios psicossociais, espirituais e de percepção nos desfechos obstétricos.

Cabe ainda chamar a atenção para o fato de os valores relativamente baixos de percepção de estresse identificados no presente estudo representam um aspecto positivo para o bem-estar das estudadas, visto que quanto maiores os escores de estresse maior é a exposição para desfechos desfavoráveis à sua saúde e, em particular, à gestação. 
Jesse e Reed (2004), estudando comportamentos de risco e bem-estar psicossocial na gestação, descobriram que, aumentando os recursos espirituais e diminuindo o estresse durante a gravidez, reforça-se o potencial para melhorar esforços de promoção da saúde na gravidez, conforme identificado entre mulheres da Appalachia.

Autores como Curry et al., 2006, consideraram como alto risco para o bemestar psicossocial escores maiores que 24, obtidos com a sub-escala de estresse do PPP.

Cabe ainda comentar que, de acordo com Jesse, Reed (2004), o bem-estar psicossocial, definido em termos de um composto de fatores, pode ser representado como níveis mais baixos de stress, níveis mais elevados de autoestima, suporte social do parceiro e de outros.

A percepção das mulheres sobre o seu bem-estar psicossocial pode ser moldada por diferentes circunstâncias relacionadas a contextos culturais específicos. Essas circunstâncias podem estar presentes em diferentes ambientes, tais como a família, a comunidade, a escola e outros (NIGENDA et al., 2003). Nesse sentido, os achados deste estudo, conforme revela a análise de variância, identificam um conjunto de variáveis que modificam as respostas psicossociais das mulheres estudadas, colocando-as em situações de maior vulnerabilidade a resultados adversos à gestação.

Quando as estudadas foram classificadas de acordo com as variáveis sociodemográficas, identificaram-se alguns fatores de risco a um tipo de perfil psicossocial que pode aumentar a vulnerabilidade a resultados desfavoráveis à gravidez. Assim, a idade da gestante acima de 35 anos e a ausência de parceiro sexual contribuíram para níveis mais elevados de estresse entre as estudadas. Da 
mesma forma, essa situação conjugal contribuiu para uma percepção mais negativa de apoio social. Por outro lado, fatores como a condição econômica mais elevada se colocaram como fatores de importância para altos níveis de autoestima das estudada.

Weisman et al., 2006, estudando grupos de mulheres em diferentes períodos de vida reprodutiva, descobriram que a maioria dos fatores de risco para resultados adversos à gravidez, além dos psicossociais e estresse, variava de acordo com o status socioeconômico (nível de escolaridade, local de residência urbana e rural, raça / etnia e renda familiar mais baixa) e colocava as mulheres sob maior risco. Estes achados sugerem para as autoras a necessidade de segmentação da população com menos recursos para acessar os serviços tradicionais de saúde.

A classificação das mulheres de acordo com o estado clínico-obstétrico mostra, no presente estudo, como essa condição afeta sobremaneira o bem-estar psicossocial das gestantes, identifica um conjunto de situações que revela o seu potencial valor como meio de identificar mulheres em risco para resultados desfavoráveis à gravidez.

A experiência de mais de duas gestações, de ter passado pelo processo de parturição (qualquer tipo de parto), aborto, complicações nas gestações anteriores e na atual, bem como restrição de crescimento intra-uterino foram situações que responderam a altos níveis de estresse entre as estudadas.

Embora no presente estudo não tenha sido tratada a questão da gravidez não planejada, mas como tal condição pode relacionar-se à paridade, as orientações de Camacho et al., 2006 podem favorecer a discussão sobre o perfil clínico-obstétrico das estudadas e bem-estar psicossocial. Neste sentido, os autores lembram-se da 
existência de associação entre depressão e gravidez indesejada. As mulheres com escolaridade mais alta e melhor rendimento financeiro apresentavam menor risco de gravidez não planejada, e aquelas provenientes de famílias populosas, multíparas, apresentavam elevado risco para depressão.

A restrição de crescimento intrauterino entre as estudadas contribuiu significantemente para uma percepção negativa do apoio social do companheiro e de outras pessoas. Novamente aparecem as variáveis explicativas: mais de duas gestações, a experiência de parto (qualquer tipo), complicações em gestações anteriores e problemas de prematuridade e baixo peso do $\mathrm{RN}$; contribuindo para colocar as mulheres em situação de baixa autoestima.

Estes achados revelam o peso que a história obstétrica incute sobre a vida e o bem-estar psicossocial das estudadas. Como sugerem Weisman et al. (2006), intervenções políticas poderiam ser destinadas a reduzir tensões crônicas que afetam as mulheres em fase de reprodução, incluindo a redução de jornada de trabalho, fornecendo importante apoio social como creches, lazer e assegurando a cobertura de saúde contínua para as mulheres e suas famílias.

Os fatores de risco psicossociais, como perda recente de alguém, história de violência, quer seja em qualquer momento da vida das estudadas ou na gestação, são aspectos que merecem consideração quando se analisa o bem-estar psicossocial de mulheres grávidas.

As mulheres que tiveram perdas de pessoas especiais em suas vidas expuseram-se a altos níveis de estresse.

A violência (física, emocional) na vida das mulheres e na gestação foi identificada, no presente estudo com altos níveis de estresse e baixa autoestima. Condição similar foi encontrada por Curry (1998), ao identificar que mulheres 
abusadas (violência de diversas naturezas) apresentaram altos níveis de estresse (maior ou igual a 24 no PPP) e foram consideradas em muito mais alto risco para resultados desfavoráveis à gestação.

Entendemos a magnitude e a gravidade da violência contra a mulher, uma vez que podem trazer conseqüências irreversíveis na vida de mulheres e crianças e concordamos com Portella (2000) que o reconhecimento social e político da violência de gênero como um fenômeno importante da vida em sociedade, é um fator fundamental para o desenvolvimento de ações e políticas públicas referentes ao enfrentamento da violência.

Abordar a violência contra a mulher não é uma tarefa fácil, porém, ao contrário do que se imagina, as mulheres falam sobre a violência, desde que sejam ouvidas. Segundo Rodrigues (2007), é necessário por parte dos profissionais de saúde um maior empenho e atenção na identificação de mulheres em situação de violência, para que encaminhamentos necessários sejam realizados.

Sensibilização e capacitação dos profissionais, orientação sobre os direitos da mulher, manter um canal aberto para diagnóstico precoce de eventuais episódios de violência e uma rede de apoio eficaz para o manejo das ações nos municípios poderiam permitir às mulheres um desvencilhamento de situações de violência na qual muitas mulheres se encontram (RODRIGUES, 2007), e no caso da violência na gravidez, detectar precocemente situações que gerem estresse e baixa autoestima nas mesmas, provenientes desta violência, evitando em tempo hábil repercussões negativas para o concepto.

Camacho et al. (2006), em revisão da literatura sobre depressão na gestação, classificam os fatores psicossociais, como a gravidez não planejada, mãe solteira, ter muitos filhos, reduzido suporte social, baixo nível de escolaridade, tabagismo, 
abuso de sustâncias e violência doméstica ou conflitos no lar, como indicadores de relevância na investigação e intervenção em casos de depressão durante o processo de gestação.

Embora as abordagens clínicas de cuidados sejam essenciais, essas não são as únicas estratégias disponíveis para melhorar muitos dos fatores de risco aqui analisados, incluindo comportamentos psicossociais não saudáveis como o tabagismo, álcool e, estresse. Poder-se-ia abordar tais comportamentos através de intervenções ao nível da comunidade ou de intervenções de políticas sociais de bem-estar.

Lazenbatt, Taylor e Cree (2009), reforçam a necessidade de os profissionais, tanto de hospitais como de comunidade, e em especial as parteiras profissionais, adquirirem mais confiança em trazer as questões da violência para a prática clínica e também de adquirir uma compreensão das dimensões psicossociais que envolvem a violência doméstica.

O planejamento de campanhas de educação e orientação em toda a comunidade para melhorar a saúde das mulheres, focalizando estratégias de combate e visibilidade de todo tipo de violência, estratégias para eliminação de comportamentos nocivos à saúde (como alimentação, fumo, álcool), a introdução de estratégias de gestão da atividade física e eliminação de stress podem reduzir os principais riscos para as complicações obstétricas e também ser benéfico para a saúde e bem-estar psicossocial das mulheres em geral.

Este estudo transversal demonstra que as gestantes atendidas no SUS do município estudado apresentam riscos para o bem-estar psicossocial que podem repercutir na saúde, aumentando a vulnerabilidade para resultados adversos à gravidez, incluindo as condições físicas crônicas como hipertensão, diabetes, 
infecções ginecológicas, deficiências nutricionais, peso abaixo dos padrões recomendado, tabagismo, consumo de álcool, e estresse psicossocial.

É importante que os serviços de saúde capacitem os profissionais, especialmente as enfermeiras, para lidarem com esta temática, bem como disponibilizem uma rede de apoio apropriada para o encaminhamento de casos detectados de risco psicossocial, para que os mesmos possam ser revertidos em tempo hábil, preservando assim, o bem-estar psicossocial das mesmas diminuindo a morbimortalidade materno-infantil.

As principais limitações deste estudo são de que o mesmo se baseou exclusivamente em dados de autorelato e de ser transversal. Um follow-up das mulheres nesta amostra servirá de base para as análises de como as modificações da gravidez, do processo de nascimento, do parto e do pós-parto alteram a saúde psicossocial ao longo do tempo e afetam os resultados da gravidez. Um estudo de coorte prospectivo também auxiliará a obter informações essenciais sobre registro de nascidos vivos para medir os resultados obstétricos e neonatais. Além disso, esta pesquisa é limitada a uma região de um estado, mas não temos razão para acreditar que as mulheres em outras áreas sejam substancialmente diferentes no que diz respeito à saúde psicossocial. 
6 CONCLUSÕES 
Os resultados deste estudo forneceram um perfil psicossocial e um perfil dos riscos ao bem estar psicossocial de gestantes da rede básica de saúde de Catanduva, permitindo tecer as seguintes conclusões:

1) As gestantes estudadas apresentaram um perfil psicossocial caracterizado por baixo nível de estresse $(18,7 \pm 5,5)$, moderada autoestima $(29,2 \pm 3,2)$ e, relativamente, alto nível de satisfação com apoio recebido do parceiro $(51,6 \pm 16,9)$ e de outras pessoas $(50,1 \pm 16,2)$.

2) O perfil sociodemográfico das estudadas apresentou características que colocam em risco o bem-estar psicossocial, aumentando a vulnerabilidade a resultados desfavoráveis à gravidez, tais como:

- A idade da gestante acima de 35 anos e ausência de parceiro sexual contribuiu para níveis mais elevados de estresse.

- Situação conjugal com ausência de companheiro contribuiu para uma percepção mais negativa de apoio social e altos níveis de estresse.

3) O estado clínico obstétrico das estudadas revela um conjunto de situações que afeta o bem-estar psicossocial e aumenta o risco para resultados desfavoráveis à gravidez como:

- A experiência de mais de duas gestações, de ter passado pelo processo de parturição (qualquer tipo de parto), problemas com o $\mathrm{RN}$ e complicações em gestações anteriores foram situações que responderam por altos níveis de estresse e autoestima mais baixa. 
- A experiência com aborto e restrição de crescimento intrauterino contribuiu com maiores níveis de percepção de estresse, e menor percepção de apoio do parceiro e de outras pessoas.

- As complicações na gestação atual foram identificadas com altos níveis de estresse entre as estudadas.

4) Os fatores de risco psicossociais, como perda recente de alguém, história de violência em qualquer momento da vida das estudadas ou na gestação colocam em risco o bem estar psicossocial, aumentando o risco de resultados desfavoráveis à gestação.

- A experiência de perda de pessoas especiais foi identificada com altos níveis de estresse.

- A violência (física, emocional) na vida das mulheres e na gestação foi identificada com altos níveis de estresse e baixa autoestima e menos apoio de outras pessoas 
REFERÊTNCIAS 
ADEWUYA A. O.; OLA B. A.; ALOBA O. O.; DADA A. O.; FASOTO O. O. Prevalence and correlates of depression in late pregnancy among Nigerian women. Depress Anxiety, v. 24, n. 1, p. 15-21, 2007.

ALIYU M. H., et al. High parity adverse birth outcomes: exploring the maze. Birth, v. 32, n. 1, p.45-59.

BEHAGUE DP, VICTORA CG, BARROS FC. Consumer demand for caesarean sections in Brazil: informed decision making, patient choice, or social inequality? A population based birth cohort study linking ethnographic and epidemiological methods. BMJ, v. 324, p. 942-945, 2002.

BENNETT, H. A. et al. Prevalence of depression during pregnancy; systematic review. Obstet. Gynecol., v. 103, n. 4, p. 698-709, 2004.

BONILHA, A. O. Cambios biológicos, psicológicos y sociales durante el embarazo. Rev. Fed. Odontol. Colomb., v. 201, p. 37-51, feb. 2002.

BRASIL. Ministério da Saúde. Manual do Programa Nacional de Humanização no Pré-natal e Nascimento - PNHPN. Brasília, DF, 2000a.

. Ministério da Saúde. Assistência pré-natal: manual técnico. 3. ed.

Brasília, DF, 2000b.

. Ministério da Saúde. Secretaria de Políticas, Área Técnica da Saúde da Mulher. Gestação de alto risco. Brasília: MS, 2000c.

. Ministério da Saúde. Federação Brasileira das Sociedades de Ginecologia e Obstetrícia - FEBRASGO. Associação Brasileira de Obstetrizes e Enfermeiras Obstetras - ABENFO. Parto, aborto e puerpério: assistência humanizada à mulher. Brasília: MS, 2003.

Ministério da Saúde. Secretaria de Atenção à Saúde. Departamento de Ações Programáticas Estratégicas. Pré-natal e puerpério: atenção qualificada e humanizada: manual técnico. Brasília: Ministério da Saúde, 2006.

CAMACHO, R. S.; CANTINELLI, F. S.; RIBEIRO, C. S; CANTILLINO, A; GONSALES, B. K.; BRAGUITTONI, E.; JUNIOR, J. R. Transtornos psiquiátricos na gestação e no puerpério: classificação, diagnóstico e tratamento. Rev. Psiq. Clín. v. 33, n. 2, p. 92-102, 2006.

CARVAlHO, D. S.; NOVAES, H. M. D. Cad. Saúde Pública. Rio de Janeiro, 20 Sup 2:S220-S230, 2004.

CERVO, A. L.; BERVIAN, P. A. Metodologia científica. 4. ed. São Paulo: Makron Books, 1996.

CURRY M. A.; BURTON, D.; FIELDS, J. The Prenatal Psychosocial Profile: A Research and Clinical Tool. Research in Nursing \& Health, v. 21 (3), p. 211-219, 1998. 
CURRY, M. A. The Interrelationships Between Abuse, Substance Use, and Psychosocial Stress During Pregnancy. J Obste. Gynecol. Neonatal Nurs / JOGNN, , v. 27, n. 6, p. 692-699, 1998.

CURRY, M. A.; CAMPBELL, R.; CHISTIAN, M. Vality and Reliability Testing of the Prenatal Psychosocial Profile. Research in Nursing \& Health, v. 17 (2), p. 127-135, 1994.

CURRY, M. A.; DURHAM,L.; BULLOCK, L. ; BLOOM, T. , and DAVIS. Nurse case management for pregnant women experiencing or at risk for abuse. J Obste. Gynecol. Neonatal Nurs / JOGNN, v. 35, n. 2, p. 181-192, 2006.

DA SILVA, V. A.; MORAES-SANTOS, A. R., CARVALHO, M. S.; MARTINS, M. L. P: TEIXEIRA N. A. Prenatal and postnatal depression among 777 low income women. Braz. J. Med. Biol. Res, v. 31, p. 799-804, 1998.

DATASUS. 2008. Disponível em: <http://www2.datasus.gov.br/DATASUS/index.php>. Acesso em 15 jun. 2010

DURAND, J. G. Gestação e Violência: estudo com usuárias de serviços públicos de saúde da grande São Paulo. 2005. Dissertação (Mestrado) Faculdade de Medicina, Universidade de São Paulo, São Paulo - SP, 2005.

FALCONE, V. M. ET AL. Atuação multiprofissional e a saúde mental de gestantes. Rev. Saúde Pública, v. 39, n. 4, p. 612-618, 2005.

FELICE, E. A. S; MOLINARI, K. M., URBANO, L.; MULLER, E. F. Assistência pré-natal no Programa de Saúde da família. CuidArte. Enfermagem, v.01, p.37 - 45, 2007.

FREITAS, G. V. S.; BOTEGA, N. J. Gravidez na adolescência: prevalência de depressão, ansiedade e ideação suicida. Rev. Assoc. Med. Bras, v. 48, p. 245-249, 2002.

FREITAS, P. F.; DRACHLER, M. L.; LEITE, J. C. C.; GRASSI, P. R. Desigualdade social nas taxas de cesariana em primíparas no Rio Grande do Sul. Rev Saúde Pública, v. 39, p. 761-767, 2005.

HARLEY, K.; ESKENAZI, B. Time in the United States, social support and health behaviors during pregnancy among women of Mexican descent. Social Science and Medicine, Jun; 62 (12) p. 3048-61, 2006.

HEAMAN, M. et al. Risk factors for spontaneous preterm birth among Aboriginal and non-Aboriginal women in Manitoba. Pediatrics Perinatal Epidemiology, v. 19, p. 181-193, 2005.

HOBEL C. J.; ARORA C. P.; KORST L. M. Corticotrophin-releasing hormone and $\mathrm{CRH}$-bilding protein. Differences between patients at risk preterm birth and hypertension. Ann. NY Acad. Sci., v. 897, p. 54-65, 1999. 
HOYME, H. E.; MAY, P. M. A. A practical approach to diagnosis of fetal alcohol spectrum disorders: clarification of the 1996 Institute of Medicine criteria. Pediatrics, v. 115, n. 1, p. 39-47, 2005.

HUTH-BOCKS, A.C., LEVENDOSKY, A.A., \& BOGAT, G.A. The effects of domestic violence during pregnancy on maternal and infant health._Violence and Victims, Vol 17(2), 169-185, 2002.

INSTITUTO BRASILEIRO DE GEOGRAFIA E ESTATÍSTICA. IBGE. Resultados da amostra do censo demográfico 2000. Disponível em: http://www.ibge.gov.br/cidadessat>. Acesso em 21 de jun. 2009.

JADRESIC V. E. Et al. Transtornos emocionales en el embarazo y el puerperio: estudio prospectivo de 108 mujeres. Rev. Chil. Neuropsiquiatr, v. 30 p. 99-106, 1992.

JESSE, E.; ALLIGOOD. M. R. Holistic obstetrical problem evaluation (hope): testing a theory to predict birth outcomes in a group of women from Appalachia. Health Care for Women International, v. 23, p. 587-599, 2002.

JESSE, E; GRAHAM M.; SWANSON M. Journal of Obstetric. Gynecol. Neonatal Nursing, v. 35, n. 1, p.68-77, Jan./Feb. 2006.

JESSE, E; REED, P.G. Effects of spirituality and psychosocial well-being on health risk behaviors in Appalachian pregnant women. J. Obst. Gynecol Neonatal Nursing, v. 33, n. 6, p. 739-747, Nov./Dec., 2004.

JESSE, E.; SEAVER ,W. ; WALLACE, D. C. Maternal psychosocial risks predict. Preterm birth in a group of women from Appalachia. Midwifery 19, 191- 202, 2003.

JESSE, D. E. Jacqueline Walcott-McQuigg,; RN, Anne Mariella, CNM,; Melvin S. Swanson,. Risks and Protective Factors Associated With Symptoms of Depression in Low-Income African American and Caucasian Women During Pregnancy. J. Midwifery Women's Health, v. 50, n. 5, p. 405-410, Sep./Oct. 2005.

JOSEFSSON, A, Berg G, Nordin C, Sydsjö G. Prevalence of depressive symptoms in late pregnancy and postpartum. Acta Obstet. Gynecol. Scand., v. 80, n. 3, p. 251255, 2001.

KASSAR, S. B. ET AL. Comparação das condições socioeconômicas e reprodutivas entre mães adolescentes e adultas jovens. Rev. Saúde Matern. Infant., v. 6, n. 4, p. 397- 403, 2006.

KROEFF, L. R. et al. Fatores associados ao fumo em gestantes avaliadas em cidades brasileiras. Rev, Saúde Pública, v. 38, n. 2, p. 261-267, 2004.

KRONBAUER, J. F.; MENEGHEL, S. N. Perfil da violência de gênero perpetrada por companheiro. Rev. Saúde Pública, São Paulo, v. 39, n. 5, p. 695-701, out. 2005. 
LAZENBATT, A.; TAYLOR, J.; CREE, L. A healthy settings framework: an evaluation and comparison of midwives' responses to addressing domestic violence. Midwifery, v. 25, p. $622-636,2009$.

MacDONALD M, STARRS A. La atención calificada durante el parto. Un cuaderno informativo para salvar la vida de las mujeres y mejorar la salud de los recién nacidos. New York (USA): Family Care Internacional, 2003.

MACHADO JUNIOR, L. C. et al. Associação entre via de parto e complicações maternas em hospital público da Grande São Paulo, Brasil. Cad. Saúde Pública, Rio de Janeiro, v. 25, n. 1, p. 124-132, jan. 2009.

MAMEDE, F. V. O efeito da deambulação na fase ativa do trabalho de parto. 2005. Dissertação (Doutorado) - Escola de Enfermagem, Universidade de São Paulo, 2005.

MARIN, G. H. et al. Consequences of smoking during pregnancy for mother and child. Rev. Saúde Matern. Infant., v. 3, n.2, p. 159-164, 2003.

MOREIRA, M. C; SARRIERA, J. C. Preditores de saúde e bem-estar psicológico em adolescentes gestantes. Psico-USF, v. 11, n. 1, p. 7-15, jun. 2006.

NIGENDA, G., Langer A, Robero M, Rojas G, Al-Osimy M, Villar J, et al. Womens' opinions on antenatal care in developing countries: results of a study in Cuba, Thailand, Saudi Arabia and Argentina. BMC Public Health, v. 3, p. 17, 2003.

NORBECK, J. S.; ANDERSON, N, J. Psychosocial predictors of pregnancy outcomes in low-income black, Hispanic, and white women. Nursing Research, v. 38, n. 4, p. 204-209, Jul./Aug. 1989.

NORBECK, J. S.; DeJOSEPH; SMITH, R. T. A randomized trial of an empiricallyderived social support intervention to prevent low birthweight among African American women. Social Science \& Medicine, v. 43, n. 6, p. 947-95 September, 1996.

OLIVEIRA, E. M. Violência contra a mulher: uma questão de gênero. Acta paulista de enfermagem, São Paulo, v. 13, pt. I, p. 171-175, 2000.

OKADA, M. M. Violência doméstica contra a mulher: estudo com puérperas atendidas em uma maternidade filantrópica. 2007. Dissertação (Mestrado) Escola de Enfermagem, Universidade de São Paulo, 2007.

OLSER J, FRISCHE G. Social differences in reproductive health. A study on birth weight, stillbirths and congenital malformations in Denmark. Scand J Soc Med, v. 21, p. 90-97, 1993.

ORGANIZAÇÃO MUNDIAL DE SAÚDE. OMS. Assistência ao parto normal: um guia prático. Genebra: OMS, 1996. 
ORTEGA L.; LARTIGUE, T.; FIGUEROA, M. E. Prevalência de depresión, através de la Escala de Depresión Perinatal de Edinburgh (EPDS), em uma muestra de mujeres mexicanas embarazadas. Perinatal Reprodut. Hum., v. 15, p. 11-20, 2001.

PASSINI JÚNIOR, R. Consumo de álcool durante a gestação. RBGO, n.7, p. 373375, 2005.

PEREIRA, P. K.; LOVISI G. M. Prevalência da depressão gestacional e fatores associados. Rev. Psiquiatria Clínica, v. 35, n. 4, p.144-53, 2008.

PORTELLA, A. P. Abordagem social sobre violência e saúde das mulheres. Jornal da redesaúde, Porto Alegre, n. 22, p.17-19, nov. 2000.

POLIT, D. F.; BECK, C. T.; HUNGLER, B. P. Fundamentos de pesquisa em enfermagem: métodos, avaliação e utilização. 5. ed. São Paulo: Artmed, 2004.

REED, P. G. Religiousness among Terminally III and Healthy Adults. Research in Nursing \& Health, Roboken, NJ, v. 9, p. 35-41, 1986.

RODRIGUES, D. T. Análise da violência doméstica entre as mulheres atendidas em uma maternidade de baixo risco. Dissertação (Mestrado) - Escola de Enfermagem, Universidade de São Paulo, São Paulo, 2007.

ROMERO, R. M. D., FIGUEROA V. D. A., GARCIA, R. S. Stress and pregnancy. Revista de lá Associación Dental Mexicana. V. 56 n. 1, p. 27-31, 1999.

RUDNICKI, S. R, GRAHAM, J. L, HABBOUSHE, D. F, ROSS R. D. Social support and avoidant coping: correlates of depressed mood during pregnancy in minority women. Women Health. 2001; 34(3):19-34.

RUIZ, M. T. Manejo do terceiro período do parto e suas repercussões no puerpério. 2007. Dissertação (Mestrado) - Escola de Enfermagem, Universidade de São Paulo, São Paulo, 2007.

SABROZA, A. R. et al. Perfil sócio-demográfico e psicossocial de puérperas adolescentes do Município do Rio de Janeiro. Brasil - 1999-2001. Cad. Saúde Pública, v. 20, supl. 1, 2004.

SOARES, V. M. N., TAVARES, C., SCHOR, N. Vidas arriscadas: uma reflexão sobre a relação entre o número de gestações e mortalidade materna. Rev. Bras. Crescim. Desenvolv. Hum, v. 18, n. 3, p. 254-263, dez. 2008.

SZIGETHY, E. M.; RUIZ, P. Depression among pregnant adolescents: an integrated treatment approach. Am J. Psychiatry, v. 158, n. 1, p. 22-27, 2001.

SZWAJCER, E. M. et al. Written nutrition communication in midwifery practice: What purpose does it serve? Midwifery, v, 25, p. 509-517, 2009. 
TIRAN, D, CHUMMUN, H. Complementary therapies to reduce physiological stress in pregnancy. Complementary therapies in Nursing Midwifery, v. 10, supl. 1, p. 162-167, 2004.

VILLANUEVA, L. A. PÉREZ-FARJADO, M. M, IGLESIAS, L. F. Factores sociodemográficos asociados a depresión and adolescentes embarazadas. Ginecol. Obstet. Mex., v. 68, p. 143-148, 2000.

ZUCCHI, M. Depressão na gravidez e prematuridade. Aspectos espistomológicos da investigação. Cad. Saúde Pública, v. 5, p. 89-97, 1999.

WADHWA P. D. et al. Stress and preterm birth: neuroendocrine, immune/inflammatory, and vascular mechanisms. Matern. Child Health J., v. 5, n. 2, p. 119-25, 2001.

WEISMAN, C. S. et al. Preconceptional Health: Risks Of Adverse Pregnancy Outcomes By Reproductive Life Stage In The Central Pennsylvania Women's Health Study (CePAWHS). Women's Health Issues, v. 16, p. 216-224, 2006.

WEISSHEIMER, A. M. Tradução, adaptação transcultural e validação para uso no Brasil do instrumento Prenatal Psychosocial Profile. Tese (Doutorado). Universidade de São Paulo. Escola de Enfermagem de Ribeirão Preto, 2007. 
APESDICES 
APÊNDICE A - Dados de identificação, socioeconômicos, clínicos e obstétricos

\section{A) Dados de Identificação e Socioeconômicos}

Data da coleta dos dados: 1

1) Nome:

2) № prontuário família:

3) № prontuário gestante:

4) Endereço;

5) Telefone para contato:

6) Idade da gestante (anos):

7) Escolaridade (até que série estudou):

8) Situação conjugal

9) Ocupação

10) Renda familiar

\section{B) Dados Obstétricos:}

11) Idade gestacional (semanas):

12)DUM:

13) Número de gestações:

14) Paridade:

15) Parto vaginal: Cesárea

16) Intervalo entre as gestações

17) Abortos:

18) Morte perinatal ( )SIM ( )NÃO

19) Causa;

20) Recém-nascidos com restrição de crescimento 
( )SIM Quantos

( )NÃO Quantos

21) Recém-nascidos pré-termo

( )SIM Quantos

( )NÃO Quantos

22) Recém-nascidos malformado

( )SIM Quantos

( )NÃO Quantos

23) Número de consultas pré-natal (inclusive hoje):

24) Alguma complicação na gestação atual: ( )SIM

( )NÃO

25) Qual?

26) Uso de medicação no momento: ( )SIM

( ) $\mathrm{NÃO}$

27) Qual?

28) Pré-natal nas gestações anteriores: ( )SIM

( )NÃO

29) Complicações nas gestações anteriores: ( )SIM ( )NÃO

30) Quais?

\section{C) Dados Clínicos:}

31) Peso atual (em Kg);

32) Peso anterior à gestação ou ao inicio do PN:

33) Pressão arterial: Sistólica:

Diastólica:

34) Pressão arterial na primeira consulta: Sistólica:

Diastólica:

35) Altura uterina na data da coleta de dados $(\mathrm{em} \mathrm{cm})$ :

36) Restrição de crescimento uterino ( )SIM

( )NÃO

\section{D) Fatores de Risco Psicossociais}

37) Perda recente de alguém especial ( )SIM

( )NÃO

38) Historia de tabagismo ( )SIM

( ) $\mathrm{NÃO}$ 
39) Historia de tabagismo em gravidez anterior ( )SIM ( )NÃO

40) Tabagista na gestação atual ( )SIM （ )NÃO

41) Ingestão de álcool em gravidez anterior ( )SIM ( )NÃO

42) Ingere bebida alcoólica atualmente ( )SIM ( )NÃO

43) Historia de uso de drogas ( )SIM ( )NÃO

44) Uso de drogas na gestação atual ( )SIM ( )NÃO

45) História de violência/abuso sexual ( )SIM ( )NÃO

46) História de violência/abuso física ( )SIM ( )NÃO

47) História de violência/abuso emocional ( )SIM ( )NÃO

48) Violência/abuso sexual na gestação atual ( )SIM （ )NÃO

49) Violência/abuso física na gestação atual ( )SIM ( )NÃO

50) Violência/abuso emocional na gestação atual ( )SIM （ )NÃO

Observações:

Coletador(a): 


\section{APÊNDICE B - Termo de consentimento livre e esclarecido}

Prezada gestante:

Sou enfermeira e aluna da Pós Graduação da Universidade de São Paulo - Escola de Enfermagem de Ribeirão Preto, USP - EERP. Estou desenvolvendo uma pesquisa intitulada "Avaliação do perfil psicossocial das gestantes atendidas na rede básica de saúde do município de Catanduva - SP" para obtenção do título de Doutora em Enfermagem sob a orientação da Prof ${ }^{\mathrm{a}}$. Dr ${ }^{\mathrm{a}}$, Marli Villela Mamede.

Esta pesquisa tem como finalidade contribuir para a melhoria da saúde das gestantes e seus bebês, e também contribuirá para a melhoria da assistência pré-natal. Pretende estudar o perfil psicossocial das gestantes, analisando o estresse, o apoio social e a autoestima das gestantes, bem como identificar os fatores de risco associados ao perfil psicossocial das mesmas.

A sua participação é muito importante para a melhoria da assistência prénatal. Garanto que você não será identificada e em momento algum o seu nome aparecerá na pesquisa, ou de qualquer outra participante. Você inclusive poderá deixar de participar da pesquisa a qualquer momento, sem prejuízos para você ou para esta Unidade de Saúde.

Ao terminar a pesquisa os dados obtidos serão tabulados e publicados, entretanto eu reforço que o nome não será revelado e a sua identidade será preservada. Esta pesquisa não terá custos para você. 
Agradeço a sua colaboração e coloco-me à disposição para os esclarecimentos que se fizerem necessários pelo telefone (17) 9107-2001 aceito ligações a cobrar, ou pelo e-mail: karinamolinari@hotmail.com.

Atenciosamente,

Karina Martins Molinari Morandin

Concordo em participar desta pesquisa, e autorizo a utilização dos dados para este estudo.

Assinatura

Data

DOCUMENTO EM DUAS (2) VIAS, UMA PARA O PESQUISADOR E OUTRA PARA A PESSOA (OU RESPONSÁVEL) QUE VAI PARTICIPAR DA PESQUISA. 
ANEEXOS 


\section{ANEXO A - PPP - VP}

Número:

\section{PERFIL PSICOSOCIAL NO PRÉ-NATAL (PPP)}

O PPP consiste de três escalas separadas que medem o estresse, o apoio social e a autoestima.

\section{Avaliação do Estresse}

Vários fatores podem causar estresse e preocupação. Por favor, marque o número correspondente à resposta apropriada, para cada uma das frases abaixo:
(1) nenhum estresse
(2) algum estresse
(3) estresse moderado
(4) estresse intenso

"O quanto (cada frase) causa estresse ou preocupação no momento para você?"

\begin{tabular}{|l|c|c|c|c|}
\hline & nenhum & algum & moderado & intenso \\
\hline $\begin{array}{l}\text { A. Preocupações financeiras (por exemplo: } \\
\text { alimentação, moradia, saúde, transporte). }\end{array}$ & 1 & 2 & 3 & 4 \\
\hline $\begin{array}{l}\text { B. Outras preocupações com dinheiro } \\
\text { (por exemplo: contas, etc). }\end{array}$ & 1 & 2 & 3 & 4 \\
\hline $\begin{array}{l}\text { C. Problemas relacionados à família } \\
\text { (companheiro, filhos, etc). }\end{array}$ & 1 & 2 & 3 & 4 \\
\hline $\begin{array}{l}\text { D. Ter de mudar de endereço, mesmo } \\
\text { que tenha sido recentemente ou que } \\
\text { acontecerá no futuro. }\end{array}$ & 1 & 2 & 3 & 4 \\
\hline $\begin{array}{l}\text { E. Perda recente de alguém especial. } \\
\text { F. Gestação atual. }\end{array}$ & 1 & 2 & 3 & 4 \\
\hline $\begin{array}{l}\text { G. Estar sofrendo violência/abuso: } \\
\text { sexual, emocional, ou física. }\end{array}$ & 1 & 2 & 3 & 4 \\
\hline H. Problemas com álcool e/ou drogas. & 1 & 2 & 3 & 4 \\
\hline $\begin{array}{l}\text { I. Problemas no trabalho (por exemplo: } \\
\text { ter sido despedida, etc). }\end{array}$ & 1 & 2 & 3 & 4 \\
\hline J. Problemas relacionados aos amigos. & 1 & 2 & 3 & 4 \\
\hline K. Sentir-se geralmente sobrecarregada. & 1 & 2 & 3 & 4 \\
\hline
\end{tabular}




\section{Avaliação do apoio}

A próxima série de perguntas é sobre o quanto você está satisfeita com o apoio que você recebe de seu companheiro e/ou de outras pessoas. Em primeiro lugar, você tem um companheiro?

1. Não (não responda essa parte, passe para o item Apoio de outras pessoas)

2. Sim

As frases abaixo descrevem vários tipos de apoio. Em uma escala de 1 a 6 , com o número 1 correspondendo a 'muito insatisfeita' e o número 6 correspondendo a 'muito satisfeita', solicito que você marque na tabela o número que corresponde a quanto você se sente satisfeita com o apoio que recebe do seu companheiro.

Apoio do companheiro:

\begin{tabular}{|l|c|c|c|c|c|c|}
\hline $\begin{array}{l}\text { A. Compartilha vivências } \\
\text { comigo. }\end{array}$ & 1 & 2 & 3 & 4 & 5 & 6 \\
\hline $\begin{array}{l}\text { B. Ajuda a manter meu } \\
\text { ânimo. }\end{array}$ & 1 & 2 & 3 & 4 & 5 & 6 \\
\hline $\begin{array}{l}\text { C. Me ajuda a sair de } \\
\text { situações difíceis. }\end{array}$ & 1 & 2 & 3 & 4 & 5 & 6 \\
\hline $\begin{array}{l}\text { D. Mostra interesse em } \\
\text { minhas atividades diárias e } \\
\text { problemas. }\end{array}$ & 1 & 2 & 3 & 4 & 5 & 6 \\
\hline $\begin{array}{l}\text { E. Sai de sua rotina para } \\
\text { fazer coisas especiais e } \\
\text { importantes para mim. }\end{array}$ & 1 & 2 & 3 & 4 & 5 & 6 \\
\hline $\begin{array}{l}\text { F. Me permite falar de coisas } \\
\text { que são bastante pessoais e } \\
\text { particulares. }\end{array}$ & 1 & 2 & 3 & 4 & 5 & 6 \\
\hline $\begin{array}{l}\text { G. Demonstra para mim que } \\
\text { valoriza o que eu faço para ele. }\end{array}$ & 1 & 2 & 3 & 4 & 5 & 6 \\
\hline $\begin{array}{l}\text { H. Tolera meus “altos e } \\
\text { baixos” e meus } \\
\text { comportamentos } \\
\text { inesperados. }\end{array}$ & 1 & 2 & 3 & 4 & 5 & 6 \\
\hline $\begin{array}{l}\text { I. Me leva a sério quando eu } \\
\text { tenho preocupações. }\end{array}$ & 1 & 2 & 3 & 4 & 5 & 6 \\
\hline $\begin{array}{l}\text { J. Me diz coisas que tornam } \\
\text { minha situação mais clara e } \\
\text { fácil de ser compreendida. }\end{array}$ & 1 & 2 & 3 & 4 & 5 & 6 \\
\hline $\begin{array}{l}\text { K. Deixa claro que ele estará } \\
\text { por perto se eu precisar }\end{array}$ & 1 & 2 & 3 & 4 & 5 & 6 \\
\hline
\end{tabular}


Por favor, agora leia as mesmas frases e responda o quanto você se sente satisfeita em relação ao apoio que recebe de outras pessoas:

\section{Apoio de outras pessoas:}

\begin{tabular}{|l|l|l|l|l|l|l|}
\hline $\begin{array}{l}\text { A. Compartilha vivências } \\
\text { comigo. }\end{array}$ & 1 & 2 & 3 & 4 & 5 & 6 \\
\hline $\begin{array}{l}\text { B. Ajuda a manter meu } \\
\text { ânimo. }\end{array}$ & 1 & 2 & 3 & 4 & 5 & 6 \\
\hline $\begin{array}{l}\text { C. Me ajuda a sair de } \\
\text { situações difíceis. }\end{array}$ & 1 & 2 & 3 & 4 & 5 & 6 \\
\hline $\begin{array}{l}\text { D. Mostra interesse em } \\
\text { minhas atividades diárias e } \\
\text { problemas. }\end{array}$ & 1 & 2 & 3 & 4 & 5 & 6 \\
\hline $\begin{array}{l}\text { E. Sai de sua rotina para } \\
\text { fazer coisas especiais e } \\
\text { importantes para mim. }\end{array}$ & 1 & 2 & 3 & 4 & 5 & 6 \\
\hline $\begin{array}{l}\text { F. Me permite falar de coisas } \\
\text { que são bastante pessoais e } \\
\text { particulares. }\end{array}$ & 1 & 2 & 3 & 4 & 5 & 6 \\
\hline $\begin{array}{l}\text { G. Demonstra para mim que } \\
\text { valoriza o que eu faço para } \\
\text { ele/ela. }\end{array}$ & 1 & 2 & 3 & 4 & 5 & 6 \\
\hline $\begin{array}{l}\text { H. Tolera meus “altos e } \\
\text { baixos" e meus } \\
\text { comportamentos } \\
\text { inesperados. }\end{array}$ & 1 & 2 & 3 & 4 & 5 & 6 \\
\hline $\begin{array}{l}\text { I. Me leva a sério quando eu } \\
\text { tenho preocupações. }\end{array}$ & 1 & 2 & 3 & 4 & 5 & 6 \\
\hline $\begin{array}{l}\text { J. Me diz coisas que tornam } \\
\text { minha situação mais clara e } \\
\text { fácil de ser compreendida. }\end{array}$ & 1 & 2 & 3 & 4 & 5 & 6 \\
\hline $\begin{array}{l}\text { K. Deixa claro que ele/ela } \\
\text { estará por perto se eu } \\
\text { precisar }\end{array}$ & 1 & 2 & 3 & 4 & 5 & 6 \\
\hline
\end{tabular}




\section{Avaliação da autoestima}

Todos nós carregamos conosco algum tipo de imagem de nós mesmos. As frases abaixo são frases que geralmente as pessoas usam para se descreverem. Por favor, leia cada uma e marque abaixo o número que indica o quanto você concorda ou não se a frase descreve você, conforme os números abaixo:
(1) Concordo completamente
(2) Concordo
(3) Discordo
(4) Discordo completamente

\begin{tabular}{|l|c|c|c|c|}
\hline & $\begin{array}{c}\text { Concordo } \\
\text { completa- } \\
\text { mente }\end{array}$ & Concordo & Discordo & $\begin{array}{c}\text { Discordo } \\
\text { comple- } \\
\text { tamente }\end{array}$ \\
\hline $\begin{array}{l}\text { A. Você sente que é uma pessoa } \\
\text { de valor, ou pelo menos que é } \\
\text { igual aos outros. }\end{array}$ & 1 & 2 & 3 & 4 \\
\hline $\begin{array}{l}\text { B. Você sente que tem um } \\
\text { grande número de qualidades. }\end{array}$ & 1 & 2 & 3 & 4 \\
\hline $\begin{array}{l}\text { C. No final das contas, você } \\
\text { sente que é um fracasso. }\end{array}$ & 1 & 2 & 3 & 4 \\
\hline $\begin{array}{l}\text { D. Você se sente capaz de } \\
\text { fazer as coisas pelo menos tão } \\
\text { bem quanto a maioria das } \\
\text { pessoas. }\end{array}$ & 1 & 2 & 3 & 4 \\
\hline $\begin{array}{l}\text { E. Você sente que não tem } \\
\text { muito do que se orgulhar. }\end{array}$ & 1 & 2 & 3 & 4 \\
\hline $\begin{array}{l}\text { F. Você tem uma atitude } \\
\text { positiva consigo mesma. }\end{array}$ & 1 & 2 & 3 & 4 \\
\hline $\begin{array}{l}\text { G. De modo geral, você se } \\
\text { sente satisfeita consigo } \\
\text { mesma. }\end{array}$ & 1 & 2 & 3 & 4 \\
\hline $\begin{array}{l}\text { H. Você queria ter mais } \\
\text { respeito por si mesma. }\end{array}$ & 1 & 2 & 3 & 4 \\
\hline $\begin{array}{l}\text { I. Às vezes, você se sente } \\
\text { inútil. }\end{array}$ & 1 & 2 & 3 & 4 \\
\hline $\begin{array}{l}\text { J. Às vezes, você acha que } \\
\text { não é boa que chega. }\end{array}$ & 1 & 2 & 3 & 4 \\
\hline $\begin{array}{l}\text { K. Você acha que controla a } \\
\text { sua vida. }\end{array}$ & 1 & & 3 & 4 \\
\hline
\end{tabular}




\section{ANEXO B - Aprovação do Comitê de Ética em Pesquisa}

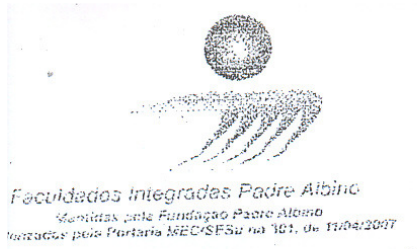

CEP-Comitẽ de Ética em Pesquisa

FIPA - Faculdades Integradas "Padre Albino"

Avenida Sấo vicente de Fauło, 1455-15809-145 - Catanduva-SP (17).

Fone. $3531.32 \%$ - Fax: $3531-3225$ - E-mail: coreme fameca@iema.com.br

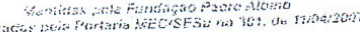

Catanduva. 31 de agosto de 2009

Oficion n" 5509

CEP Irbn:

Ref.: Registro de Projeto de Trabalho Aprovado no CEP-FIPA.

Prezado(a) Senhor(a):

Vimos informar V.Sa. que o Projeto do Trabalho de Pesquisa intitulado "Avaliação do Perfil Psicossocial das Gestantes atendidas pelo Sistema Único de Saúde do Município de Catanduva, SP", foi avaliado por este Comitê de Ética e Pesquisa e considerado aprovado. de acordo com as exigências das Resoluções do Conselho Nacional de Saúde $n^{\circ}$ 196/96 e 251/97 da CONEP.

O registro de aprovação do referido Projeto no Comitê de Ética em Pesquisa da Faculdade de Medicina de Catanduva é sob n $51 / 09$

Cabe ao pesquisador elaborar e apresentar ao CEP/FIPA. o relatório parcial mostrando relação risco/beneficio e o relatório final sobre a pesquisa (Resolução do Conselho Nacional de Saride $n^{\circ}$ 196, de 10.10.1996. inciso LX.2. letra "c").

Sendo o que temos a informar, subscrevemo-nos.

Atenciosamente.

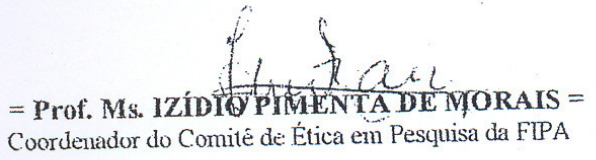

Pescuisador Responsável:

Enf. Ms. Karina Martins Molinari Morandin

Docente do Curso de Finfermagem das Faculdades Integradas Padre Albino
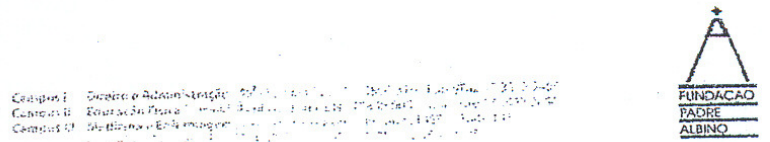